Vol $17 \cdot$ No $1 \cdot$ January 2009

Change at the Poles: $\mathrm{A}$ Paleoscience Perspective

\title{
Editors:
}

Julie Brigham-Grette, Ross Powell, Louise Newman and Thorsten Kiefer

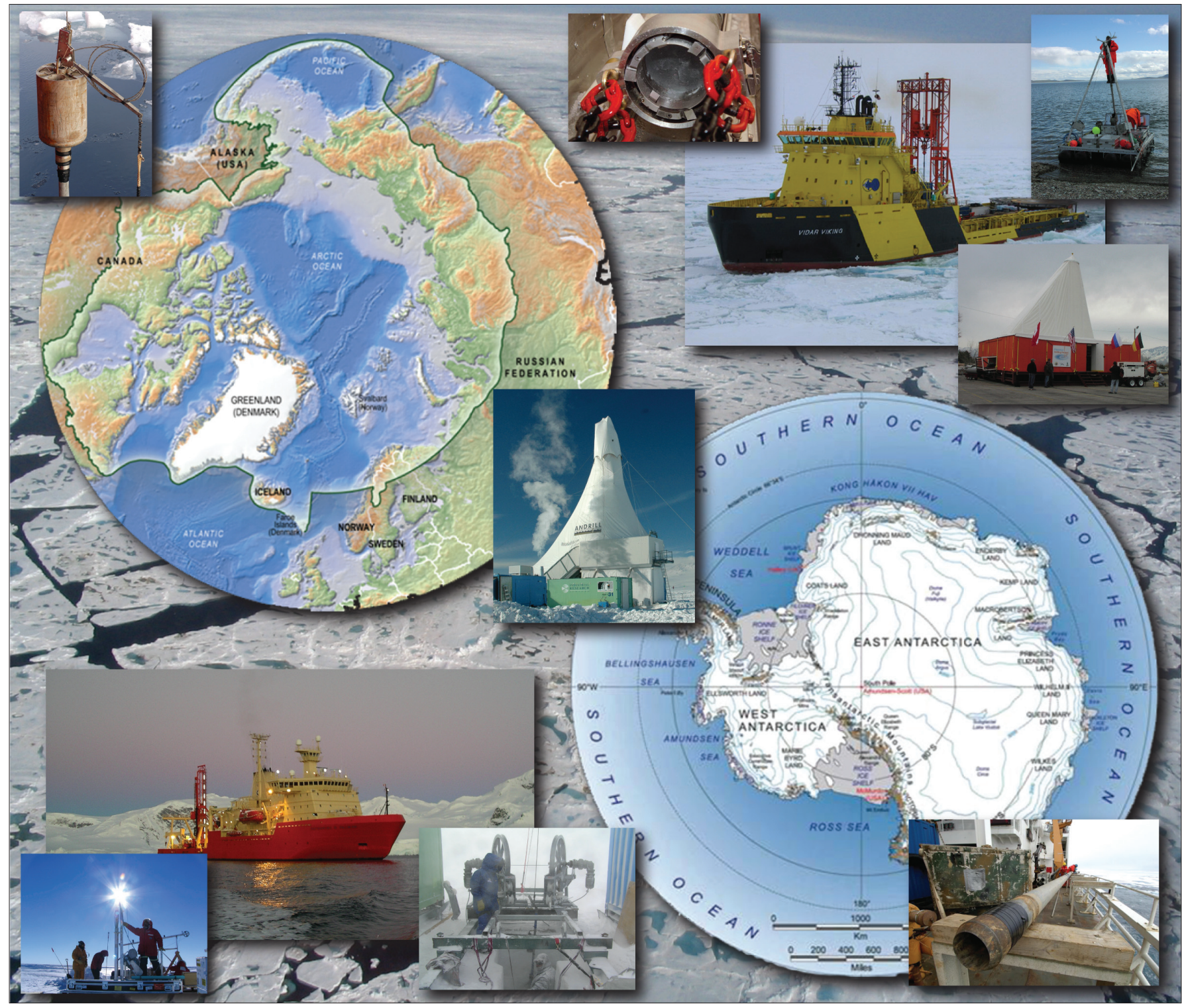

Rugged yet modern technology is necessary in the remote polar regions to recover worldclass geoscientific datasets that are critical for reconstructing global paleoclimate and con straining climate models. (Cover design by Tom Naughton; image credits on back page). 


\section{Editorial: Change at the Poles - A Paleoscience Perspective}

Julie Brigham-Grette ${ }^{1}$ and Ross Powell ${ }^{2}$

'Department of Geosciences, University of Massachusetts, Amherst, USA; juliebg@geo.umass.edu

2Department of Geology and Environmental Geosciences, Northern Illinois University, DeKalb, USA; ross@geol.niu.edu

The transfer of heat between tropical and polar regions is fundamental to balancing longitudinal climate gradients in the Earth System. Paleoclimate records demonstrate, however, that this atmospheric and oceanic meridional "dance" is actually never quite in balance. Rather, external orbital (Milankovitch) forcing and system feedbacks combine to produce complex sets of spatial and temporal cycles that are recorded at regional and hemispheric scales through various geological proxies. Characterizing this natural variability is important, particularly in the face of observations that our planet is undergoing rapid change, largely caused by human practices.

Some of the most iconic images of contemporary change include the truly remarkable loss of Arctic summer sea ice and the disintegration of gigantic sections of ice shelves around the Antarctic Peninsula. One primary scientific theme of the International Polar Year (2007-2009; www. ipy.org/) is to advance the frontiers of polar science and expand our understanding of the magnitude and rates of processes and feedbacks, not only through transglobal linkages between polar regions but also through interactions of the poles with the rest of the world.

Because many readers of PAGES News may be unaware of the broad dimensions of polar paleoclimate science, this issue serves to highlight the spectrum of ongoing studies contributing to interna- tional initiatives that are establishing new benchmarks in polar research. The papers represent a wide range of efforts, covering a variety of proxy records, using numerous types of field operations, laboratory techniques, and data analyses. These studies require scientists to deal with extreme climatic and logistical challenges. International funding agencies are recognizing the need to support the development of sophisticated equipment to be used to overcome these practical challenges. Much of this has been achieved through difficult but innovative national and international collaborations, which create an advanced and sophisticated polar geoscience knowledge base for use in solving globally relevant questions, especially through global models that fully incorporate polar processes.

With this issue we would like to recognize the contributions of individual scientists resourcefully pushing to obtain the funding for innovative scientific programs. Many of the studies highlighted here represent significant contributions to quantifying how past change is measured in a variety of polar systems. Furthermore, exciting new initiatives advancing polar science continue to be developed and have the potential to produce future results relevant to both the PAGES and general scientific communities. Significant value will be added after the IPY in the form of workshops and conferences aimed at synthesizing these remarkable records.
Additionally, we need to acknowledge the technicians and engineers who have been creatively overcoming logistical and operational challenges to develop the equipment/instrumentation technology necessary for allowing polar science to make these amazing advances.

The IPY science umbrella has generated a number of topical and integrative initiatives that require open input from the science community at large. These include Bipolar Climate Machinery (BIPOMAC) (PAGES news, 2008, 16(1)), aimed at integrating records from both the northern and southern hemisphere, APEX (Arctic Paleoclimate Extremes), aimed at the Arctic paleoclimate "extremes" versus the "normal" conditions of the climate system, and ACE (Antarctic Climate Evolution), aimed at the study of the climate and glacial history of Antarctica through paleoclimate and ice sheet modeling investigations, resolved to integrate terrestrial and marine geological and geophysical evidence for past change. As plans for synthesis workshops unfold, we invite the science community to become involved in contributing to these benchmark efforts. Additionally, in early 2008, PAGES launched a new Working Group on Arctic climate of the last 2 millennia (Arctic2k), which generates and synthesizes high-resolution paleoclimate data to assess the timing and variability of Arctic climate change during this period (www.pages-igbp.org/science/arctic2k/).

\section{PAGES Calendar 2009}

\section{Apr 2009 - Vienna, Austria \\ (3) Data-Assimilation Techniques for Paleoclimate Data \\ www.pages-igbp.org/calendar/}

\section{8 - 20 May 2009 - Vihula, Estonia (3) Peatland Archives of Holocene Climate Variability \\ www.pages-igbp.org/calendar/}

\author{
20 - 25 May 2009 - Addis Ababa, Ethiopia \\ (3) $2^{\text {nd }}$ Eastern African Quaternary Association \\ Workshop \\ www.pages-igbp.org/calendar/
}

06 - 11 Jun 2009 - Obergurgl, Austria

Mechanisms of Quaternary Climate Change: Stability of Warm Phases in the Past and Future www.esf.org/index.php?id=5310

\section{3 - 26 Jun 2009 - Guadalajara, Mexico $11^{\text {th }}$ International Paleolimnology Symposium www.geofisica.unam.mx/paleolimnologia/}

\author{
06 - 07 Jul 2009 - Corvallis, USA \\ (5) PAGES $1^{\text {st }}$ Young Scientists Meeting: \\ Retrospective Views on Our Planet's Future \\ www.pages-osm.org/ysm/
}

\author{
08 - 11 Jul 2009 - Corvallis, USA \\ (2) PAGES $3^{\text {rd }}$ Open Science Meeting: \\ Retrospective Views on Our Planet's Future \\ www.pages-osm.org/osm/
}




\section{PAGES YSM/OSM update}

PAGES 1st Young Scientists Meeting (6-7 July 2009) and 3rd Open Science Meeting (8-11 July 2009) in Corvallis, Oregon, USA, are shaping up to be very exciting meetings. Preliminary programs are online and are being regularly updated (see $p$ 47). Abstract submission is now open (deadline 16 March 2009). OSM registration is also open (YSM registration to follow abstract review). More at www.pages-osm.org/

Facilities are available for groups wishing to hold side meetings alongside the YSM/OSM. To discuss this option, contact Thorsten Kiefer (kiefer@pages.unibe.ch).

\section{Science Plan}

Following the development of the new PAGES Scientific Foci over the last few years, the PAGES SSC and IPO have produced a Science Plan and Implementation Strategy. This plan provides an overview of PAGES scientific directions, objectives, and structure. Details of overlap with other programs, and opportunities for cross-program collaborations are also highlighted.

The plan is currently undergoing external review, however the draft is available for download from our website (www. pages-igbp.org/). Please address comments on the plan to the PAGES IPO or to any SSC member. If you are interested in learning about the science happening on the ground, check the overview of PAGES Working Groups on our website (www. pages-igbp.org/science/workinggroups. html)

\section{New PAGES publications}

A review paper by Jones et al. titled "Highresolution palaeoclimatology of the last Millennium: a review of current status and future prospects" has just been published in The Holocene (19(1): 3-50). This review represents the results from a PAGES/ CLIVAR Intersection meeting that took place in Wengen, Switzerland in 2006.

A summary paper detailing a new reconstruction of sea surface temperatures at the Last Glacial Maximum has been published by the IMAGES- and PAGES-supported MARGO group (Multiproxy Approach for the Reconstruction of the Glacial Ocean Surface). See MARGO Project Members, 2009: Nature Geoscience, doi:10.1038/ ngeo411.

The special issue of Palaeogeography, Palaeoclimatology, Palaeoecology "Regional high-resolution multiproxy climate reconstruction for South America: state of the art and perspectives", will also be published soon. It represents conference pro- ceedings from a LOTRED-South America workshop held in October 2006 in Mendo$\mathrm{za}$, Argentina. Until the issue is completed in total, 8 of the in-press articles are already available online (see PAGES Product Database: www.pages-igbp.org/products/ under special issues).

Six proxy-specific White Papers on "Proxy Data Uncertainties", resulting from a PAGES/CLIVAR workshop (Trieste, Italy, June 2008), are also now available for download from the PAGES product database, under other.

\section{New offices for PAGES IPO}

The PAGES International Project Office (IPO) has moved and now shares offices with the Oeschger Centre for Climate Change Research at the University of Bern. Also housed in the same building is the coordination office of the IPCC Working Group 1, co-chaired by Thomas Stocker, a former PAGES SSC member and Swiss Director. The PAGES staff is excited to be working in such an inspiring environment. Come by for a coffee if you are in the area, or consider a more extensive working visit at the PAGES IPO as a PAGES guest scientist (see PAGES website for more information).

\section{Changeover of PAGES Co-Chair}

Julie Brigham-Grette, co-editor of the special section of this newsletter issue and PAGES longest serving SSC member, ended her final term on the SSC at the end of 2008. Her 9 years of service, with 5 years as PAGES Chair (the last as Co-Chair with Heinz Wanner), were a monumental contribution to PAGES. Her high level of leadership and commitment were key to the development of PAGES in the last decade and we thank her on behalf of the paleoscience community. Julie's research interests will keep her actively involved in PAGES in the future.

Bette Otto-Bliesner, who the SSC elected to replace Julie, will now share responsibilities with the current Co-Chair, Heinz Wanner (University of Bern). Bette has served on the SSC since 2006, and is also an SC member of the Paleoclimate Modelling Intercomparison Project (PMIP2). Her work at the U.S. National

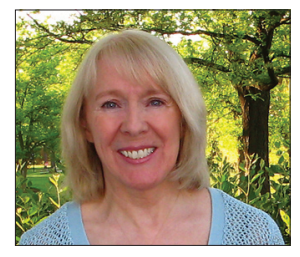
Center for Atmospheric Research focuses on the use of climate models to investigate past climate change and climate variability across a wide range of timescales. Bette has already been involved in Executive Committee activities in the lead up to the changeover, so the transition will be a smooth one. We welcome her to the new position.

\section{New SSC members for 2009}

Two new members join the SSC in 2009. Fatima Abrantes (Portugal) is located at the Marine Geology Department at the National Institute of Industrial Engineering and Technology in Portugal. Fatima is a paleoceanographer, with special expertise in diatoms and past ocean productivity. Fatima has close ties to IMAGES, having served on their SciCom and ExCom, and to the Integrated Ocean Drilling Program (IODP), as well as to IGBP, PAGES umbrella program, as a member of the Portuguese IGBP National Committee.

Steve Colman (USA) is Director at the Large Lakes Observatory and Professor in the Department of Geological Sciences at the University of Minnesota, Duluth. He has a distinguished re search career in Quaternary paleoclimatology, geomorphology and limnogeology. Steve is well versed in PAGES activities and has served as US-NSF Program Director of the Paleoclimate and Earth System History Programs.

At the end of 2009, PAGES will be looking for replacements for another 3 members. The deadline for nominations is 1 June 2009. For more details on PAGES SSC, please see www.pages-igbp.org/people/ sscmembers/

\section{Next 2 issues of PAGES News}

The $2^{\text {nd }}$ issue for 2009 will contain a special section on past sea level and will be guestedited by Mark Siddall (mark.siddall@ bristol.ac.uk), Claire Waelbroeck (claire. waelbroeck@lsce.ipsl.fr) and William Thompson (wthompson@whoi.edu). The $3^{\text {rd }}$ issue for 2009 will contain a special section on advances in paleolimnology, guest edited by Reinhard Pienitz (Reinhard. Pienitz@cen.ulaval.ca) and André Lotter (a.f.lotter@uu.nl). If you are interested in contributing a science highlight to either of these special sections, please contact the editors directly.

Equally welcome are your contributions to the open section of the newsletters, unrelated to the special topic. Guidelines and deadlines for contributions can be found at www. pages-igbp.org/products/newsletters/ instructions.html 


\section{User-friendly data portal provides access to a transient paleoclimate simulation covering the last 21 kyr}

Oliver Timm ${ }^{1}$, A. Timmermann ${ }^{1}$ and S.H. DeCarlo ${ }^{1,2}$

'International Pacific Research Center, University of Hawai'i at Manoa, Honolulu, USA; timm@hawaii.edu ${ }^{2}$ Asia-Pacific Data-Research Center, University of Hawai'i at Manoa, Honolulu, USA

\section{Modern information technology facilitates access to large datasets from transient paleoclimate model simulations. A recently archived model simulation over the last $\mathbf{2 1} \mathrm{kyr}$ is now online and can be used by paleoclimatologists in their research activities.}

Modern paleoclimatology is built on decades of laborious field campaigns that have provided researchers with a spectacular proxy archive of Earth's past climate. With the upsurge in computer technologies, Global Climate Models (GCM) and Earth System Models of Intermediate Complexity (EMIC) have become fundamental tools in paleoclimate research. The synergy of the two disciplines (i.e., model and data) requires a mutual exchange of all forms of information. In particular, access to large volumes of model data poses a major challenge for many paleoresearchers.

Here, we describe a recently published 21 kyr transient paleo-simulation from the Last Glacial Maximum (LGM) to pre-industrial times that was conducted with an EMIC. The full set of ocean and atmospheric model data are now publicly available through a user-friendly data portal.

\section{Model simulation description}

The transient 21-kyr paleoclimate simulation was conducted with version 3 of the ECBilt-CLIO model (Opsteegh et al., 1998; Goosse and Fichefet, 1999). ECBilt-CLIO consists of three coupled subsystems: a simplified 3-layer global dynamical atmosphere, a 3D primitive equation global ocean model, and sea-ice component. The 3 components are coupled by exchange of momentum, heat, and freshwater. Sea ice is calculated from the surface heat fluxes and advection by the ocean circulation (thermodynamic-dynamic). Soil moisture and river runoff into the ocean close the hydrological cycle. A small correction in the freshwater flux is applied over the oceans, in order to correct for a modelspecific excessive precipitation over the $\mathrm{N}$. Atlantic and Arctic.

We increased the $\mathrm{CO}_{2}$ sensitivity of the standard version of the model to mimic that of state-of-the-art GCMs (Timm and Timmermann, 2007). The model was forced with time-dependent boundary conditions. Starting from an LGM equilibrium state, the orbital parameters are continuously updated according to Berger (1978). Atmospheric concentrations for
$\mathrm{CO}_{2}, \mathrm{CH}_{4}$ and $\mathrm{N}_{2} \mathrm{O}$ are prescribed following the time-evolution measured in Antarctic and Greenland ice cores. Ice-sheet related variations in topography and albedo for the period from $21 \mathrm{kyr}$ BP to present were included following the ICE4G reconstruction of Peltier (1994). Vegetation cover was not modified during this simulation (i.e., conditions were kept constant at the level of AD 1970). Millennial-scale variability, such as Heinrich event I, the Younger Dryas or the $8.2 \mathrm{kyr}$ BP event, were not included in this transient simulation. Therefore, the current model results are suitable for the study of orbitally controlled climate changes. Simulations with prescribed freshwater forcing in the N. Atlantic are currently in progress, which will allow the generation of millennial-scale variability in the model. More details about the model and the transient forcing can be found in Timm and Timmermann (2007), Timm et al. (2008) and Timmermann et al. (subm.).

\section{Accessing the data}

The atmospheric and oceanic data of the 21-kyr transient simulation can be accessed through the website of the AsiaPacific Data-Research Center (APDRC, see link below). The APDRC presently supports two access modes: Live Access Server (LAS) and Open-source Project for a Network Data Access Protocol (OPeNDAP). The LAS server is a user interface designed for the purpose of obtaining a quick graphical overview of gridded data fields (Fig. 1). For users not familiar with Ferret, Grid Analysis and Display System (GrADS) or Matrix Laboratory (MATLAB) software, the LAS interface to the 21-kyr transient paleosimulation (see link below) provides a comfortable way of generating time series for individual grid points (such as for sediment or ice core locations), Hovmoeller diagrams (for either longitude, latitude or depth sections), or longitude-latitude maps for individual times. Moreover, it is possible to compute longitude, latitude or time-averages over any of the data fields and compare different fields with each other (using the left access bar). In this way, the user can define their own datasets from the existing climate variables. Figure 1 illustrates some of the graphical capabilities of the LAS web-access to the 21-kyr transient paleo-model simulation (see link below for tutorial).

B) Timeseries Temperature $1200\left({ }^{\circ} \mathrm{C}\right)$
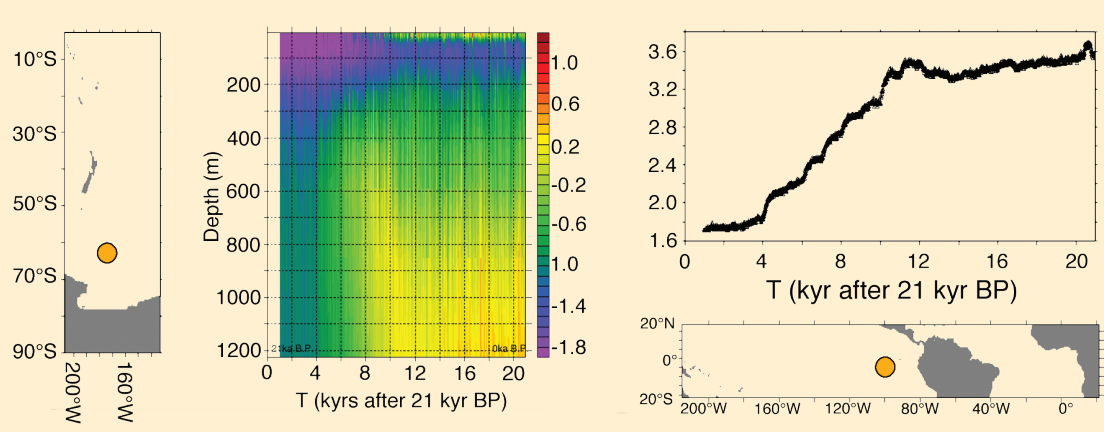

C) $\quad \mathrm{SST}$ at $11 \mathrm{kyr} \mathrm{BP}\left({ }^{\circ} \mathrm{C}\right)$

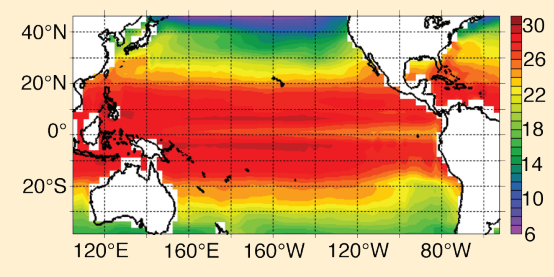

D) Y-T Hovmoeller of winds at $800 \mathrm{hPa}$

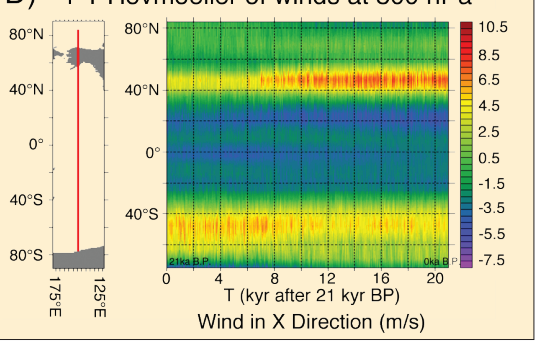

Figure 1: Illustration of the graphical capabilities of Live Access Server: $\boldsymbol{A}$ ) Depth-time Hovmoeller diagram for an upper ocean (to $1200 \mathrm{~m}$ depth) location (orange circle) south of New Zealand; $\boldsymbol{B}$ ) Time series of ocean temperature (at $1200 \mathrm{~m}$ depth) west of the Galapagos Islands (orange circle); C) Map of SST at $11 \mathrm{kyr}$ BP for Pacific region; $\boldsymbol{D}$ ) Latitude-time Hovmoeller diagram of zonal wind component at 154 W. Note: "O yr after 21 kyr BP" is 21 kyr BP. 


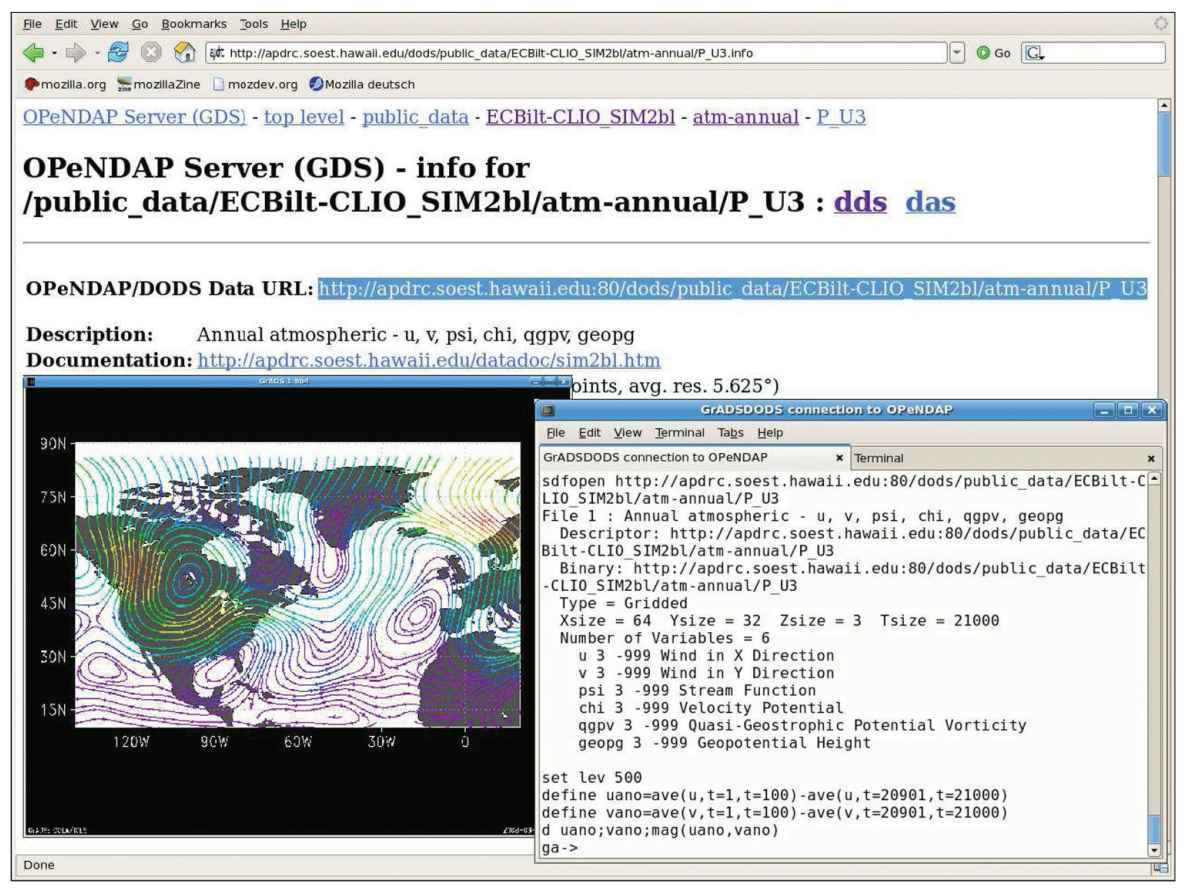

Figure 2: Screen shot of the direct integration of the atmospheric model data into GrADS through the OPeNDAP server. Shown are the differences in the 500-hPa wind field (streamlines) between LGM and pre-industrial times.

In comparison, the OPeNDAP server allows researchers to work directly with the data within their data visualization/manipulation tools (e.g., GrADS, Ferret or MATLAB), provided their software version supports the OpeNDAP access of remote datasets.

When selecting OPeNDAP, the APDRC will guide the user through the oceanic/ atmospheric datasets to the sub-categories. By clicking on "info", the user can obtain the necessary URL and additional information on the variables in the dataset (see screen shot Fig. 2). The URL is needed to open a connection from the research- data sources will allow a deeper insight into the underlying physical mechanisms behind glacial-interglacial cycles and millennial-scale variability.

\section{Note}

APDRC: http://apdrc.soest.hawaii.edu/

Data portal to the $21 \mathrm{kyr}$ paleo-simulation: http://apdrc.soest.hawaii.edu/las/servlets/ dataset?dset=APDRC $\% 20$ PublicAccess $\% 20$ Products/ECBilt-CLIO\%20SIM2bl

Project page with description and tutorial examples: http://apdrc.soest.hawaii.edu/projects/ paleomodeling/index.html

\section{Acknowledgements}

This research was supported by NSF (grant ATM06-28393). Additional support was provided by the Japan Agency for Marine-Earth Science and Technology (JAMSTEC), NASA (grant NNX07AG53G), and NOAA (grant NA17RJ1230) through their sponsorship of research activities at the International Pacific Research Center.

\section{References}

Goosse, H. and Fichefet, T., 1999: Importance of ice-ocean interactions for the global ocean circulation: A model study, Journal of Geophysical Research,104(C10): 23337-23356, doi:10.1029/1999JC900215. remote data.

We hope that this easy web-access to paleo-model data will stimulate new model-data intercomparison studies focusing on the last glacial termination and the Holocene. Unrestricted access to transient paleoclimate simulations will facilitate the climatic interpretation of geobiochemical information from marine and terrestrial proxy archives. Independent validation of model simulations with proxy records will further help to test the robustness of the model results. The combination of both

Opsteegh, J.D., Haarsma, R.J., Selten, F.M. and Kattenberg, A. 1998: ECBILT: A dynamic alternative to mixed boundary conditions in ocean models, Tellus, 50A(3): 348-367, doi:10.1034/j.1600-0870.1998.t01-1-00007.

Timm, 0., and Timmermann, A. 2007: Simulation of the last 21,000 years using accelerated transient boundary conditions, Journal of Climate, 20(17): 4377-4401. doi: 10.1175/JCLI4237.1

Timm, 0., Timmermann, A., Abe-Ouchi, A., Saito, F. and Segawa, T., 2008: On the definition of seasons in paleoclimate simulations with orbital forcing, Paleoceanography, 23: PA2221, doi:10.1029/2007PA001461.

Timmermann, A., Timm 0., Stott, L. and Menviel, L., 2008: The roles of $\mathrm{CO}_{2}$ and orbital forcing in driving southern hemispheric temperature variations during the last 21,000 years, accepted in Journal of Climate.

\section{High- to low-latitude teleconnections during glacial terminations associated with ENSO-like variability}

Leopoldo D. Pena ${ }^{1,2}$ and Isabel CaCho $^{1}$

'Department of Stratigraphy, Paleontology and Marine Geosciences, University of Barcelona, Spain;

${ }^{2}$ Now at Lamont Doherty Earth Observatory of Columbia University, Palisades, USA; leopoldo@ldeo.columbia.edu

\section{Long-term changes in ENSO-like dynamics during deglaciations are linked to southern high-latitude regions through atmospheric and oceanic teleconnection mechanisms.}

Many studies have recognized that EI Niño-Southern Oscillation (ENSO) variability influences climate patterns around the globe (Cane, 1998; Federov and Philander, 2000). This has led to considerable efforts to unravel the history of ENSO and establish its role in past global changes. An increasing number of studies point towards tropical regions, and more particularly to ENSO-like variability (i.e., long-term ENSO variability), as one of the missing pieces in the cause of the Pleistocene glacialinterglacial climate variability. However, evidence for the nature of long-term ENSO variability is still conflicting. In particular, periods of global deglaciation have not shown prevailing El Niño-like or La Niñalike conditions in the tropical Pacific (Beaufort et al., 2001; Koutavas et al., 2002, 2006; Stott et al., 2002). Discrepant evidence may result from the inherently limited temporal resolution and fragmentary nature of the different proxy records. Modeling studies have provided a framework for the ENSO-like variability associated with orbital variations (Cane, 1998, 2004; Clement et al., 1999, 2000; Zebiak and Cane, 1987) and highlight the potential role of orbital dynamics in forcing the ENSO-like variability, through the modulation of the annual cycle of sea surface temperature, atmospheric convection and inter-tropical convergence zone migration in the eastern tropical Pacific (ETP). Although their conceptual basis is sound, tropical climate models still lack more accurate representations of high-low latitude teleconnection mechanisms, partially due to a limited understanding of the processes involved. These limitations highlight the importance of paleo-records to provide informa- 
tion on the processes linking ENSO-like variability and high-latitude climate.

\section{Orbital forcing of ENSO-like variability}

New high-resolution paleorecords from the ETP were generated from a marine sediment core (ODP Site 1240) (Fig. 1) to reconstruct long-term ENSO-like variability and its linkage to orbital forcing (Pena et al., 2008). Past thermocline seawater properties were reconstructed by analyzing both stable isotopes $\left(\delta^{18} \mathrm{O}, \delta^{13} \mathrm{C}\right)$ and paleotemperatures $(\mathrm{Mg} / \mathrm{Ca})$ in the calcite shells of the thermocline dwelling foraminifer species (N. dutertrei). This allowed the calculation of seawater $\delta^{18} \mathrm{O}$ in the deep thermocline (DT- $\delta^{18} \mathrm{O}_{\text {sw }}$ ) as an indicator of local salinity changes (Fig. 1). Saltier waters at the thermocline are associated with an intensified Equatorial Undercurrent (EUC) and strengthened upwelling in the ETP (Pena et al., 2008). Thus, more positive values of DT- $\delta^{18} \mathrm{O}_{\text {sw }}$ indicate saltier waters at the thermocline, which are interpreted as stronger EUC and enhanced upwelling conditions. Accordingly, periods characterized by positive DT- $\delta^{18} \mathrm{O}_{s w}$ excursions (stronger EUC) are indicative of enhanced La Niña-like conditions in the ETP.

The DT- $\delta^{18} \mathrm{O}_{s w}$ record displays salinity variations of thermocline waters (and hence upwelling intensity) that closely match the fluctuations in orbital precession (Fig. 1). Low precession periods are associated with enhanced upwelling in the ETP (La Niña-like conditions), high precession periods with reduced upwelling (Pena et al., 2008). This observation is in agreement with model simulations, where the shift in the timing of the perihelium (point on orbit nearest to the sun) from boreal winters (high precession index) to boreal summers (low precession index) reinforces the seasonally asymmetric wind field above the equator (Clement et al., 1999). This strengthens the E-W asymmetry in the atmosphere (enhancing the Walker circulation) and eventually in the ocean, promoting the development of La Niña-like conditions (Clement et al., 1999).

\section{Teleconnection mechanisms}

Some low precession periods that would be expected to show DT- $\delta^{18} \mathrm{O}_{s w}$ maxima deviate from this precessional pattern (Fig. 1). These periods coincide with low obliquity conditions. In contrast, the largest DT- $\delta^{18} \mathrm{O}_{s w}$ excursions associated with an intensified La Niña-like state in the ETP take place during glacial terminations with concurrent low precession and high obliquity conditions (Fig. 1). An obliquity signature has previously been described

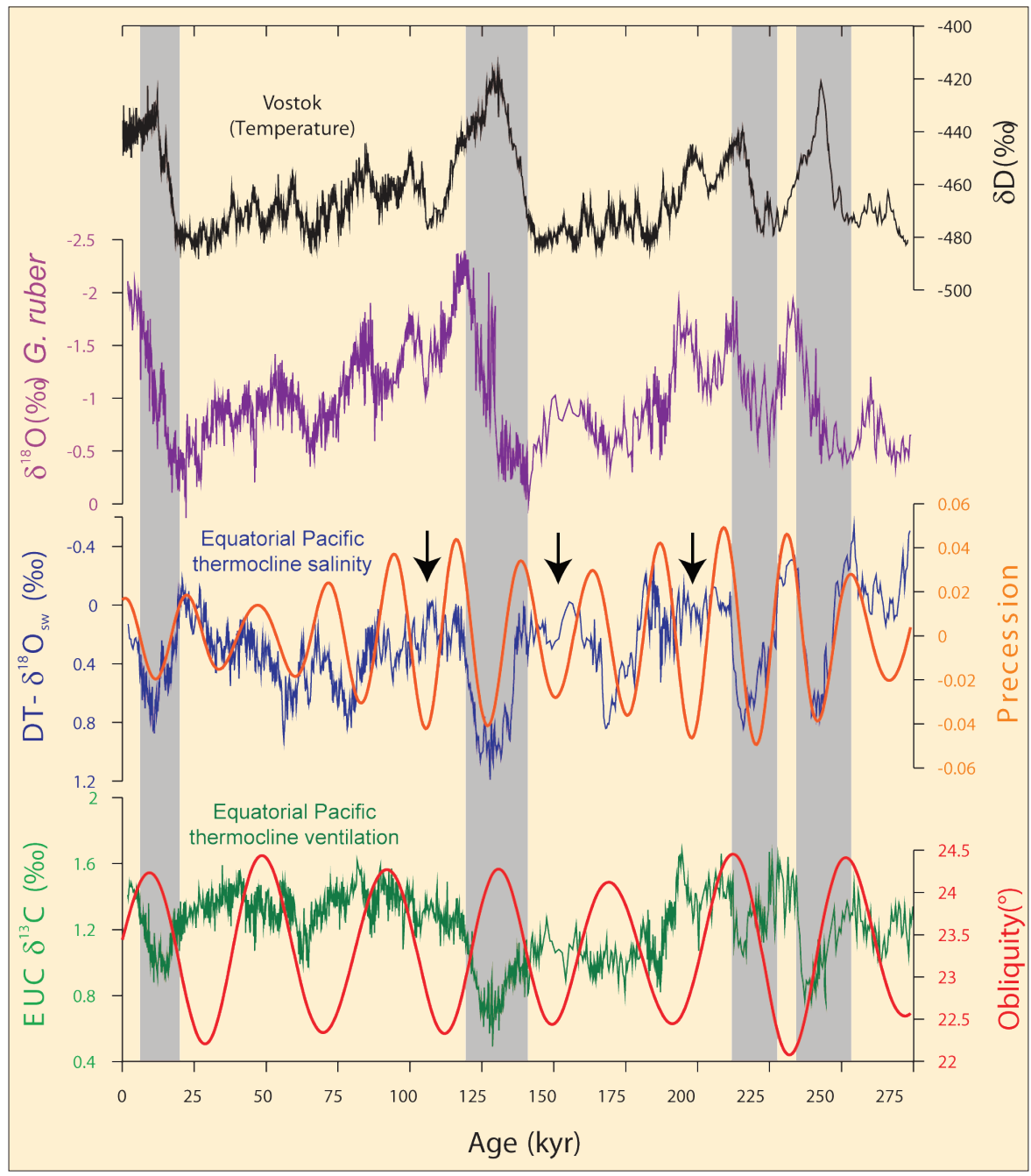

Figure 1: East tropical Pacific ODP Site 1240 records ( $0^{\circ} 01.31^{\prime} \mathrm{N}, 86^{\circ} 27.76^{\prime} \mathrm{W} ; 2921 \mathrm{~m}$ water depth); Antarctic Vostok deuterium ( $\delta D$; black) (Petit et al., 1997); Site $1240 \mathrm{G}$. ruber $\delta^{18} \mathrm{O}$ record for stratigraphic reference (purple; Pena et al., 2008); calculated deep thermocline seawater $\delta^{18} \mathrm{O}\left(\mathrm{DT}-\delta^{18} \mathrm{O}\right.$; blue), after removal of global ice volume effect, as a proxy for relative salinity changes in the ETP thermocline; orbital precession index (orange); $\delta^{13} \mathrm{Crecord}$ measured on N. dutertrei and associated with the Equatorial Undercurrent (EUC) (green); orbital obliquity index (red). Vertical shadowed bars mark periods of intense DT- $\delta^{18} \mathrm{O}$ and $\delta^{13} \mathrm{C}$ excursions coinciding with low precession and high obliquity. Black arrows indicate periods where $D T-\delta^{S W} \mathrm{O}_{s w}$ values deviate from the precessional pattern.

in tropical Pacific records (Lea et al., 2000) and is significantly depicted in the frequency spectrum analyses of the ETP thermocline (Pena et al., 2008). The influence of obliquity on the ENSO-like variability is puzzling because the insolation forcing due to obliquity changes is rather small at low latitudes $\left(<3 \mathrm{Wm}^{-2}\right)$. Therefore, it is unlikely that the 41-kyr periodicity in tropical records arises as a direct climatic response to obliquity-driven insolation changes (Lee and Poulsen, 2005).

It is more plausible that the obliquity influence is propagated from high latitudes (where the obliquity-related insolation changes are stronger) to low latitudes by means of atmospheric teleconnections (Chiang and Lintner, 2005), or via the ocean through equatorward advection of sub-surface waters (Bostock et al., 2004; Lee and Poulsen, 2005). Intense negative $\delta^{13} \mathrm{C}$ excursions in the thermocline waters of the ETP (Figs. 1 and 2) during glacial terminations are a persistent feature in numerous tropical records, and have previously been explained as a signal advect- ed from the Southern Ocean (Ninnemann and Charles, 1997; Shackleton et al., 1983; Spero and Lea, 2002). At Site 1240, these negative $\delta^{13} \mathrm{C}$ excursions occur in parallel with the enhancement of La Niña-like conditions (high DT- $\delta^{18} \mathrm{O}_{s w}$ ) during glacial terminations (Fig. 2). Moreover, these isotopic excursions are synchronous with the onset of the deglacial atmospheric $\mathrm{pCO}_{2}$ increase recorded in Antarctic ice cores (Pena et al., 2008; Spero and Lea, 2002). The low $\delta^{13} \mathrm{C}$ signal is due to the resumption of the circum-Antarctic upwelling of "old" waters that are eventually incorporated into intermediate water masses (most likely subantarctic mode water) and advected into the tropical thermocline through the "oceanic tunnel" (Pena et al., 2008; Spero and Lea, 2002). This scenario is supported by the close match between decreasing sea salt sodium fluxes in Antarctic ice cores (ssNa flux), an indicator of Antarctic sea ice extension (Wolff et al., 2006), and the ETP $\delta^{13} \mathrm{C}$ minimum during the deglaciation (Fig. 2). During this period, high obliquity resulted in increased 
summer insolation at high latitudes and therefore in a decrease in sea ice around Antarctica. With the retreat of sea ice, a resumption of Southern Ocean upwelling could be driven by a southward shift and/ or an intensification of the westerly winds around Antarctica, a feature supported by different model studies (Rojas et al., 2008; Toggweiler et al., 2006). The southward shift of the westerlies could also be induced by the establishment of La Niñalike conditions in the ETP (Toggweiler, 1999; Toggweiler et al., 2006), an observation that has been recently confirmed by means of meteorological satellite information during El Niño and La Niña periods (Pena et al., 2008; Yuan, 2004).

\section{The last deglaciation scenario}

The combination of low precession and high obliquity conditions during the last deglaciation resulted in a particular sequence of events: Perihelium during boreal summer (low precession) enhances the seasonal wind field divergence and temperature gradients in the ETP shifting the system towards La Niña-like conditions. Thus, the establishment of La Niña-like

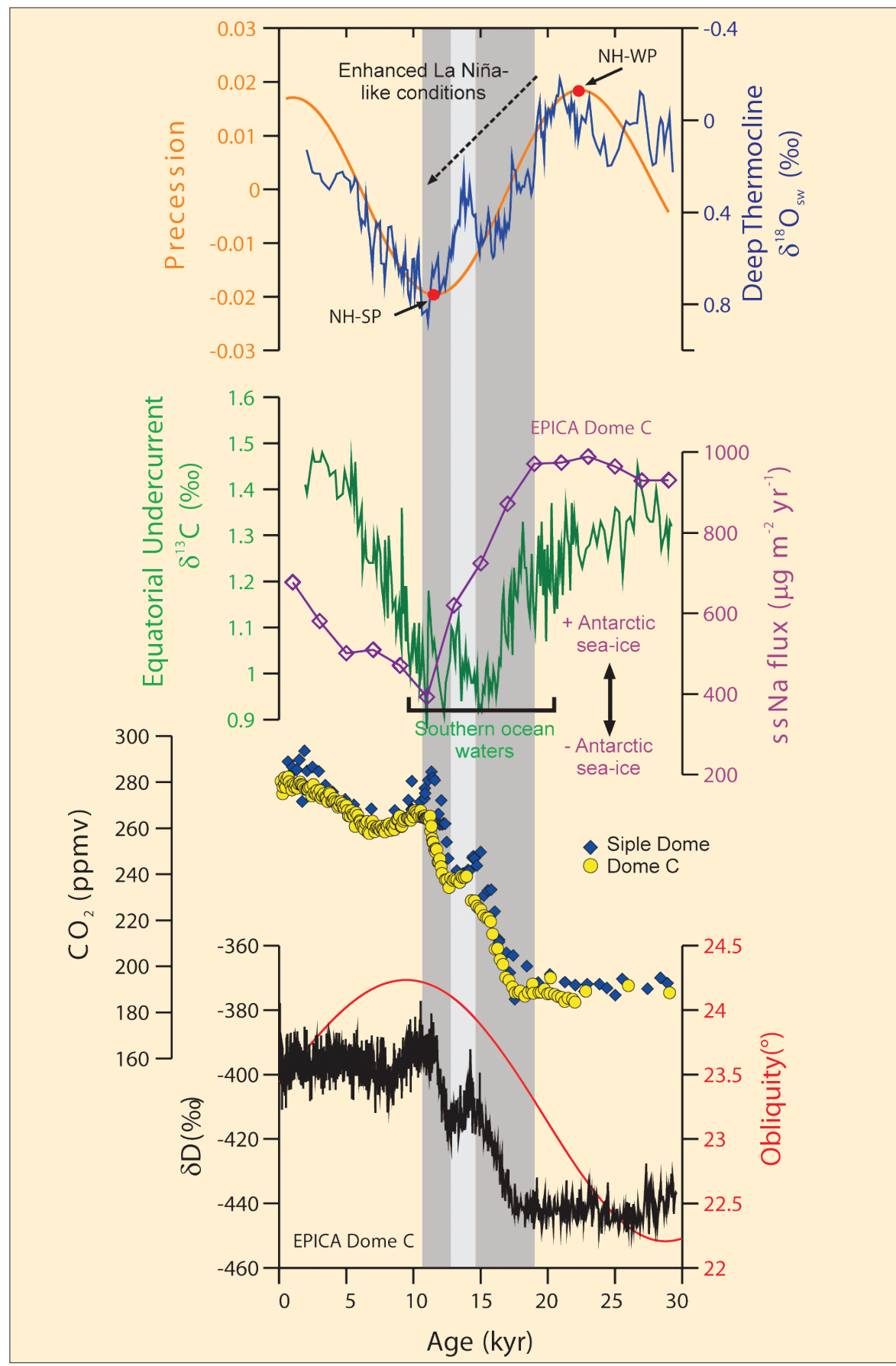

Figure 2: Detail of the last $30 \mathrm{kyr}$ of Deep Thermocline $\delta^{18} \mathrm{O}_{\text {sw }}$ (blue) compared to the thermocline $\delta^{13} \mathrm{C}$ (green) at Site 1240 (Pena et al., 2008). The orbital precession index (orange) is plotted for reference. NH-WP = Northern Hemisphere Winter Perihelium; NH-SP = Northern Hemisphere Summer Perihelium. Also included is the sea salt sodium flux record (purple), as an indicator of Antarctic sea ice extension (Wolffet al., 2006). Antarctic $\mathrm{CO}_{2}$ records from Siple Dome (blue diamonds) (Ahn et al., 2004) and EPICA Dome C (yellow circles) (Monnin et al., 2001) have been plotted for reference, as well as the Dome C deuterium ( $\delta D$; black) (Jouzel et al., 2007) and the obliquity (red). Dark gray bar indicates the period of enhanced La Niña-like conditions in the ETP, light gray bar highlights a reversed interval of weaker La Niña-like conditions coincident with a plateau in the Antarctic $\mathrm{CO}_{2}$ record and the Antarctic Cold Reversal period.

conditions induces a southward shift of the westerlies in the southern hemisphere. In parallel, high obliquity conditions increase summer insolation at high latitudes and cause Antarctic sea ice retreat. Eventually, the combination of a southward shift of the westerlies and poleward retreat of sea ice favors the intensification of circumAntarctic upwelling, which advects more "old" waters to the surface that are ultimately incorporated into intermediate water masses and propagated through "oceanic tunnel" advection towards tropical thermoclines.

\section{Acknowledgements}

We acknowledge support from the Gary Comer Science and Education Foundation, Natural Environmental Research Council, UK-Ocean Drilling Program (ODP), "Ramón y Cajal" program (MEC-Spain) and the Catalan Government. Samples were provided by ODP (sponsored by the U.S. National Science Foundation and participating countries under management of Joint Oceanographic Institutions).

\section{Note}

All presented data will be available from the NOAA Paleoclimatology website at www.ncdc. noaa.gov/paleo/paleo.html

\section{References}

Clement, A.C., Seager, R. and Cane, M.A., 1999: Orbital controls on the El Niño/Southern Oscillation and the tropical climate, Paleoceanography, 14: 441-456.

Koutavas, A., Lynch-Stieglitz, J., Marchitto, T.M. and Sachs, J.P., 2002: El Niño-Like Pattern in Ice Age Tropical Pacific Sea Surface Temperature, Science, 297: 226-230

Pena, L.D., Cacho, I., Ferretti, P. and Hall, M.A., 2008: El Niño-Southern Oscillation-like variability during glacial terminations and interlatitudinal teleconnections, Paleoceanography, 23: PA3101, doi:10.129/2008PA001620.

Spero, H.J. and Lea, D.W., 2002: The Cause of Carbon Isotope Minimum Events on Glacial Terminations, Science, 296: 522-525.

Wolff, E.W., et al., 2006: Southern Ocean sea-ice extent, productivity and iron flux over the past eight glacial cycles, Nature, 440: 491-496.

For full references please consult:

www.pages-igbp.org/products/newsletters/ref2009_1.html 


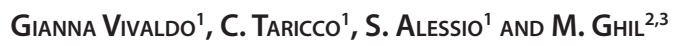

'Department of General Physics, University and Institute of Interplanetary Space, Torino, Italy; taricco@ph.unito.it

${ }^{2}$ Geosciences Department and Laboratory of Dynamic Meteorology, Ecole Normale Supérieure, Paris, France; ${ }^{3}$ Department of Atmospheric and

Oceanic Sciences and Institute of Geophysics and Planetary Physics, University of California, Los Angeles, USA

The radiometric and tephro-analysis dating of shallow-water lonian Sea cores is summarized. The 2-kyr series of volcanic pyroxene grains provides information on the volcanic activity of the Campanian area for the period that precedes detailed documentation of eruptions.

The key to gaining information on climate analogs and periodicities, on decadal to centennial timescales, is the measurement of proxy records over the recent millennia with multi-annual resolution and matching accuracy in dating. Accurate dating of non-laminated sediment records is difficult but crucial in achieving meaningful climate reconstructions. Here we describe an approach for constraining the chronology of shallow marine sediment cores from the Ionian Sea with an accuracy of better than $1 \%$.

The cosmogeophysics group in Torino (founded by Giuliana Cini Castagnoli) has been studying sediment cores collected from the Tyrrhenian and Ionian Seas for many years; in particular the group has performed the absolute dating of shallowwater cores drilled on the Gallipoli Terrace (Gulf of Taranto, Ionian Sea). Due to the proximity of the volcanically active Campanian area (Fig. 1), the Gallipoli Terrace is well situated for accurate sediment dating: tephra layers correspond to historically documented eruptions, thus allowing accurate dating and determination of the sedimentation rate. Figure 1 show the locations of four gravity cores, collected from $200 \mathrm{~m}$ water depth. By applying the methods described in the following paragraphs, we demonstrated that the sedimentation rate has remained constant to a very good approximation over the last two millennia and across the whole Gallipoli Terrace.

Sedimentation rates were first deduced from the top $20 \mathrm{~cm}$ of the four cores by measuring the excess ${ }^{210} \mathrm{~Pb}$ activity with respect to the ${ }^{226} \mathrm{Ra}$ isotope. This method showed that $1 \mathrm{~cm}$ of sediment was deposited in about 15.5 years. Moreover, the ${ }^{210} \mathrm{~Pb}$ dates were in agreement with the ${ }^{137} \mathrm{Cs}$ peaks produced by nuclear bomb testing in 1963-64 AD. This result indicates that the sediments in the upper parts of the cores remained undisturbed during the extraction process (Bonino et al., 1993; Cini Castagnoli et al., 1990).

Using the sedimentation rate obtained by the ${ }^{210} \mathrm{~Pb}$ method, we searched in the deeper sections of the cores for the presence of volcanic material corresponding to

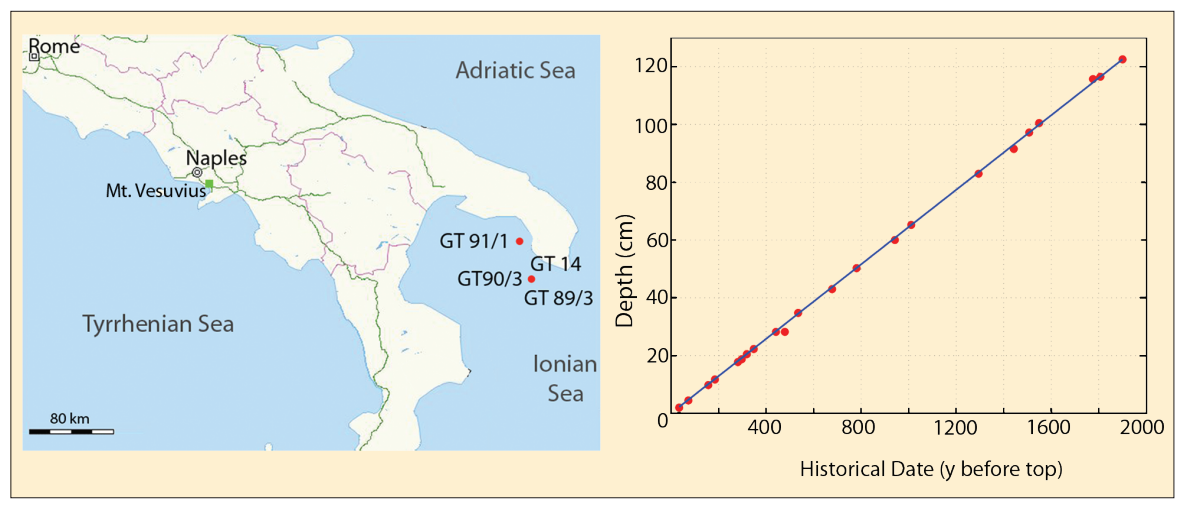

Figure 1: a) Map showing location of drilling sites (red circles) and location of Mt. Vesuvius (green square). $\boldsymbol{b}$ ) Timedepth relationship over the last $2 \mathrm{kyr}$. The depth at which a volcanic peak is found in the sediment is plotted versus the historical date of the corresponding eruption, expressed in years before 1979 AD, the date of the core top. historically documented volcanic events. Peaks in the number density of pyroxene grains that were clearly of volcanic origin, as shown by a characteristic morphology (Bonino et al., 1993), were considered as markers for volcanic eruption events. In the $2 \mathrm{kyr}$-long pyroxene series measured in core GT89-3, we identified 22 peaks that correspond to known historical eruptions that occurred in the Campanian area over the last two millennia, starting with the 79 AD eruption that buried Pompeii and ending with the documented eruption of 1944 (Arno' et al., 1987). The very sharp

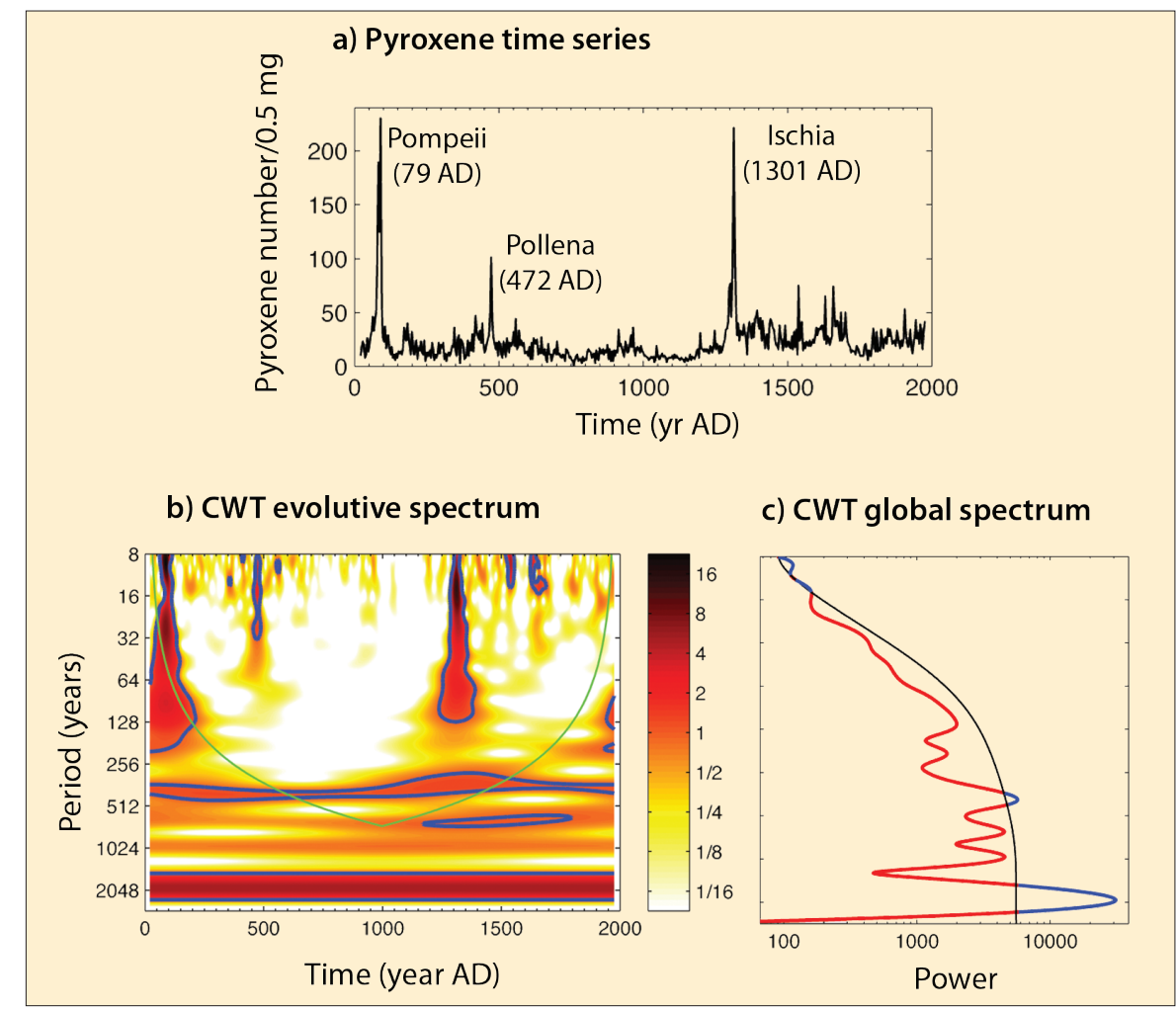

Figure 2: $\boldsymbol{a})$ Pyroxene series measured in the GT89-3 shallow-water lonian core. $\boldsymbol{b}$ ) Evolutive spectrum of pyroxene series by Continuous Wavelet Transform (CWT) with complex Morlet wavelet (parameter $\omega_{0}=6$ ). Power is normalized dividing it by the level of significance at $90 \%$ confidence, computed according to the statistical test described by Torrence and Compo (1998). Blue lines correspond to normalized power equal to 1. The green line represents the cone of influence, outside which power values are affected by zero padding at the edge of the series; such padding is performed before computing the CWT convolution in the frequency domain via a Fast Fourier Transform (FFT), in order to avoid aliasing in the time domain. c) Global wavelet spectrum (colored line) and corresponding significance level at $90 \%$ confidence (black line). Blue color highlights portions of the spectrum above this level. 
pyroxene peaks indicate that bioturbation by bottom-dwelling organisms is limited. Through pyroxene measurements performed in the cores extracted at different locations on the Gallipoli Terrace and through the remarkable coincidence among $\mathrm{CaCO}_{3}$ profiles in all the cores, Cini Castagnoli et al. (1990; 1992) provided evidence that the sedimentation rate is uniform across the Terrace. This result supports the high reliability of the dates for the climate records from this area.

Figure 1 shows the time-depth relationship over the last two millennia. Each pyroxene peak corresponds to a historical volcanic eruption. The linear regression gives $h=(0.0645 \pm 0.0002) \mathrm{yr}_{\mathrm{BT}^{\prime}}$ where $h$ is depth (in cm), $\mathrm{yr}_{\mathrm{BT}}$ means year-before-top (top = 1979 AD) and the correlation coefficient is $r=0.99$; the slope of this straight line is the sedimentation rate. The highly linear relationship demonstrates that the sedimentation rate has remained constant over the last two millennia to a very good approximation. The pyroxene series, covering the last two millennia with a temporal resolution of $3.87 \mathrm{yr}$ (corresponding to a sampling interval of $2.5 \mathrm{~mm}$ ), is shown in Fig. 2a. The three largest peaks correspond to the eruptions of Pompeii (Mt. Vesuvius; 79 AD), Pollena (Mt. Vesuvius; 472 AD) and Ischia (Mt. Arso; 1301 AD). In a recent paper (Taricco et al., 2008), we focused on the long-term variability of this series and, using several advanced spectral methods, identified both a millennial trend and a $400-y$ oscillation, with a high confidence level.

Here we investigate the decadal variability in the volcanic record, possibly related to the length of the activity cycles of Mt. Vesuvius. Detailed information on these cycles is available from 1638 AD and is documented in the catalogue of Arnò et al. (1997). Each cycle ends with an explosive eruption of moderate-to-violent intensity, followed by a dormancy phase of variable duration; the average interval between successive explosive eruptions is roughly $15 \pm 3$ years. Such cyclic build-ups of pressure, followed by rapid releases, are called relaxation oscillations, which are suspected to occur in the multi-phase (liquidsolid) environment of magma chambers under a volcano. For different volcanoes, the activity cycles can be fairly regular, as is the case for Mt. Vesuvius, or very irregular (Barmin, 2002). The qualitative regularity and mean period between successive eruptions can help diagnose the regime in which the volcano's hidden dynamics operates and possibly help predict future eruptions (e.g., Palumbo, 1997).

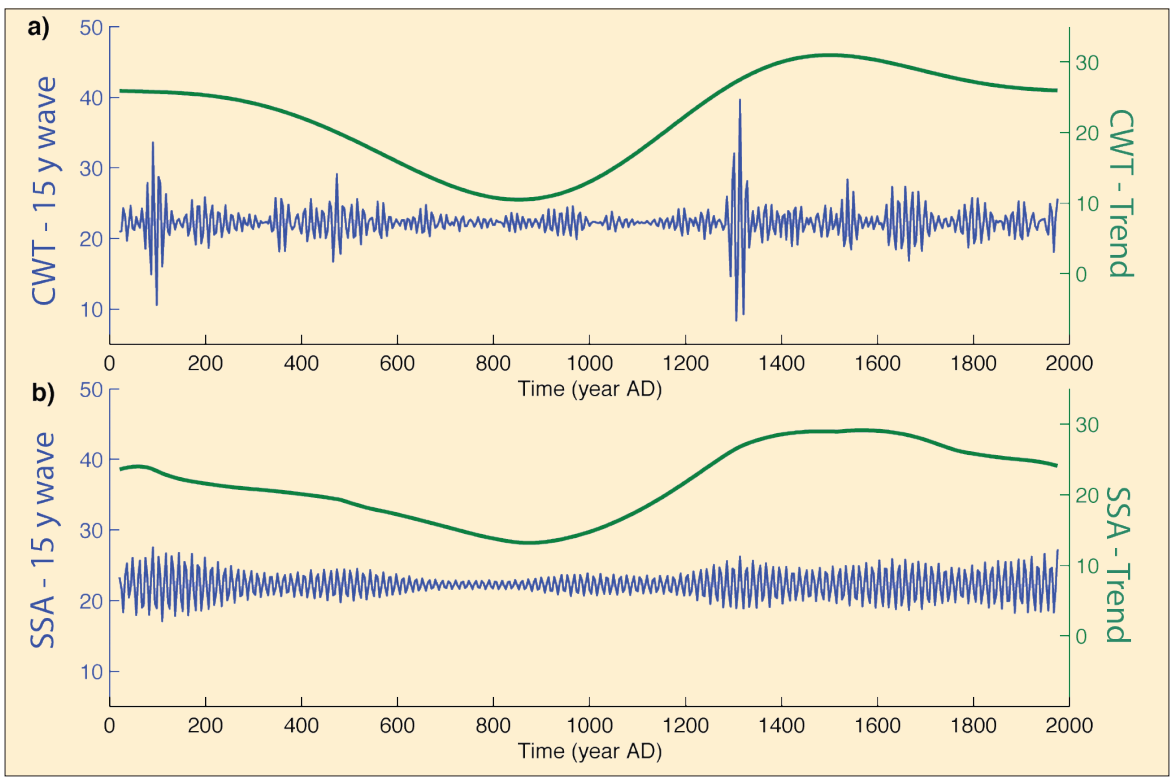

Figure 3: Reconstructed high-frequency $\left(\sim 1 / 15 \mathrm{yr}^{-1}\right)$ component (purple lines) and trend (green lines) of the pyroxene series. The reconstructions are obtained by a) Continuous Wavelet Transform (CWT) and b) Singular Spectrum Analysis (SSA).

In Figures $2 \mathrm{~b}$ and $\mathrm{c}$ we show the results of the spectral analysis of the pyroxene series, performed by Continuous Wavelet Transform (CWT). Figure $2 b$ shows the CWT evolutive spectrum as a function of time and period ( $1 /$ frequency). By averaging power over time at each period, the global wavelet spectrum, shown in Fig. 2c, is obtained. Besides the long-term components (trend and 400-yr oscillation), we notice significant power (with a $90 \%$ confidence level) in the high-frequency region and in particular around periods of $\sim 15 \mathrm{yr}$; this periodicity could be connected to the average interval between the explosive eruptions of the Vesuvius. The presence and statistical significance of the 15 -yr component is confirmed by Singular Spectrum Analysis (SSA; Ghil et al., 2002; Ghil and Taricco, 1997) and Monte-Carlo SSA (not shown).

Having revealed such regularity in this long time series allows one to study it prior to $1638 \mathrm{AD}$, when detailed information about recurring eruptions of Mt. Vesuvius is not available. The $15-\mathrm{yr}$ oscillation, reconstructed by Inverse CWT, is shown in Figure 3a. The CWT's high temporal resolution at high frequencies captures strong amplitude modulations. The amplitude modulations obtained in Figure $3 \mathrm{~b}$ by SSA are consistent with those in Figure 3a but are much smoother.

In the last 2 kyr we can distinguish three intervals (Figs. 3a, b): the intervals prior to $600 \mathrm{AD}$ and post $1200 \mathrm{AD}$ exhibit higher amplitudes of the 15-yr cycle, and are separated by an interval (600 - 1200 AD) of lower amplitudes. The same three regimes are also present in the long-term trend revealed in the record by both CWT and SSA (Figs. 3a, b) and are also visible in the evolutionary wavelet spectrum (Fig. 2b). Higher levels of overall volcanic activity of Mt. Vesuvius, concomitant with an increased pyroxene background level, are thus accompanied by higher-amplitude 15 -yr cycles, both before 600 AD and after 1200 AD.

The pyroxene measurements performed by the Torino cosmogeophysics group in the lonian sediments are thus the basis of a very accurate dating of multiproxy records over the last two millennia. Moreover, this high-resolution pyroxene series can provide information about the volcanic activity in the Campanian area before the period for which detailed documentation of eruptions is available.

These well-dated sediments are also providing climate information over the last two millennia. Currently, we are preparing for publication the results obtained from a high-resolution record of foraminiferal $\delta^{18} \mathrm{O}$ that exhibits highly significant centennial and decadal oscillatory components of climate variability.

\section{References}

Arnò, V., Principe, C., Rosi, M. Santacroce, R., Sbrana, A. and Sheridan, M.F., 1987: Eruptive History, In: Santacroce R. (Ed), SommaVesuvius, Quaderni de La Ricerca Scientifica CNR, Roma, Italy, 114(8): 53-103.

Bonino, G., Cini Castagnoli, G., Callegari, E.,and Zhu, G.M., 1993: Radiometric and tephroanalysis dating of recent lonian sea cores, Nuovo Cimento C, 16: 155-161.

Cini Castagnoli, G., Bonino, G., Caprioglio, F., Provenzale, A., Serio, M. and Zhu, G.M., 1990: The carbonate profile of two recent Ionian sea cores: evidence that the sedimentation rate is constant over the last millennia, Geophysical Research Letters, 17: 1937-1940.

Cini Castagnoli, G., Bonino, G., Provenzale, A., Serio, M. and Callegari, E., 1992: The $\mathrm{CaCO}_{3}$ profiles of deep and shallow Mediterranean sea cores as indicators of past solar-terrestrial relationship, Nuovo Cimento C, 15: 547-563.

Taricco, C., Alessio, S. and Vivaldo, G., 2008: Sequence of eruptive events in the Vesuvio area recorded in shallow-water Ionian Sea sediments, Nonlinear Processes in Geophysics, 15: 25-32.

For full references please consult:

www.pages-igbp.org/products/newsletters/ref2009_1.html

(1) 


\section{0 years of climate variability inferred from Arctic lake} sediments

Darrell S. Kaufman

Department of Geology, Northern Arizona University, Flagstaff, USA; Darrell.Kaufman@nau.edu

\section{A compilation of 14 new proxy records from Arctic lake sediments documents late Holocene climate and environmental change across North America and northwest Europe.}

\section{New records from Arctic lakes}

"PAGES-Arctic2k" (www.pages-igbp.org/ science/arctic $2 \mathrm{k} /$ ) was launched in March 2008 to generate new high-resolution paleoclimate records for investigating Arctic climate change during the past two millennia. As a contribution to the Arctic2k initiative and to the International Polar Year, a group of Arctic paleoscientists focusing on lake sediments recently completed a special issue of the Journal of Paleolimnology. The 14 papers report new records of Holocene climate and environmental change from Arctic lakes, with an emphasis on the last $2 \mathrm{kyr}$. The compendium stems from the Arctic System Sciences (ARCSS) 2 kyr project, which was funded in 2005 by the US National Science Foundation.

The journal volume represents a coordinated response to the pressing need for additional, high-quality proxy-climate records from high latitudes. The studies contribute to the long-term perspective on natural climate variability that is needed to understand historically unprecedented changes now occurring in the Arctic. They focus on lakes from across the N. American Arctic and NW Europe (Fig. 1; see also Gajewski et al., this issue). One of their overarching goals is to assess recent warming against the backdrop of the last two millennia. Records of this duration are needed to investigate the conditions prior to the last major cold interval-the Little Ice Age (LIA) - when most of the Arctic experienced the coldest temperatures of the last 8 kyr. Records of this duration are also the focus of other campaigns for paleoclimate research globally, ultimately providing the basis for a global synthesis of the climate of the last 2 kyr.

Lakes are widely distributed in the Arctic, and they contain the most accessible proxy records that consistently extend through the late Holocene and longer. A large network of proxy climate records is needed to capture the spatial variability of climatic change, and to study spatial patterns of atmospheric circulation at a synoptic scale.

Quantifying past climate from records in lakes is among the greatest challenges in paleolimnology. Absolute values of temperature, precipitation, and other variables are needed to gauge the magnitude

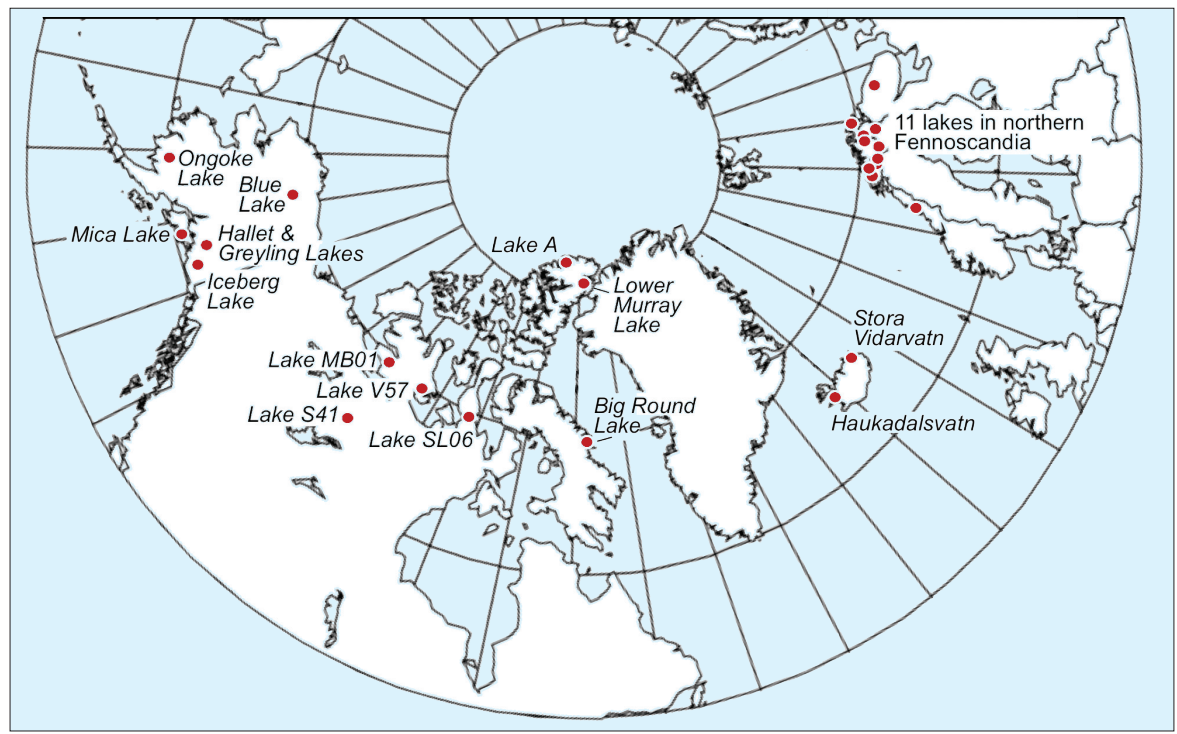

Figure 1: Location of lakes included in a new special issue of the Journal of Paleolimnology dedicated to reconstructing late Holocene climate and environmental change from Arctic lake sediments.

of past climate change and to compare with the output of climate-model simulations. The studies in the new compendium rely on multiple sedimentological and biological indicators that primarily reflect changes in summer temperatures, the main control on physical and biological processes in lakes at high latitudes. Some reflect other aspects of the climate system, including nutrient availability and winter storm-track trajectories.

\section{Results from proxy records}

Four of the studies in the volume used varve thickness from glacier-fed lakes to infer past summer temperatures. The strength of these records is their annual resolution and accurate timescale. Cook et al. generated a varve-inferred temperature record from Ellesmere Island that covers the past $5 \mathrm{kyr}$, making it the longest annually resolved lacustrine record from the Arctic. Bird et al. present the first annually resolved summer-temperature record from north of the treeline in northern Alaska. In southern Alaska, Loso developed a 1.3 kyr record, and in Baffin Island, Thomas and Briner reconstructed summer temperature for the past $1 \mathrm{kyr}$. On Ellesmere Island, Tomkins et al. used a novel sedimentary feature (sedimentary pellets) to interpret ice-cover extent.

Three papers focused on the use of chironomids to develop quantitative temperature records from both northern Canada (Porinchu et al., MacDonald et al.) and Iceland (Axford et al.), and two on the use of pollen for temperature reconstructions from Fennoscandia (Bjune et al.) and northern Canada (Peros and Gajewski). Additionally, Chipman et al. used diatoms to reconstruct lake-level fluctuations from SW Alaska. Sedimentation rates at sites suitable for these biological proxies are usually lower than in glacier-fed lakes, and time-averaging and sample-size requirements are relatively high. The resulting records typically have only centennial resolution but they extend back at least 2 kyr. Most of the temperature reconstructions based on these proxies show broad similarities with others averaged over the northern hemisphere.

Nine studies reported results of organic-matter and biogenic-silica analyses, which were mainly used as part of a multiproxy approach. McKay and Kaufman used the organic-matter content from two nearby glacier-fed lakes in south-central Alaska, together with geomorphologic evidence for late Holocene glacier fluctuations within the catchments, and their previously published biogenic-silica-inferred temperature record, to reconstruct relative changes in effective moisture. Geirsdóttir et al. showed that biogenic-silica content was correlated with spring/earlysummer temperature in Iceland, and they used organic-matter content to interpret the impact of landscape stability. Finally, Schiff et al. analyzed the oxygen-isotope composition of diatoms from a coastal 


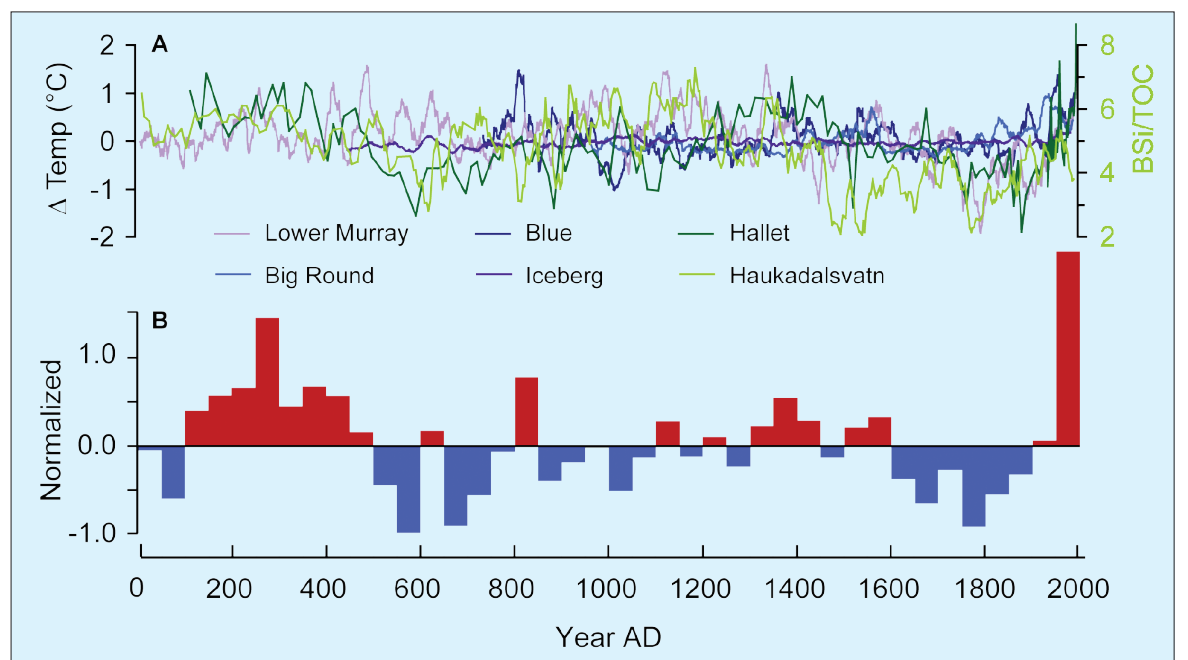

Figure 2: Summary of the 6 new proxy climate records from Arctic lakes with sub-decadal to annual resolution. $\boldsymbol{A}$ ) 5 records were calibrated using instrumental climate records to infer past summer temperature and are plotted as anomalies relative to the average of the last millennium ( $\triangle T$ Temp). 1 record (Haukadalsvatn) was not calibrated and is plotted according to the raw ratio of biogenic-silica to total-organic content (BSi/TOC); $\boldsymbol{B}$ ) The records were stacked by binning the data into 50-year intervals, normalizing each to a mean of zero and a variance of 10 , then averaging the values for each bin. The records include Lower Murray Lake (Cook et al.), Big Round Lake (Thomas and Briner), Blue Lake (Bird et al.), Iceberg Lake (Loso), Hallet Lake (McKay and Kaufman), and Haukadalsvatn (Geirsdóttir et al.).

lake in southern Alaska to infer changes in the trajectory of storm tracks in a region dominated by the influence of the Aleutian low-pressure system.

\section{High-resolution records}

Of the new proxy records, six are resolved at sub-decadal to annual scale, including four based on varve thicknesses and two on biogenic-silica content (Fig. 2). They were calibrated using instrumental climate records to develop regression models to infer numerical values of past summer temperature downcore. The temperature variation for these records averages $\pm 0.73^{\circ} \mathrm{C}(1 \sigma)$. Stacking the records by binning the data into 50 -year intervals, normalizing each to a mean of zero and a variance of $1 \sigma$, then averaging the values for each bin reveals a coherent structure to the time series. Most striking is the most recent half-century, which exhibits the single highest average normalized temperature values and a shift to higher temperatures that is twice as large as any other consecutive interval during the last 2 kyr.

\section{Future plans}

In the future, the new lacustrine proxy records will be integrated into a larger network of sites that includes other pa- leoclimate archives. These will be used to investigate the spatial and temporal variability of climate change in the Arctic, and will be integrated into experiments using general circulation models. These data-model comparisons are aimed at distinguishing patterns of forced climate change from internal variability in the Arctic climate system. The effort will be part of the PAGES Arctic $2 k$ initiative and will be facilitated by data management provided through the World Data Center for Paleoclimatology (www.ncdc.noaa.gov/paleo/) and the PAGES Arctic2k Metadatabase (www.pages.unibe.ch/science/arctic2k/). More information about this project, including an overview of the climate-modeling component, is available at: www.arcus. org/synthesis $2 \mathrm{k} /$

\section{Acknowledgements}

I thank the authors of the 14 papers now in press in the Journal of Paleolimnology, and the 41 peer reviewers for their generous input. I thank $M$. Brenner and T. Whitmore for editorial support, N. McKay for data analysis, and the WDC for Paleoclimatology for data archival. Research and project coordination were funded primarily by the US-NSF Arctic System Science Program.

\section{References}

Bird, B.W., Abbott, M.B., Finney, B.P. and Kutchko, B., in press: A 2000 year varve-based climate record from the central Brooks Range, Alaska, Journal of Paleolimnology, 41 (1): Jan. 2009.

Cook, T., Bradley, R.S., Stoner, J.S. and Francus, P., in press: Five thousand years of sediment transfer in a High Arctic watershed recorded in annually laminated sediments from Lower Murray Lake, Ellesmere Island, Nunavut, Canada, Journal of Paleolimnology, 41(1): Jan. 2009.

Geirsdóttir, A., Miller, G.H., Thordarson, T. and Ólafsdóttir, K.B., in press: A 2000 year record of climate variations reconstructed from Haukadalsvatn, west Iceland, Journal of Paleolimnology, 41(1): Jan. 2009.

Loso, M.G., in press: Summer temperatures during the Medieval Warm Period and Little Ice Age inferred from varved proglacial lake sediments in southern Alaska, Journal of Paleolimnology, 41(1): Jan. 2009.

McKay, N.P. and Kaufman, D.S., in press: Holocene climate and glacier variability at Hallet and Greyling Lakes, Chugach Range, southcentral Alaska, Journal of Paleolimnology, 41(1): Jan. 2009

Thomas, E.K. and Briner, J.P., in press: Climate of the past millennium inferred from varved proglacial lake sediments, northeast Baffin Island, Arctic Canada, Journal of Paleolimnology, 41(1): Jan. 2009.

For full references please consult:

www.pages-igbp.org/products/newsletters/ref2009_1.html

\section{Holocene paleoclimate of the Canadian Arctic Islands: The ACVAST project}

Konrad Gajewski ${ }^{1}$, M. Peros ${ }^{1}$, S. Finkelstein ${ }^{2}$ and M. Fortin ${ }^{1}$

'Department of Geography and Ottawa-Carleton Institute of Biology, University of Ottawa, Canada; gajewski@uottawa.ca; Department of Geography, University of Toronto, Canada

\section{Multi-proxy studies of a series of lakes across the Canadian Arctic Islands are providing the first continuous and quantitative estimates of Holocene climate variability for the region. These reconstructions highlight the impact of climate variations on biological production and biodiversity in Arctic ecosystems.}

Arctic ice cores provide critical records of Holocene climate variability. However, to map the spatial patterns of past climates and explain local ecological responses to climate variability, an extensive array of sites is needed. Continuous records from lake sediments provide a major source of information toward this goal. 
The largest extent of tundra in the world is in the Canadian Arctic Archipelago, yet the postglacial environmental history of this region is little known. As opposed to Greenland, where numerous studies of both ice cores and lake sediments have been undertaken, few series from the Canadian Arctic have been published. In addition to difficult access and high costs, a deterrent to funding of Arctic lake sediment studies has been the perception, in North America at least, that pollen analysis is a "blunt instrument" in Arctic environments. Only recently has this perception been challenged (Gajewski, 2006).

A recent project, Arctic Climate Variability at Several Timescales (ACVAST), has enabled the analysis of many lake sediment cores from across the Canadian Arctic Islands (Fig. 1), providing an array of sites with continuous records of Holocene environmental variability. Multi-proxy analyses (pollen, diatoms and chironomids, biogenic silica and sedimentary properties) are being performed on these cores. Due to the recent publication of several modern datasets for calibration (Barley et al., 2006; Bunbury and Gajewski, subm.; Fortin and Gajewski, subm. a; Gajewski, 1995, 2002; Gajewski et al., 2005; Kerwin, 2000; Ritchie et al., 1987; Whitmore et al., 2005), quantitative reconstructions of past climates from pollen, chironomids and sediment biogenic silica are possible. Modern calibration data from many parts of the Arctic are also available for diatoms (Bouchard et al., 2004) but a lack of sufficient modern analogs, taxonomic difficulties and dissolution of diatoms is hampering down-core reconstruction efforts. Additionally, new high-resolution modern climate data are available for calibration model development (Atkinson and Gajewski, 2002; Atkinson et al., 2000).

\section{Results from the central and western Arctic}

Results from three sites (Fig. 2) show how Holocene climate changes affected terrestrial and aquatic primary production. These sediment cores were dated by radiocarbon and ${ }^{210} \mathrm{~Pb}$ methods. In spite of the well-known difficulties with dating cores in low-organic Arctic sediments (Gajewski et al., 1995), the general reliability of the chronologies is confirmed by stratigraphic correlation with pollen sequences and reconstructions based on glacial geology (for discussion see Peros and Gajewski, 2008a; Peros et al., subm.).

The use of heavy liquid separation as a pollen processing technique (Zabenskie et al., 2006) has increased the feasibility of producing pollen records from Arctic lake sediments to at least centennial resolution. The modern analog method (Overpeck et al., 1985) was used with pollen percentage data of Lakes KR02 and JR01 (Fig. 2) to reconstruct July temperature for the Holocene, and shows that the early Holocene was $1-2^{\circ} \mathrm{C}$ warmer than the early $20^{\text {th }}$ century (Fig. 2; Peros and Gajewski, 2008a; Zabenskie and Gajewski, 2007). However, these estimates, based on percentage pollen data, may underestimate the actual temperature change. This underestimation is suggested by the pollen influx (grains $\mathrm{cm}^{-2} \mathrm{yr}^{-1}$; indicative of pollen and plant production), which shows large changes in production that closely parallel the ice melt record from the Agassiz Ice Cap (Fisher et al., 1995; Fig. 2). Changes in pollen concentrations and influx are important components of pollen records from the Canadian Arctic. Many Arctic plants have broad environmental tolerances, so their ranges are wide and changed little during the Holocene, and pollen percentage diagrams may not indicate high variability. However, plant productivity and density are closely related to climate and are recorded by concentration and influx measures (Gajewski, 1995; Peros and Gajewski, 2008a, b). We also identify a long-term cooling during the mid- to late-Holocene from Melville, Banks, Somerset and Prince of Wales Islands (Gajewski, 1995; Gajewski et al., 2000; Gajewski and Frappier, 2001; Gajewski and Atkinson, 2003; Kauffman et al., 2004; Peros et al, subm.).

Millennial-scale variations, such as those seen in pollen influx at KR02, occur coherently with changes in temperatures interpreted from ice core isotope and melt series (Alley, 2004; Fisher et al., 1995). For example, a period of high pollen influx between 8-7 kyr at KR02 coincides with an increase in temperatures in Greenland and across N. America (Viau et al., 2006),

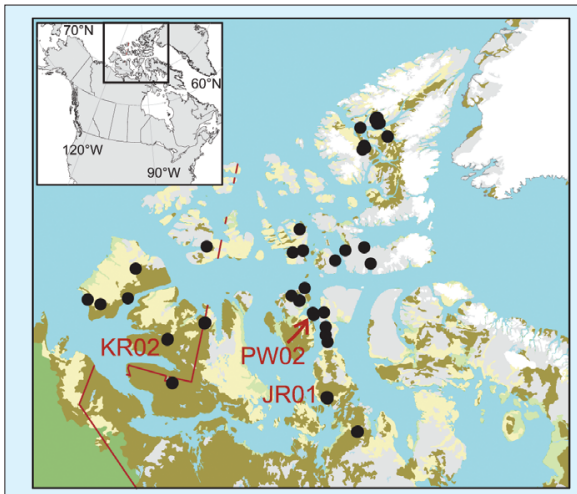

(a) Lake sediment cores and relatively high melt percentages in the Agassiz Ice Cap (Fig. 2).

Diatom-based paleolimnological reconstructions continue to improve as issues around dissolution, taxonomy (e.g., Paull et al., 2008), autecology (ecology of individual species) and biogeography are understood. Cores from different Arctic regions, or even on the same island, have greatly different assemblages (Finkelstein and Gajewski, 2007, 2008), indicating distinct biogeographic patterns and high biodiversity at some sites, in spite of their Arctic locations. While this variability makes it difficult to correlate records across the Arctic, it provides new information on the controls of diatom distribution, and what these organisms represent in fossil sequences. The relationship between diatom diversity and production is complex (Fig. 2), with a negative relationship in some cases (Fig. 2, Lake PW02; Finkelstein and Gajewski, 2008) and a positive one in others (Fig. 2, Lakes JR01 and KR02; LeBlanc et al., 2004; Podritske and Gajewski, 2007); trends likely related to local factors such as habitat complexity and nutrient availability. Sections of many Arctic lake sediment cores lack diatoms but the reasons for these diatom-free zones are not clear (Smith, 2002; Podritskie and Gajewski, 2007; Gajewski, 2008; Paull and Gajewski, subm.).

\section{Regional syntheses}

We have performed multi-proxy syntheses using cores from Victoria Island (KR02) and the Boothia Peninsula (JR01). Only broad-scale trends are coherent between the different proxies in the same core, and differences in the interpretations and reconstructions of these different proxies at the same site remain (Fig. 2; Fortin and Gajewski, subm b; Paull and Gajewski, subm). It is not yet clear if these differences are due to differential climate impacts on the

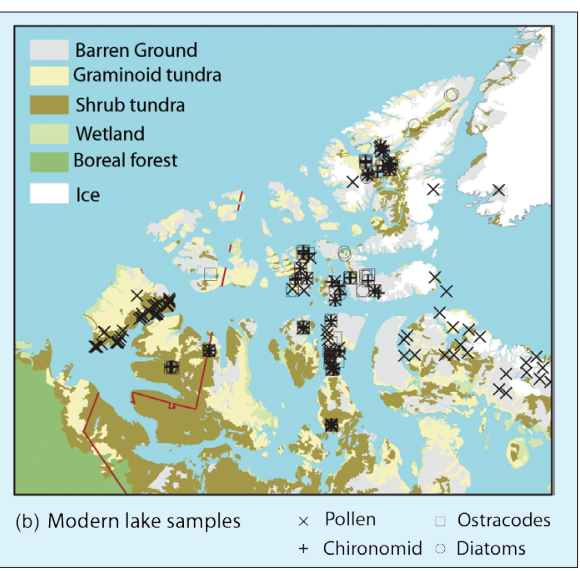

Figure 1: Maps of the Canadian Arctic Archipelago showing research sites of the AVCAST Project. a) Locations of lake sediment cores, with the three core sites in Figure 2 highlighted. b) Locations of modern lake sediment samples used for compilation of the calibration datasets, classified by the microfossil type. For data see: pollen - Whitmore et al. (2005); chironomid - Gajewski et al. (2005) and Barley et al. (2006); diatom-Bouchard et al. (2004); and ostracode-Bunbury and Gajewski (subm.). 
various biological communities, or to deficiencies in the modern calibration datasets used to compute the reconstructions. However, sufficient agreement exists between the ecological interpretations of the proxy data within one core and between the quantitative reconstructions of the proxies to suggest that these issues can be resolved by additional datasets from these regions.

\section{General conclusions}

These new results greatly improve previous estimates of the spatial and temporal extent of early Holocene warmth and subsequent cooling in the Arctic (e.g.,

a) Lake KRO2 - Victoria Island
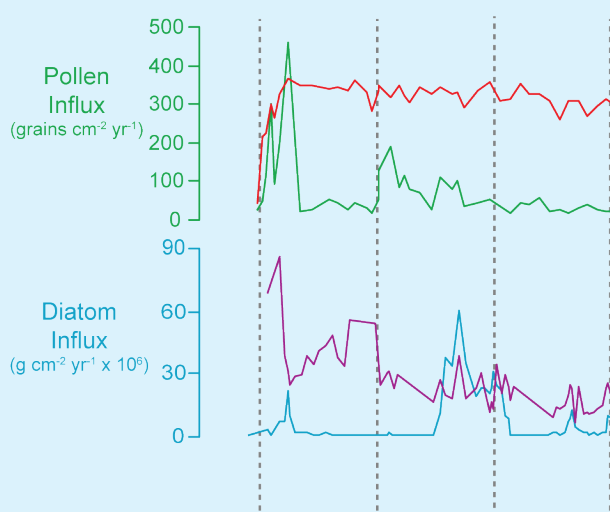

b) Lake PW02 - Russell Island
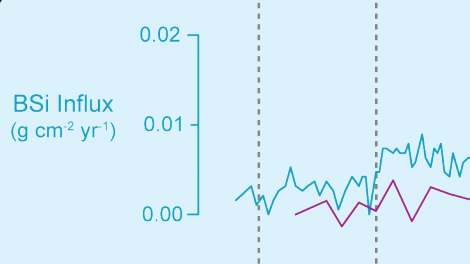

c) Lake JR01 - Boothia Peninsula
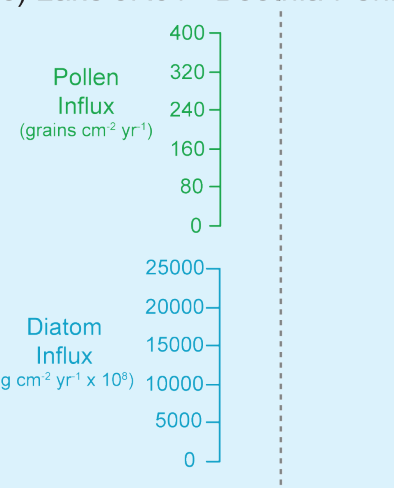

d) Regional paleoclimate records

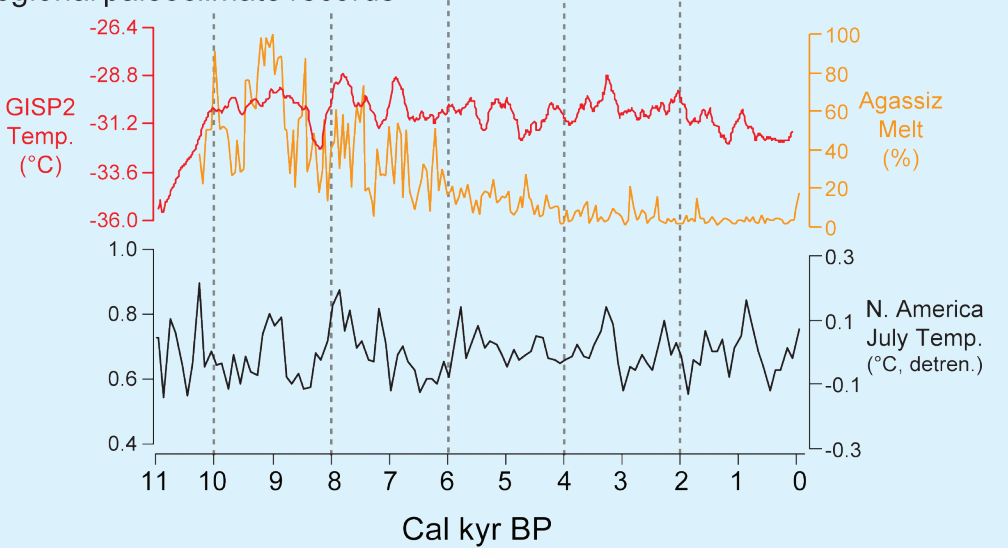

Figure 2: a-c) Paleoenvironmental data from 3 lakes showing pollen influx (green) and pollen-percentage derived temperature reconstruction (red) (KR02, Peros and Gajewski, 2008a; JR01, Zabenskie and Gajewski, 2007), diatom influx (blue) and diatom species richness (purple) (KRO2, Podritske and Gajewski, 2007; PW02, Finkelstein and Gajewski, 2008:JR01. LeBlancetal. 2004). d) N. America pollen-based mean July temperature reconstruction (black, Viau et al., 2006), Agassiz Ice Cap \% melt data (orange, Fisher et al., 1995), and GISP2 ice core paleo-temperature reconstruction (red, Alley, 2004). The very high values of the most recent diatom and sediment biogenic silica (BSi) accumulation records from Lakes KRO2 and PWO2 have been truncated to better show Holocene variability (see publications above).

Gajewski and Atkinson, 2003; Kaufman et al., 2004). Although the number of paleoenvironmental reconstructions in the Canadian Arctic has increased, the site density is still low, and more replication, especially of high temporal-resolution data for the early and mid-Holocene, is needed to quantify the spatial differences in climate and local effects of Holocene climatic changes on ecosystems. In addition, other issues remain, including (a) the need for more modern calibration data and consolidation of existing datasets to improve our ability to reconstruct past climate variables, (b) the need for better taxonomic harmonization across datasets, and (c) difficulties with radiocarbon dating, which in the Canadian Arctic is hampered by a lack of suitable organic material of terrestrial origin and the presence of widespread carbonate bedrock (Gajewski et al., 1995). Despite these challenges, our knowledge of environmental change in the Canadian Arctic has greatly improved and with additional research, a deeper understanding of this important region will no doubt be realized.

All ACVAST data are available on the LPC website (www.lpc.uottawa.ca) and deposited at the NOAA World Data Center for Paleoclimatology (www.ncdc.noaa. gov/paleo/index.html).

\section{Acknowledgements}

ACVAST is funded by the Canadian Foundation for Climate and Atmospheric Sciences.

\section{References}

Finkelstein, S.A. and Gajewski, K., 2008: Responses of Fragilarioid-dominated diatom assemblages in a small Arctic lake to Holocene climatic changes, Russell Island, Nunavut, Canada, Journal of Paleolimnology, DOl:10.1007/s10933-008-9215-5

Gajewski, K. and Atkinson, D., 2003: Climate change in the Canadian Arctic, Environmental Reviews, 11: 69-102.

Peros, M. and Gajewski, K., 2008a: Holocene climate and vegetation change on Victoria Island, western Canadian Arctic, Quaternary Science Reviews, 27: 235-249.

Podritske, B. and Gajewski, K., 2007: Diatom community response to multiple scales of Holocene climate variability in a small lake on Victoria Island, NWT, Canada, Quaternary Science Reviews, 26 : 3179-3196.

Zabenskie, S. and Gajewski, K., 2007: Post-glacial climatic change on Boothia Peninsula, Nunavut, Canada, Quaternary Research, 68 : 261-270.

For full references please consult:

www.pages-igbp.org/products/newsletters/ref2009_1.htm 


\section{Stable isotopes in tree rings from the Russian Arctic- a proxy for winter precipitation?}

Steffen Holzkämper and Peter Kuhry

Department of Physical Geography and Quaternary Geology, Stockholm University, Sweden; steffen.holzkamper@natgeo.su.se

\section{Stable carbon and oxygen isotopes in tree rings from the NE European Russian Arctic are closely related to measured winter precipitation.}

Dendroclimatology studies shed light on the climate conditions prior to the instrumental data period. The classical approach is to derive past summer temperatures from the tree ring width or more recently, from tree ring density. By studying stable carbon and oxygen isotopes in tree ring cellulose, additional climate parameters may be retrieved, though the underlying mechanisms and relations between climate and tree ring isotopes are complex and may vary for different locations (McCarroll and Loader, 2004).

\section{Study area}

The Moreju River, located in NE European Russia (Fig. 1), lies in the transition zone of continuous to discontinuous permafrost. The area can be described as lowland tundra dominated by wetland vegetation, willow bushes, dwarf shrubs and lichens. The river system is eroded into the lowland plain and the relief between the river level and the surrounding plain ranges from $5-20 \mathrm{~m}$. In one valley incision, we found a small forest patch with 10-12 m high trees that survive due to the local absence of permafrost near the riverbank and favorable microclimate conditions. In summer 2004, we collected Siberian spruce (Picea obovata) samples from this forest island, $\sim 80 \mathrm{~km}$ from the Barents Sea coast $\left(68.1^{\circ} \mathrm{N}, 60.0^{\circ} \mathrm{E}\right)$. The climate in the study area is Arctic, with mean annual temperatures around $-5^{\circ} \mathrm{C}$ and annual precipitation $\sim 450 \mathrm{~mm}$. Five climate stations lie within 200-500 km of the study site (Fig. 1), with the longest of the monitoring records extending back to AD 1883. Analysis of the observed meteorological data shows that climate is highly correlated between the sites. Thus it can be assumed that the climate conditions impacting the Moreju River are similar to those measured at the weather stations, especially given that the regional landscape is flat (Holzkämper et al., 2008).

The amount of snow falling during the winter time is an important parameter for the growth of trees. A thick snow cover is likely to melt away late in spring, consequently shortening the growing season, especially the early period of rapid growth (Vaganov et al., 1999). On the other hand, snow cover protects young seedlings from wind abrasion and extremely cold temperatures, and thus provides a positive effect on the growth of younger trees. Past snow depths can be approximated from winter precipitation records, i.e., for the months November to April, when the average temperatures are well below $0^{\circ} \mathrm{C}$. A comparison of monthly winter precipitation with the observed snow depth at the climate station of Khoseda Khard (Fig. 1) confirms that winter precipitation is regionally recorded with sufficient accuracy.

\section{Methods}

Isotopes were analyzed from three trees from the study area (Holzkämper et al., 2008). The tree ring record spans from AD 1864-2003. For the analysis, wood from single tree rings was cut from discs, a-cellulose was extracted and isotope ratios were measured. The $\delta^{13} \mathrm{C}$ data were corrected for the decrease in atmospheric $\delta^{13} \mathrm{C}$ values due to the rise in $\mathrm{CO}_{2}$ caused by fossil fuel combustion since the beginning of industrialization (Francey et al., 1999). All tree ring series were quality checked and detrended using standard procedures (Holmes et al., 1986). The correlations between the resulting tree ring width index, $\delta^{18} \mathrm{O}, \delta^{13} \mathrm{C}$ and observed monthly air temperature and precipitation were calculated.

\section{Results}

No consistent correlation between tree ring width and air temperatures was found in the analyzed trees. Significant anti-correlations ( $95 \%$ significance level), however, were observed between tree ring width from one year and the precipitation that fell during the preceding winter months (Nov-Apr) in 2 out of 3 trees (Fig. 2a,b; see Holzkämper et al., 2008 for more details).

The $\delta^{13} \mathrm{C}$ data (Fig. 2c) of the individual trees show a rather weak correlation pattern with temperature. On the other hand, there is a significant positive correlation between $\delta^{13} \mathrm{C}$ and winter precipitation in one of the analyzed trees. The carbon isotope composition in tree rings depends on the rate of photosynthesis (carboxylation) and stomatal conductance. These can be influenced by a number of parameters, among which air humidity, temperature and soil moisture status are the most important. Therefore it is not surprising that $\delta^{13} \mathrm{C}$ values between different trees do not express exactly the same variability and that not all trees show the same dependence on winter precipitation. Site specific conditions, such as the depth of the groundwater table, surrounding vegetation and wind exposure may enhance or weaken the influence of snow depth on the stable isotope value of the tree ring cellulose.

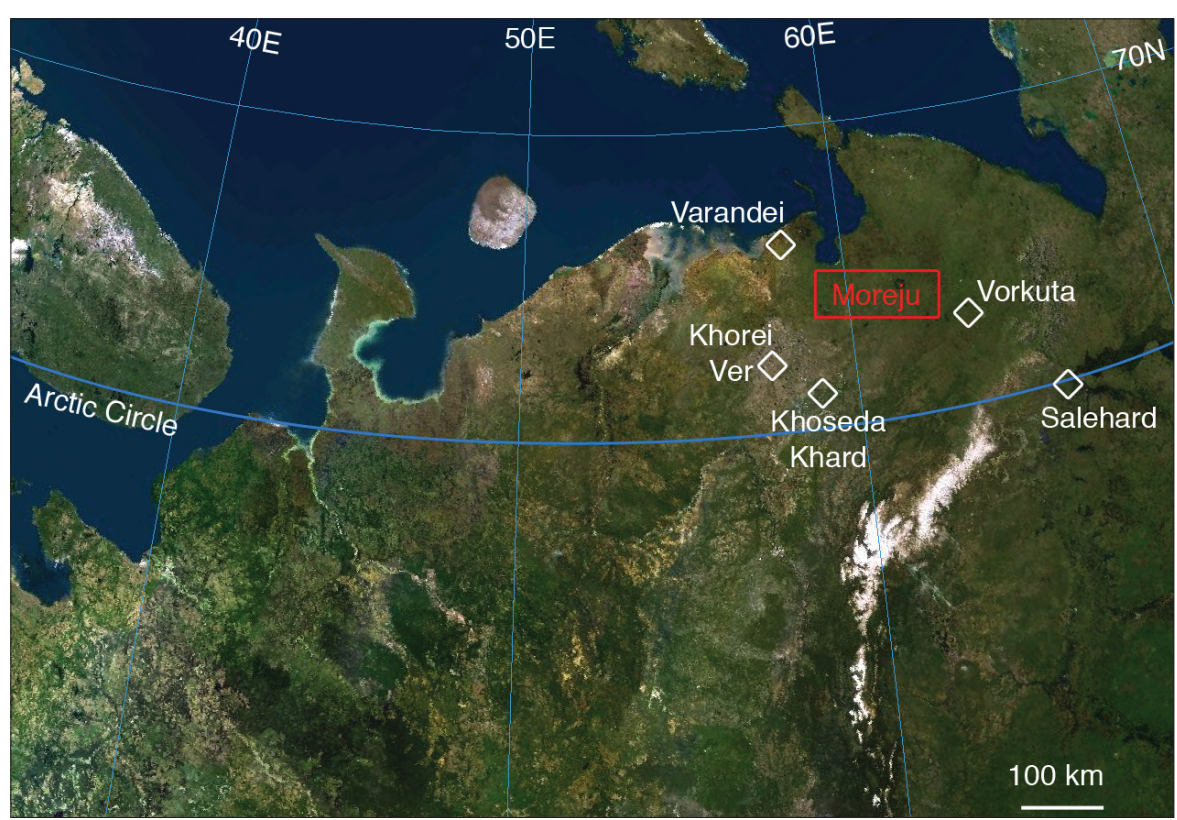

Figure 1: Map showing location of study site (Moreju) and surrounding climate stations (white diamonds). Map provided by United Soft Media Verlag GmbH. 
The $\delta^{18} \mathrm{O}$ composition of tree rings depends on the oxygen isotope ratio in the source water (precipitation), as well as on processes in the soil and in the tree. Important parameters are ground-based evaporation and transpiration in the leaves, leading to an enrichment of ${ }^{18} \mathrm{O}$. Other relevant factors are the water vapor time, recycling of moisture from the landscape, cloud track and fallout histories of the water vapor reaching the site, and the temperature during precipitation (Kohn and Welker, 2005).

A positive correlation between $\delta^{18} \mathrm{O}$ (Fig. 2c) of the individual trees and the temperature of different months can be observed but the patchy distribution of the correlated months indicates that the influence of temperature is small. On the other hand, the precipitation amount of the previous winter months explains a large source, which might have changed over

portion of the observed variability. For example, correlation coefficients around -0.5 were calculated for the months November to February for the tree that also showed a positive correlation between $\delta^{13} \mathrm{C}$ and winter precipitation. It is likely that winters with a thick snow cover that is depleted in ${ }^{18} \mathrm{O}$ will result in relatively low soil moisture $\delta^{18} \mathrm{O}$ values; in turn these oxygen isotopes are incorporated into the ring cellulose during the next year's growth season. As discussed before, site specific conditions make the isotope values more or less sensitive to changes in the thickness of the winter snow pack.

In summary, the thickness of the snow cover and the timing of snow melt have a strong impact on ring width and the $\delta^{13} \mathrm{C}$ and $\delta^{18} \mathrm{O}$ composition of the ring cellulose, as the early summer months are most critical for wood formation. Cellulose isotopes may therefore be used as a proxy

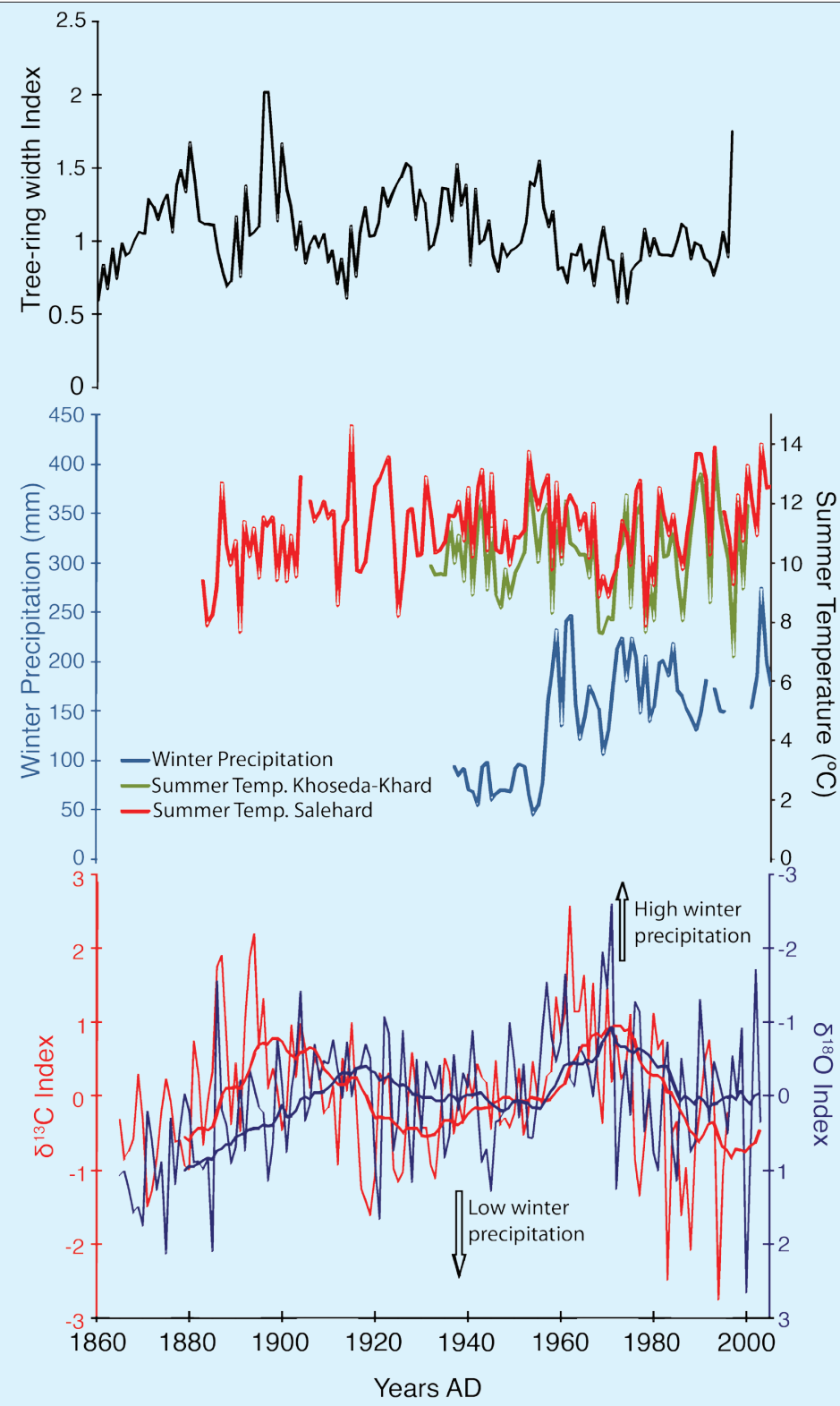

Figure 2: a) Tree ring width index (standardized average of the 3 study trees). b) Summer temperature (Jun-Aug) of Khoseda-Khard (green), and Salehard (red) weather stations, and average winter precipitation (Nov-Apr) of Vorkuta, Khorei-Ver and Khoseda-Khard weather stations (blue; data from Russian Weather Service). c) Comparison between the $\delta^{18} \mathrm{O}$ index and $\delta^{13} \mathrm{C}$ index (with running means, index is the standardized average isotope value of the trees). Note inversed $y$-axes, thus peaks (troughs) represent high (low) winter precipitation. for winter precipitation, provided that the site specific conditions are sufficiently well understood.

\section{Prospects}

Interpreting the stable carbon and oxygen isotope ratios extracted from tree ring cellulose can be used to reconstruct past climate and environmental changes, as revealed by the relatively high correlation coefficients with the observed climate. Which climate parameter is actually recorded by the stable isotopes is, however, dependent on site-specific conditions and has to be evaluated by comparison with observed meteorological data. The advantage of isotopes over ring width data is the absence of any biologically induced aging trend that disturbs the low frequency climate signal from the ring width curves. Also, they may add information about climate parameters, such as winter precipitation and snow cover. However, the complexity of processes that influence the isotope composition of the ring cellulose is large and requires better understanding. More isotope data from tree rings will help to shed light on the underlying processes, and modeling approaches and data from other climate archives from the same region, such as lake sediments and stable isotopes in single moss species in peat, are needed to decipher the different mechanisms acting on different temporal and spatial scales.

\section{Note}

All data produced by the project will be stored with NOAA/NGDC (www.ncdc.noaa.gov/paleo/ paleo.html) and PANGAEA/WDC-MARE (www. pangaea.de/) and contribute to the PAGES Arctic2k Project (www.pages-igbp.org/science/ $\operatorname{arctic} 2 \mathrm{k} /$ ).

\section{Acknowledgements}

The study was financed by the EU-GLIMPSE Project (contract EVK2-CT-2002-00164) and EUCARBO-North Project (contract 036993).

\section{References}

Francey, R.J., Allison, C.E., Etheridge, D.M., Trudinger, C.M., Enting, I.G., Leuenberger, M., Langenfelds, R.L., Michel, E. and Steele, L.P. 1999: A 1000-year high precision record of $\delta^{13} \mathrm{C}$ in atmospheric $\mathrm{CO}_{2}$, Tellus, 51B: 170-193.

Holzkämper, S., Kuhry, P., Gunnarson, B., Kultti, S., Sonninen, E., 2008 Stable isotopes in tree rings as proxies for winter precipitation changes in the Russian Arctic over the past 150 years, Geochronometria, 32 (accepted, pending minor revisions).

Kohn, M.J. and Welker, J.M., 2005: On the temperature correlation of $\delta^{18} 0$ in modern precipitation, Earth and Planetary Science Letters, 231: 87-96.

McCarroll, D. and Loader, N.J., 2004: Stable isotopes in tree rings, Quaternary Science Reviews, 23: 771-801.

Vaganov, E.A., Hughes, M.K., Kirdyanov, A.V., Schweingruber, F.H. and Silkin, P.P., 1999: Influence of snowfall and melt timing on tree growth in subarctic Eurasia, Nature, 400: 149-151.

For full references please consult:

www.pages-igbp.org/products/newsletters/ref2009_1.html 


\title{
Arctic thermokarst lakes and the carbon cycle
}

\author{
Mary Edwards' ${ }^{1}$, K. Walter ${ }^{2}$, G. Grosse ${ }^{3}$, L. Plug ${ }^{4}$, L. Slater ${ }^{5}$ and P. Valdes ${ }^{6}$
}

'School of Geography, University of Southampton, UK; M.E.Edwards@soton.ac.uk

${ }^{2}$ Water and Environmental Research Center, University of Alaska, Fairbanks, USA; ${ }^{3}$ Geophysical Institute, University of Alaska, Fairbanks, USA; ${ }^{4}$ Department of Earth Sciences, Dalhousie University, Halifax, Canada; ${ }^{5}$ Department of Earth and Environmental Science, Rutgers University, Newark, USA; ${ }^{6}$ School of Geographical Sciences, University of Bristol, UK.

Arctic thermokarst lakes may be a significant carbon source during interglacial periods. A new IPY study will better quantify their current dynamics and model their past and future contributions to the carbon budget.

\section{Methane emission from thermokarst lakes}

Methane, a major greenhouse gas (GHG), is produced in the anerobic bottoms of wetlands and lakes through microbial decomposition of organic matter. Methane escapes to the atmosphere via plants, molecular diffusion, and ebullition (bubbling). Recent observations have shown that certain Arctic thermokast lakes (TKL) have particularly high rates of methane emission (Zimov et al., 1997; Walter et al., 2006; 2007a). TKL form in Arctic regions where ice-bearing permafrost warms and thaws due to a local change in ground conditions and/or regional climate change. This can trigger melting of ground ice, surface collapse and the development of lakes in the resulting basins. TKL deepen and expand due to thermal and mechanical erosion of shore banks. Such lakes have formed intermittently across Arctic landscapes throughout the last $14 \mathrm{kyr}$ since deglaciation (Romanovskii et al., 2000; Walter et al., 2007b).

Today, TKL tend to be relatively small but numerous, and lakes may cover 20$40 \%$ of the land surface in some regions, notably the unglaciated terrain of northeast Siberia and Alaska (Fig. 1). TKL often undergo a dynamic cycle of formation and drainage. Once formed, they expand with continued thawing of surrounding soils. Eventually, expansion leads to catastrophic drainage into streams, other lakes or the sea, as a result of tapping, gully erosion along melting ice wedges, or erosion after overflow during snowmelt. Lake drainage results in suberial basins that support terrestrial or wetland vegetation types. Over time, new permafrost aggrades in the drained basins, which can support the formation of new lakes in these basins. The presence in some areas of large, deep lakes dating to the early Holocene and extensive lake basins suggest that thaw-lake initiation earlier in the Holocene resulted in much larger lakes than those that exist today. It is possible that climate warming will lead to increased lake development and thus to increased methane emissions, adding to the greenhouse effect and generating a positive feedback on climate warming. It is therefore important to learn

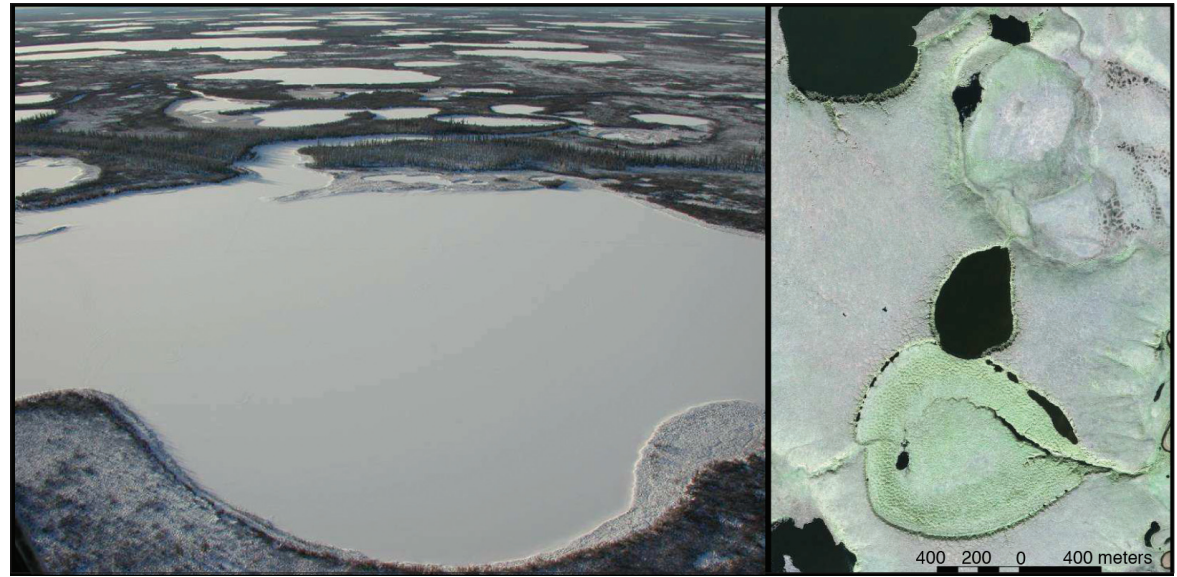

Figure 1: Left, oblique aerial view of TKL in NE Siberia (photo K.M. Walter). The lake is ca. 300 m across; Right, high-resolution IKONOS image of TKL and drained basins on the Seward Peninsula, Alaska. as much as possible about this methaneproducing system.

\section{Temporal development of thermokarst lakes}

TKL are predominantly interglacial phenomena. Although thaw-lake deposits are reported from glacial-age sediments, most radiocarbon dates associated with thaw-lake sediments are of late-glacial or
Holocene age. Several thaw-lake deposits are also described from the last interglaciation (Edwards and McDowell, 1991; Andreev et al., 2004; Ilyashuk et al., 2006). The dating record suggests that lake formation was particularly dynamic during the early Holocene. If the considerable flux of methane observed from these lakes today is typical, TKL may have been a globally important source of atmospheric meth-

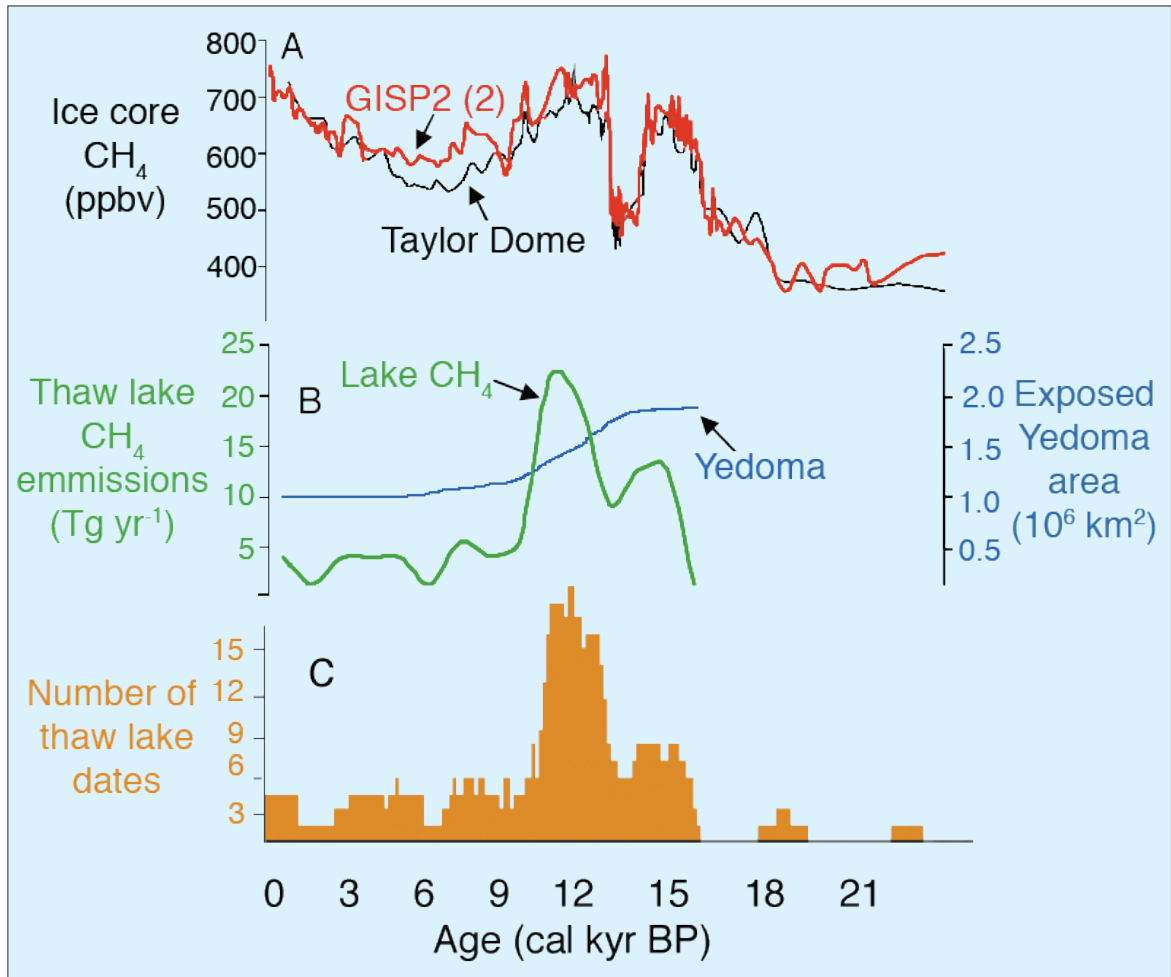

Figure 2: $\boldsymbol{A})$ Holocene atmospheric methane levels from ice-core data. B) Estimated emissions from TKL related to number of incipient lakes and the area of N. Siberian shelf inundated during the early Holocene marine highstand. "Yedoma" refers to ice-rich deposits that occupy large areas of N. Siberia, including the shelf regions covered by a marine transgression during deglaciation. C) Radiocarbon-dated thaw-lake deposits; Figure after Walter et al. 20076 . 


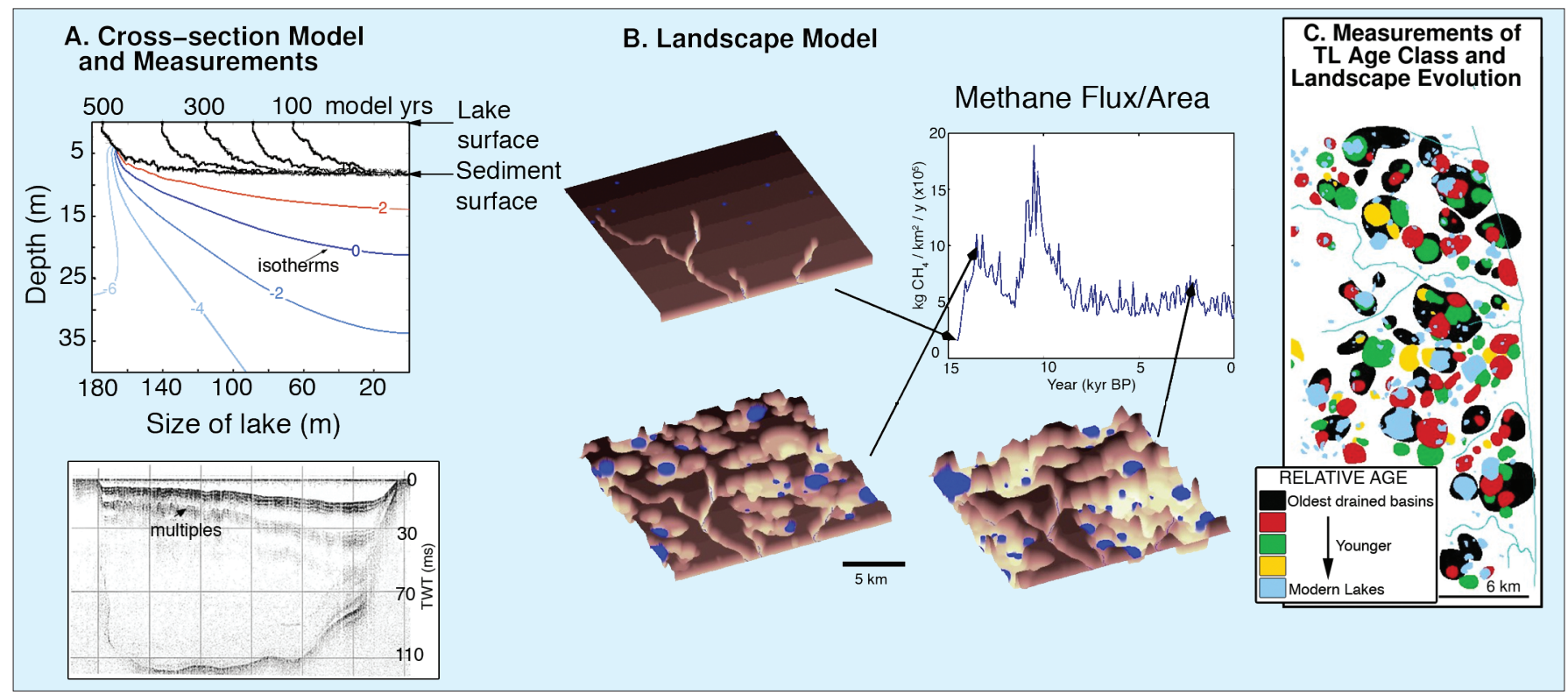

Figure 3: Components of the thaw-lake process model. A) Upper panel shows a model of the thermal and geomorphic evolution of a single Thermokarst Lake (TKL) in cross-section. Black lines represent lake-margin position of a right-to-left expanding lake at 100-yr-intervals, blue/red lines indicate ground temperature contours after 500 yr (isotherms), Lower panel is a shallow seismic/GPR imaging of talik and lake sediment (image shows lake and talik of Lake Nikolai, from Schwamborn et al., 2000). TWT: Two-Way-Time. B) The 3D Landscape Model: conceptual illustrations of the landscape at different times in a simulation, and a plot of a hypothetical methane flux for the Holocene. C) Elements of a TKL landscape classified into age classes, constrained by ${ }^{14} \mathrm{C}$ dates and paleo-studies. This will be used to test the 3D model using spatial statistics (example shown is from the Northern Seward Peninsula study area).

ane during deglaciation and throughout the Holocene (Walter et al., 2007b; Fig. 2).

Although TKL have been studied for decades, until recently most interest had been in the processes shaping their formation rather than their role in biogeochemical cycles and the climate system (but see work by Billings and Petersen, 1980, and Hinkel et al., 2003 on the role of drained lake basins as carbon sinks). Our study is focused on the relationship between permafrost degradation, thaw-lake development and the carbon cycle. In particular, we aim to resolve the magnitude of methane release from lakes to the atmosphere during the late Quaternary, and in the future as climate continues to warm.

\section{New research}

Two projects, funded by NSF IPY (PI: Walter) and NASA Carbon Cycle Sciences (PI: Grosse), respectively, began during the summer of 2008. They involve three interlinked goals. The first component is a modern process study involving (i) Mapping and classification of contemporary TKL and the landscapes in which they are found, (ii) Identification of pathways of carbon release and storage, and (iii) Development of process models of thawlake formation, development and carbon cycling. In this way we will improve upon the first-approximation estimates of Walter et al. (2006) as to the current contribution of TKL to the global atmospheric methane budget. Quantification of gas fluxes will be integrated with the activities of Flagship Observatories in the Arctic Observing Network (AON) in Alaska, Russia, and Sweden (Arctic Ob- serving Network; http://aon.iab.uaf.edu/ index.html). We are establishing a new Pan-Arctic Lake-Ice Methane Monitoring Network (PALIMMN) collaboratively with ongoing Arctic projects and through outreach and education (Student-PALIMMN) (www.alaska.edu/uaf/cem/ine/walter/ ongoing_projects.xml). These will be related to data compiled from a range of remote sensing analyses to develop maps and a classification of themokarst and TKL for regions of Alaska and Siberia (Grosse et al., 2006). Remote sensing tools will be used to quantify the trajectory of spatial thaw lake dynamics during the last 55 years and to monitor methane emissions from TKL using a variety of radar sensors (Walter et al., 2008).

The second component involves assembling paleoenvironmental data to test our argument that thaw-lake formation in Siberia and Alaska can explain a significant proportion of northern hemisphere methane emissions during the Holocene deglaciation. Field studies of lake development through time, based on dated sediment profiles of current and paleo-lake basins, will be central to the paleoenvironmental component of the study. These will be complemented by high-resolution measurements of electrical resistivity/induced polarization and ground-penetrating radar (GPR), and seismic observations of thawed sediments underlying lake beds ("talik"). Furthermore, assays of carbon content and methane production potential of a range of lacustrine and terrestrial sediments observed in thaw-lake basins will allow better quantification of these lakes as both sources and sinks of carbon through time. These data are critical to the development of numerical process models (see below), which will simulate thaw-lake dynamics under a range of environmental conditions.

The final part of the project involves projecting the dynamics and related GHG emissions of thaw-lake cycling into the future as permafrost warms and thaws under global warming. This requires modeling, for which two process models are being developed: (i) A single-lake model, which simulates the dynamics of a lake basin (West and Plug, 2008; Plug and West, in press), and (ii) A landscape model, which includes hill-slope processes, surface water movement, and landscape-scale permafrost dynamics.

The models will first be validated by comparison with observed modern landscapes. Subsequently, simulations of late-Quaternary lake development will be evaluated against the observed temporal patterns available from stratigraphic and paleoenvironmental records. We have the possibility to use both transient climate simulations from the fast Earth-System model FAMOUS (Jones et al., 2005) for 21-0 kyr BP and Holocene time-slices from regional paleoclimate model simulations for Beringia (Edwards et al., 2006). We can then assess the effectiveness of these modeling hierarchies at simulating past conditions. The final step in modeling will be the coupling of the thaw-lake process models with the higher resolution HADCM3 (Johns et al., 2003) for simulations of the period 2000-2200 AD. 


\section{References}

Grosse, G., Schirrmeister, L. and Malthus, T.J. 2006: Application of Landsat-7 satellite data and a DEM for the quantification of thermokarst-affected terrain types in the periglacial Lena-Anabar coastal lowland, Polar Research, 25: 51-67.

Plug, L.J. and West, J.J., in press: Thaw lake expansion in a twodimensional coupled model of heat transfer, thaw subsidence and mass movement, Journal of Geophysical Research, doi:10.1029/2006JF000740
Romanovskii, N.N., Hubberten, H.-W., Gavrilov, A.V., Tumskoy, V.E., Tipenko, G.S., Grigoriev, M.N. and Siegert, C., 2000: Thermokarst and Land-Ocean Interactions, Laptev Sea Region, Russia, Permafrost and Periglacial Processes, 11: 137-152.

Walter, K.M. Zimov, S.A. Chanton, J.P. Verbyla, D. and Chapin F.S., 2006 Methane bubbling from Siberian thaw lakes as a positive feedback to climate warming, Nature, $443 ;$ : 71-75.
Walter, K.M., Edwards, M.E., Grosse, G., Zimov, S.A. and Chapin F.S.III., 2007b: Thermokarst lakes as a source of atmospheric $\mathrm{CH}_{4}$ during the last deglaciation, Science, 318: 633-636.

For full references please consult:

www.pages-igbp.org/products/newsletters/ref2009_1.htm

\title{
Initial results of HOTRAX address a wide range of Arctic paleoclimate issues
}

\author{
Dennis A. Darby ${ }^{1}$, L. Polyak ${ }^{2}$ and M. Jakobsson ${ }^{3}$
}

'Deptartment of Ocean, Earth and Atmospheric Sciences, Old Dominion University, Norfolk, USA; ddarby@odu.edu

2Byrd Polar Research Center, Ohio State University, Columbus, USA; 'Deptartment of Geology and Geochemistry, Stockholm University, Sweden

\section{The Healy-Oden Trans-Arctic Expedition (HOTRAX'05) obtained an exceptional collection of sediment cores from across the Arctic Ocean to address the key unresolved issues of Arctic paleoceanography.}

The HOTRAX expedition retrieved 21 jumbo piston cores averaging $\sim 12 \mathrm{~m}$ in length from a complete transect across the Arctic Ocean, in combination with multibeam bathymetric surveys and chirp-sonar subbottom profiling, and 8 cores of up to $16 \mathrm{~m}$ in length from the continental margin off Alaska (Fig. 1). These Alaskan margin cores have extremely high sedimentation rates $(1.5 \mathrm{~m} / \mathrm{kyr})$ that provide unprecedented Holocene paleoceanographic records, while the central Arctic cores provide records that permit comparisons between earlier warm intervals and those of the Holocene. Together with previously collected core material, we are now better able to grasp the complex array of sediment archives in the Arctic Ocean and to address the important issues of past climate change.

The paleoclimate record in the Arctic has been sorely lacking compared to the rest of the World Ocean because of the difficulties in obtaining quality Arctic records. Even with the greatly improved technology, which includes better icebreakers, coring equipment, improved multibeam and chirp profilers critical for locating potential core sites, and, yes, even with the warming climate providing record low ice extent in the last two years, challenges exist that are unique to the Arctic. HOTRAX made significant strides in providing quality records but more will be required in order to overcome the obstacles to a comprehensive Arctic paleoclimate history.

Climate change in the Arctic commands the close attention of the scientific community as average temperatures in the Arctic over the past 30 years have increased at almost twice the rate of the planet as a whole and sea ice is disappearing at alarming rates. Climate models based on these observations suggest that the Arctic is rapidly moving toward a new, low-ice or even seasonally ice-free state that has not been witnessed in human history. In fact, data from long drill cores recovered by the Arctic Coring Expedition (ACEX; Fig. 1) from the Lomonosov Ridge suggest that the Arctic perennial ice cover may have been around for at least $14 \mathrm{Myr}$ (Darby, 2008). Its disappearance would be a truly monumental change, going far beyond human history.

Of course, the core recovery and resolution of sampling in the ACEX drill cores, upon which this is based, are not sufficient to confirm that there were no ice-free periods over this long time interval. Evidence of past reduced ice cover has been documented from coastal Arctic records from the Miocene (Williams et al., 2008), at least part of the Pliocene, and some of the Quaternary Interglacials (e.g., BrighamGrette and Carter, 1992; CAPE members, 2006) and the early Holocene (England et al, in press; Funder and Kjaer, 2007). This highlights the need for higher resolution records in the Arctic Ocean covering as much of the Cenozoic as possible. To understand the range of variability for future Arctic climates, we need to explore paleoclimate archives with a special focus on

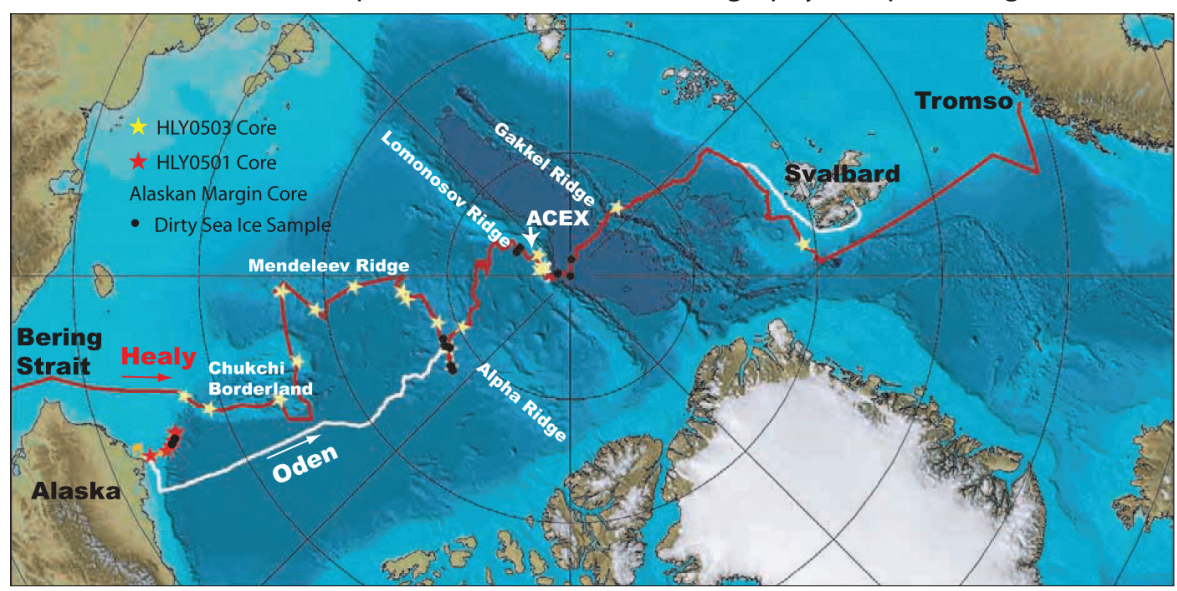

Figure 1: International Bathymetric Chart of the Arctic Ocean (Jakobsson et al., 2008) showing core locations from the Healy-Oden Trans-Arctic Expedition (HOTRAX) in 2005. At each core site, in addition to the 10-cm-diameter piston core and gravity trigger core (2-3 $m$ in length), there is a multicore consisting of 7-8 half-m-long tubes containing the sediment water interface. Black circles indicate the location of several dirty sea-ice samples collected during HOTRAX (used to provide insights on sea ice drift). low-ice periods of the recent geological past. Great strides have been made with the Greenland ice core records (Bond et al., 1993; Calder et al., 2008) but for all the advances they have brought, the Arctic Ocean record of change is still critical because the Greenland records appear to be more closely linked to the North Atlantic than the Arctic, and it is this single ocean that serves as the primary heat sink for the northern hemisphere.

The initial results of work on the HOTRAX cores and other Arctic archives are being prepared for publication in a special issue of Global and Planetary Change (GPC). In another special issue celebrating IPY slated for publication later this year in the Canadian Journal of Earth Science, there are three papers based on HOTRAX cores. Because stratigraphy and age control are the these special issues have several HOTRAX papers focusing on this topic. A variety of tools are used to determine the age models for these sediment records including AMS radiocarbon dating, ${ }^{210} \mathrm{~Pb},{ }^{10} \mathrm{Be}$, amino-acid racemization rates, luminescence, biostratigraphy and paleomagnetic intenfoundation of any paleoclimate history, 


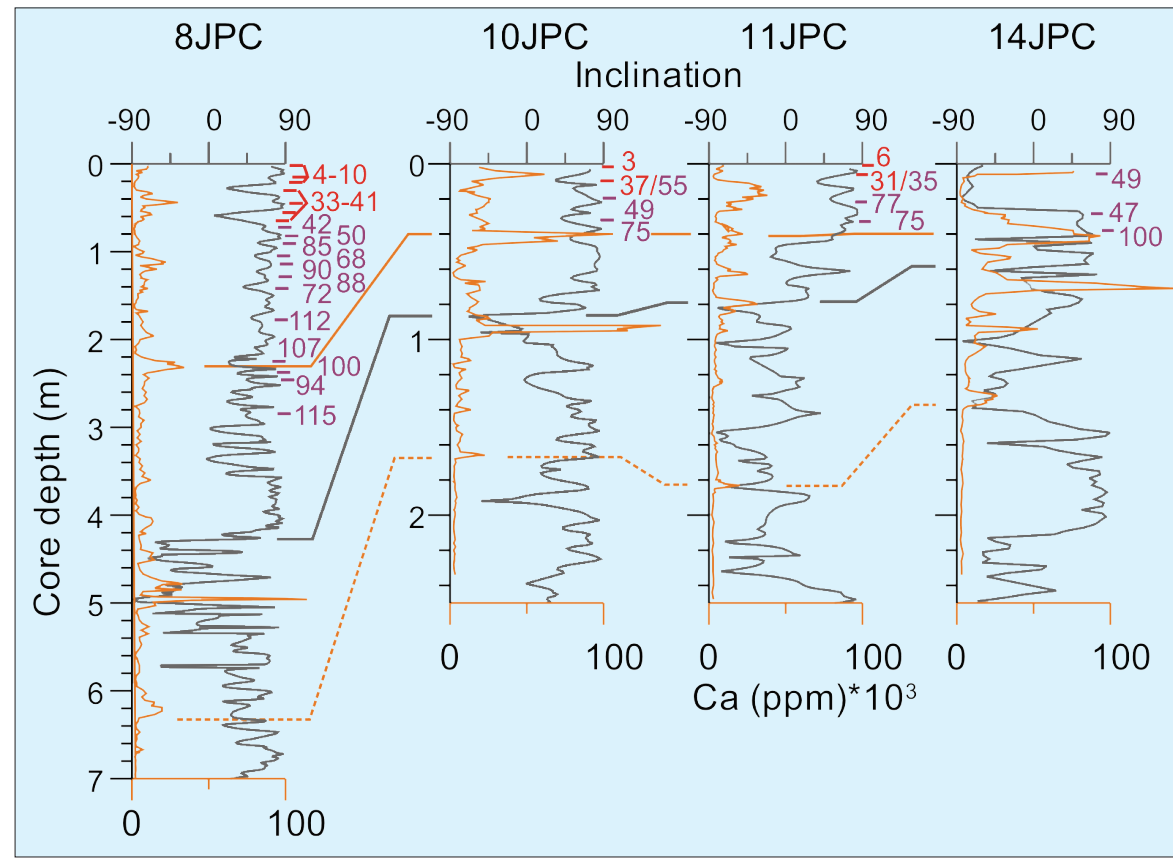

Figure 2: Correlation of paleomagnetic inclination (gray plots) and detrital carbonates (XRF Ca content; orange plots) for upper parts of HOTRAX cores 8, 9, 10 and 14JPC from Mendeleev-Alpha Ridges, south to north (see Fig. 1 for core location) (from Polyak et al., in review). Correlation lines are shown for a prominent carbonate layer at ca. MIS 5/6 boundary (orange), prominent inclination drop within MIS 7 (gray), and base of detrital carbonate deposition (dashed orange). Radiocarbon and amino-acid racemization ages (kyr) are shown in red and purple, respectively. Radiocarbon ages in core HLY0503-8JPC are grouped for simplicity. Note a two-fold change in core depth scale between southern and northern Mendeleev Ridge cores (i.e., between cores 8JPC and 10JPC).

sity fluctuations dated elsewhere from global and regional datasets. These papers also reveal the problems with dating Arctic sediments, in particular dissolution and uncertain reservoir corrections that might even change during the Holocene due to the influence of differing water masses on some slope areas.

Other papers deal with depositional changes in the Holocene and processes responsible for the extremely high sedimentation rates along the Alaskan margin. The important role of sea-ice transport and deposition of sediment in the Arctic is generally accepted but there are still many questions remaining, e.g., just how important sea ice melt-out is to the deposits in various parts of the Arctic. In the GPC HOTRAX issue a number of papers based on cores from the central Arctic Ocean with longer stratigraphy and lower sedimentation rates provide new stratigraphic constraints, especially for the Upper Quaternary, and correlate records between areas with different depositional environments.

Figure 2 exemplifies the correlation of cores along the Mendeleev and Alpha Ridges, based on normal remanent mag- netization (NRM) records, along with distribution of detrital carbonates (indicated by Ca concentrations), and radiocarbon and amino-acid racemization (AAR) dates. Being overall much lower than on the Alaskan margin, sedimentation rates in the central Arctic appear to change dramatically, from nearly a hiatus in some areas during the height of glacial intervals to several $\mathrm{cm} /$ kyr during deglaciations and interglacial intervals. In addition to HOTRAX materials, the GPC special issue presents related data from the Siberian seas and modeling results of the MIS6 glaciation-potentially the biggest ice sheet in the history of the Eurasian Arctic.

\section{Note}

Data from this research is being archived at the Joint Office for Science Support at the University of Colorado. Metadata on the HOTRAX collection are posted on the NGDC MGG website (www.ngdc.noaa.gov/mgg/curator/curator. html).

\section{References}

Bond, G., Broecker, W., Johnsen, S.J., McManus, J., Labeyrie, L., Jouzel, J. and Bonani, G., 1993: Correlations between climate records from North Atlantic sediments and Greenland ice, Nature, 365 143-147.

Calder, C.A., Craigmile, P.F. and Mosley-Thompson, E., 2008: Spatial variation in the influence of the North Atlantic Oscillation on precipitation across Greenland, Journal of Geophysical Research, 113:D06112, doi.1029/2007JD009227

Darby, D.A., 2008: The Arctic perennial ice cover over the last 14 million years, Paleoceanography, 23: PA1507, doi:10.1029/2007PA001479

Jakobsson, M., Macnab, R., Mayer, L., Anderson, R., Edwards, M., Hatzky, J., Schenke, H.W. and Johnson, P., 2008: An improved bathymetric portrayal of the Arctic Ocean: Implications for ocean modeling and geological, geophysical and oceanographic analyses, Geophysical Research Letters, 35: L07602.

Polyak, L., et al., in review: Late Quaternary stratigraphy and sedimentation patterns in the western Arctic Ocean, Global and Planetary Change.

\title{
Lake El'gygytgyn's emerging IPY record of Pliocene to recent Arctic change
}

\author{
Julie Brigham-Grette ${ }^{1}$, M. Melles², P. Minyuk ${ }^{3}$, C. Koeberl ${ }^{4}$ and Science Party \\ 'Department of Geosciences, University of Massachusetts, Amherst, USA; juliebg@geo.umass.edu \\ ${ }^{2}$ Institute of Geology and Mineralogy, University of Cologne, Germany; ${ }^{3}$ North-East Interdisciplinary Scientific Research Institute, Magadan, Rus- \\ sia; ${ }^{4}$ Department of Geological Sciences, University of Vienna, Austria

\section{effort to collect the complete paleoclimate archive from this region back to 3.6 Myr ago.} \\ Lacustrine sediments representing the last 3 glacial cycles from NE Russia chronicle the magnitude and \\ dynamics of millennial-scale change across the western Arctic. Logistics are now underway in a multi-national
}

Imagine looking at a circum-Arctic map of northern hemisphere glacial ice extent and being given the opportunity to select an ideal setting where one might record an undisturbed time-continuous terrestrial record of Arctic climate change. Unprecedented, Lake El'gygytgyn (pronounced el'geegitgin), is such a place, formed by astrophysical chance 3.6 Myr ago, when a meteorite struck Earth $100 \mathrm{~km}$ north of the Arctic Circle in Chukotka on the drainage divide between the Arctic Ocean and the Bering Sea (Layer, 2000) (Fig. 1).

When the meteorite hit, the middle Pliocene Arctic was exceedingly different from today, with mean annual tem- peratures estimated at $12^{\circ} \mathrm{C}$ warmer and global averages $3-4^{\circ} \mathrm{C}$ warmer than today (Dowett, 2007; Saltzman et al., 2008). At that time, most of the Arctic borderlands were heavily forested, the Arctic Ocean lacked permanent sea ice, and the Greenland Ice Sheet did not exist, at least in its present form (Brigham-Grette and Carter, 
1992; Miller and Brigham-Grette et al., in press). In fact, after the impact, a million years passed before onset of the first major glaciation of the northern hemisphere (Haug et al., 2005). The El'gygytgyn Crater measures $\sim 18 \mathrm{~km}$ in diameter and lies nearly in the center of what was to become Beringia-the largest contiguous landscape in the Arctic to have escaped continental-scale glaciation. Within the crater rim today, Lake El'gygytgyn measures $12 \mathrm{~km}$ in diameter and is $170 \mathrm{~m}$ deep, enclosing 350-400 m of sediment deposited since the time of impact (Gebhardt et al., 2007).

\section{Deep Drilling Initiation}

After several years of preparation, pre-site survey work and arduous logistical planning, Lake El'gygytgyn is now the focus of a challenging interdisciplinary multinational drilling campaign that is part of the International Continental Drilling Program (ICDP). With drilling initiated in November 2008, the goal is to collect the longest time-continuous record of climate change in the terrestrial Arctic, and to compare this record with those from lower latitude marine and terrestrial sites to better understand hemispheric and global climate change. Coring objectives include replicate overlapping lake sediment cores of $330 \mathrm{~m}$ and $420 \mathrm{~m}$ length at 2 sites (D1 and D2 in Fig. 1; four cores total) near the deepest part of the lake. Coring shall be continued $300 \mathrm{~m}$ (D1) and $100 \mathrm{~m}$ (D2) into the underlying impact breccia and brecciated bedrock, in order to investigate the impact process and the response of the volcanic bedrock to the impact event. One additional land-based core (site D3, lake shore) to $\sim 200 \mathrm{~m}$ in lake sediments now overlain by frozen alluvial sediments will allow better understanding of sediment supply to the lake and spatial depositional heterogeneity since the time of impact. This latter drill site at the west edge of the lake outside the talik (unfrozen ground in an area of permafrost) will also be used for permafrost studies and be permanently instrumented for future ground temperature monitoring, as part of the Global Terrestrial Network for Permafrost (www. gtnp.org/). Drilling of the primary D1 and D2 sites will take place from February to the middle of May 2009, using the lake ice as a drilling platform. The project is using a new GLAD-800 drilling system modified for extreme weather conditions by Drilling, Observation and Sampling of the Earths Continental Crust Inc. (DOSECC). Moreover, the science and logistics involves close cooperation with the Russian Academy of Sciences (Far East Geological

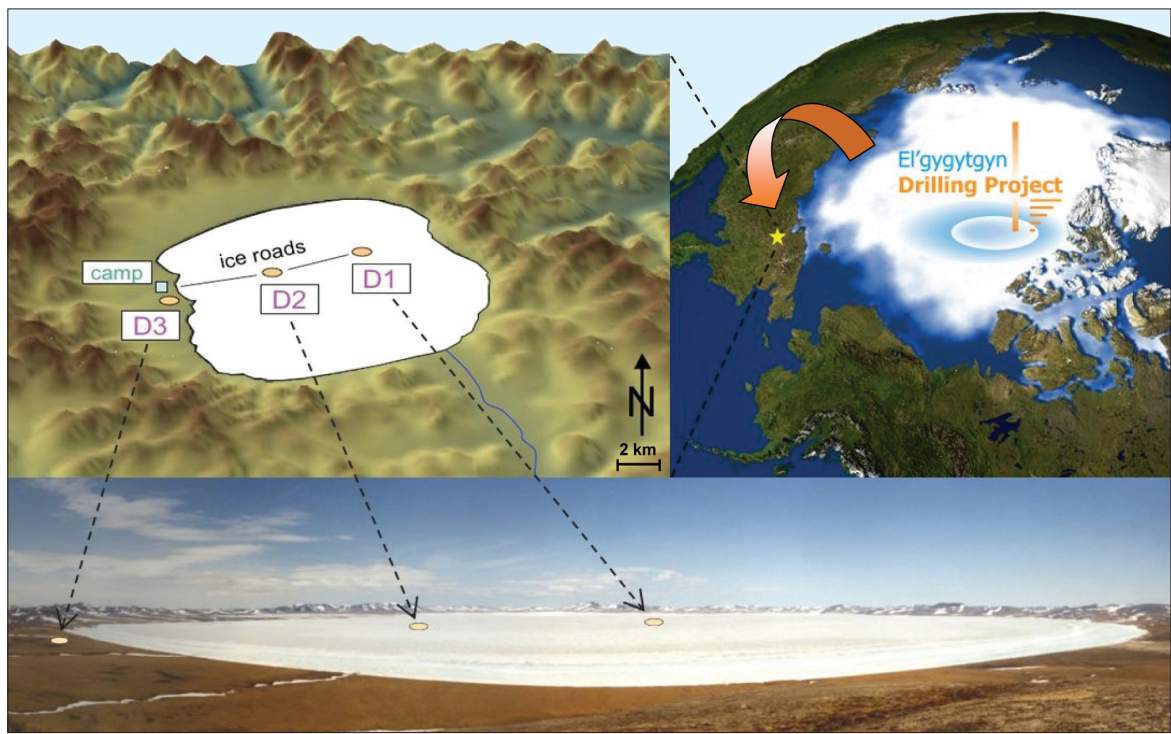

Figure 1: Top right: Location of Lake El'gygytgyn at $67.5^{\circ} \mathrm{N}$ and $172^{\circ} \mathrm{E}, \sim 100 \mathrm{~km}$ north of the Arctic Circle in Chukotka NE Russia (base map courtesy of Arctic Climate Impact Assessment). Top left: Digital elevation model (Conrad Kopsch, AWI) with drill site locations, projected onto a panoramic view of Lake El'gygytgyn (bottom) taken in May, facing north (Volker Wennrich, Cologne).

Institute, Vladivostok; and Northeast Interdisciplinary Scientific Research Institute, Magadan) and Roshydromet's Arctic and Antarctic Research Institute, St. Petersburg.

In summer 2009, the cores will be flown by chartered cargo plane to St. Petersburg. Later they will be trucked to the University of Cologne, Germany, where sub-sampling by the international team and their students will start in September. The archive core halves will be shipped to the University of Minnesota LacCore Facility, USA for post-moratorium studies.

\section{Pilot Cores and Initial Results}

The impetus for deep drilling at Lake El'gygytgyn is largely based on field and laboratory studies carried out over the past decade. Seismic work in the lake and morphostratigraphic work in the catchment and surrounding region confirmed that the lake record was undisturbed, without evidence of glaciation or desiccation (Niessen et al., 2007; Glushkova and Smirnov, 2007). A 12.9-m-long sediment core retrieved from the deepest part of the lake in 1998 revealed a basal age of $\sim 250$ kyr and demonstrated, using a variety of proxies, the sensitivity of this lacustrine environment to record high-resolution climate change across NE Asia at millennial timescales (Brigham-Grette et al., 2007; Melles et al., 2007; Nowacyzk et al., 2007; Forman et al., 2007; plus 7 other papers in same issue; Fig. 2). A 16.7-m-long sediment core taken nearby in 2003 dated to nearly $300 \mathrm{kyr}$ and confirmed the reproducibility of the record (Juschus et al., 2007). This research also showed that nearly every proxy can be systemically linked to changes in the duration of seasonal lake ice cover, regional temperature, and changes in hy- drologic input driven largely by high latitude precessional cycles and feedbacks. For example, the magnetic susceptibility and sedimentology showed that perennial ice cover during glacial summers led to anoxia in the hypolimnion (bottom layer in a thermally stratified lake), which had a profound impact on the biogeochemistry at the sediment/water interface (Nowacyzk et al., 2007; Minyuk et al., 2007). Knowledge of the basin geomorphology and sedimentation processes informs us of likely changes in landscape weathering and sedimentation rates (Asikainen et al., 2007; Glushkova and Smirnov, 2007). We have also demonstrated that while gravitational sediment transport occurs in the basin, such events do not cause erosion of the continuous stratigraphy in the center of the lake where drilling is planned. Documenting the dynamics and controls on the lake's seasonal ice cover (Nolan et al., 2003; Nolan and Brigham-Grette, 2007) has been key to understanding lake Moreover, this work has been critical to developing safety plans for ice thickening and engineering prior to drilling from the lake's frozen surface.

\section{Potential Implications}

Our ability to inform policy makers about global/regional climate and related environmental change and its uncertainties depends on our capacity to understand the role of the Arctic region in modulating past periods of change under different climate forcing conditions. Of prime interest to the scientific community is determining why and how the Arctic climate system evolved from a warm forested ecosystem into a cold permafrost ecosystem between 2-3 Myr ago. A continuous depositional circulation and beach geomorphology. 


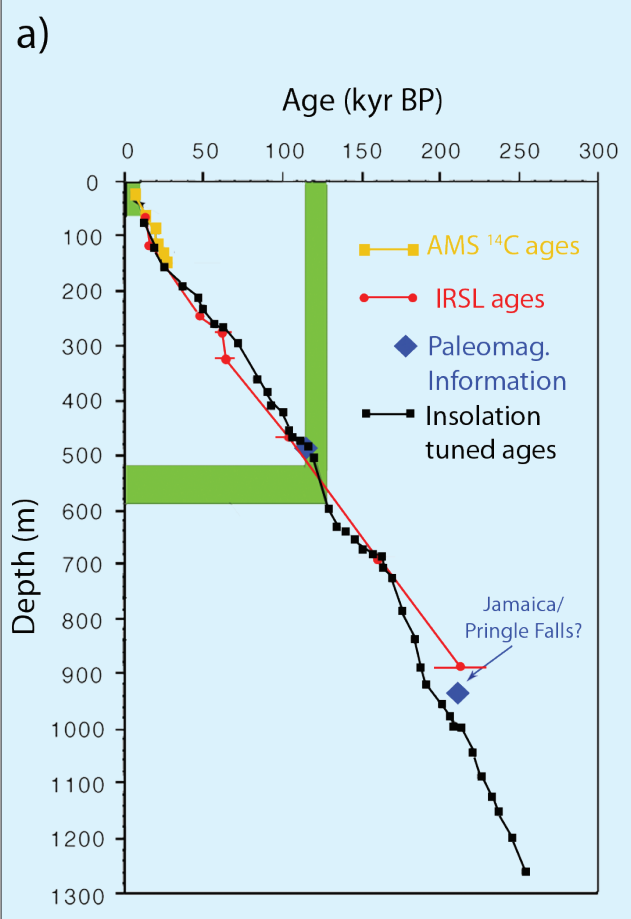

b)

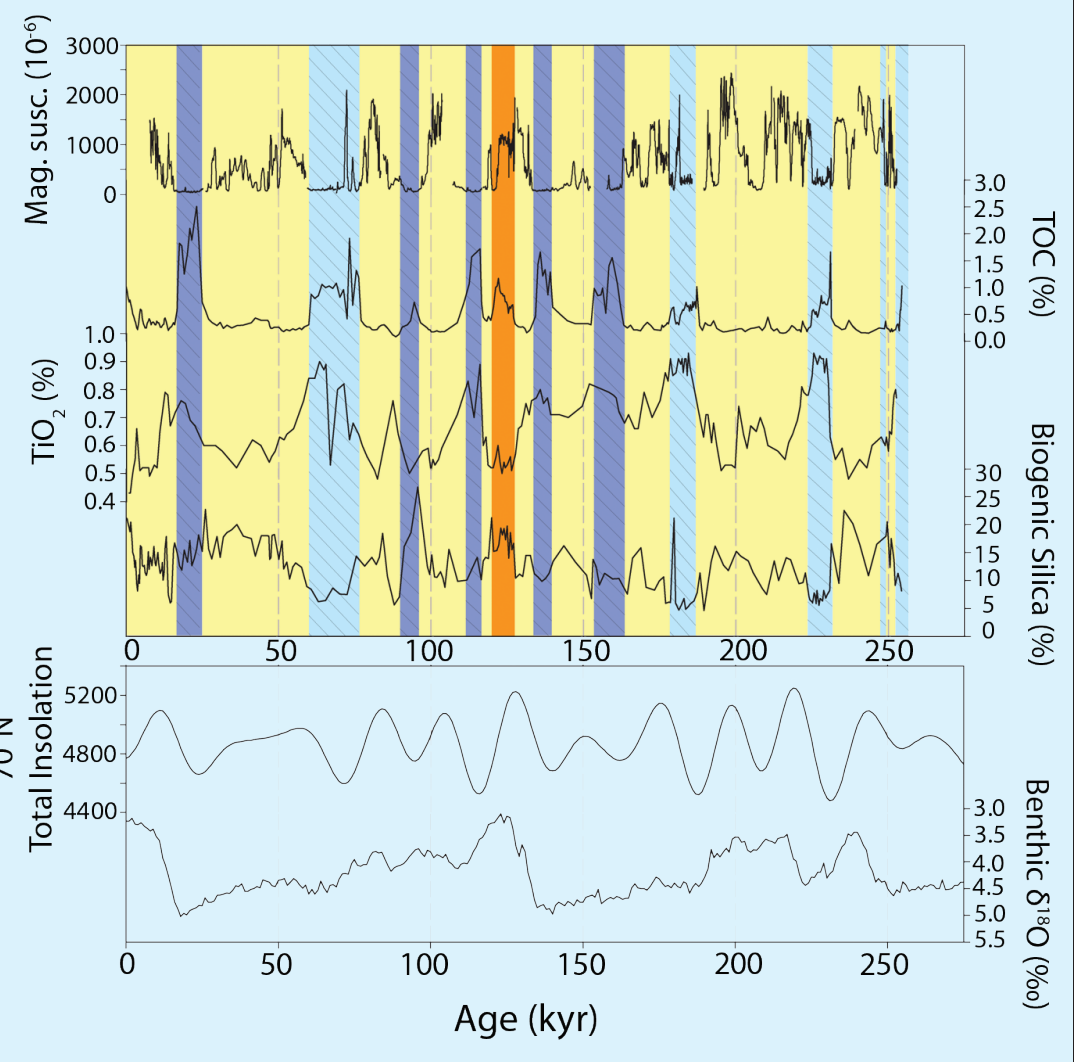

Figure 2: The age model of core PG1351 (taken next to D1, Fig. 1) from Lake El'gygytgyn based on radiocarbon ages, infrared stimulated luminescence ages (IRSL), paleomagnetics and interglacial pollen assemblages (Forman et al., 2007; Nowacyzk et al., 2002; 2007; Lozhkin et al., 2007). a) Green bars represent the warmest portion of the last interglacial (MIS 5e) and the Holocene. The black line represents the revised orbitally-tuned chronology based on precession (Nowacyzk et al., 2007). b) High-resolution proxies (magnetic susceptibility, total organic carbon (TOC), Titanium Dioxide (TiO2), and biogenic silica) strongly controlled by temperature, productivity, hydrology, and variability in seasonal lake ice cover. During colder intervals (cold and moist - blue; cold and dry - purple) sediments are laminated when the lake remains ice covered in summer, ventilation ceased, and bottom waters became anoxic; warmer intervals (warm-yellow; peak warm - orange) are marked by non-laminated sediments, suggesting lake ventilation during open water summers (see climate modes of Melles et al., 2007). These proxies are plotted against the age model, insolation (Berger and Loutre, 1991) and the benthic $\partial^{18} \mathrm{O}$ stack of Lisiecki and Raymo (2005). Figure produced by Kenna Wilkie.

record in this unique lake will provide a means of capturing the mechanisms and dynamics of glacial/interglacial and millennial-scale change from this region over the duration of the " $41 \mathrm{kyr}$ world" and late Cenozoic "100 kyr world". This record will then be compared with other long records from around the world but especially the low-latitude ocean records, to evaluate polar amplification, model systemic teleconnections and leads/lags relative to insolation forcing. This record will also provide insight into whether rapid change events identified during the last glacial cycle are typical of earlier glacial periods. We hope to provide the science community with an understanding of the poorly documented regional sensitivity of the NE Asian Arctic to millennial-scale abrupt change (Heinrich and D/O scale) and interglacial warmth detected at global vs. regional scales, within the timeframe of the
EPICA ice cores, long Asian loess and lake records, and comparable marine records. Climate modeling is also an important aspect of the program in allowing these relationships to be evaluated systematically.

\section{Note}

All data produced by the project will be stored with NOAA/NGDC (www.ncdc.noaa.gov/paleo/ paleo.html) and PANGAEA/WDC-MARE (www. pangaea.de/).

\section{Acknowledgements}

The Lake El'gygytgyn Drilling Project is an international effort funded by ICDP, the US National Science Foundation Earth Sciences Division and Office of Polar Programs, the German Federal Ministry for Education and Research (BMBF), Alfred Wegener Institute, and GeoForschungsZentrum-Potsdam, and the Russian Academy of Sciences Far East Branch. The leading Russian institutions include Roshydromet's Arctic and Antarctic Research Institute, the Northeastern Interdisciplinary Scientific Research Institute, and the Far East Geological Institute. The deep drilling system for Arctic operations was developed by DOSECC, Inc.

\section{References}

Brigham-Grette, J., Melles, M., Minyuk, P. and Scientific Party, 2007: Overview and Significance of a $250 \mathrm{ka}$ Paleoclimate Record from El'gygytgyn Crater Lake, NE Russia, Journal of Paleolimnology, 37: 1-16.

Gebhardt, A.C., Niessen, F. and Kopsch, C., 2006: Central ring structure identified in one of the world's best-preserved impact craters, Geology, 34: 145-148.

Melles, M., Brigham-Grette, J., Glushkova, O.Yu., Minyuk, P.S., Nowaczyk, N.R. and Hubberten, H.W., 2007: Sedimentary geochemistry of a pilot core from Lake El'gygytgyn - a sensitive record of climate variability in the East Siberian Arctic during the past three climate cycles, Journal of Paleolimnology, 37: 89-104.

Nowaczyk et al., 2002: Magnetostratigraphic results from impact crater Lake El'gygytgyn, northeastern Siberia: A 300 kyr long high resolution terrestrial paleoclimatic record from the Arctic, Geophysical Journal International, 150: 109-126.

Nowaczyk N.R., Melles, M. and Minyuk, P., 2007: A revised age model for core PG1351 from Lake El'gygytgyn, Chukotka, based on magnetic susceptibility variations correlated to northern hemisphere insolation variations, Journal of Paleolimnology, 37: 65-76.

For full references please consult:

www.pages-igbp.org/products/newsletters/ref2009_1.htm

\section{Looking for a job in paleoscience?}

\section{Try the PAGES free Jobs Database!}

All the international paleoscience jobs from listservers in the one place. Browse or add jobs at: www.pages-igbp.org/resources/jobs/ 


\section{Antarctic Paleobiology: Glacial refugia and constraints on past ice-sheet reconstructions}

Louise Newman' ${ }^{1}$, P. Convey ${ }^{2}$, J.A.E. Gibson ${ }^{3}$ and K. Linse ${ }^{2}$

'PAGES International Project Office, Bern, Switzerland; newman@pages.unibe.ch

${ }^{2}$ British Antarctic Survey, Cambridge, UK; ${ }^{3}$ Tasmanian Aquaculture and Fisheries Institute, University of Tasmania, Hobart, Australia

\section{Paleobiological approaches reveal the long-term (Myr) survival of Antarctic terrestrial, marine and freshwater fauna in glacial refugia, which provides constraints for models of past ice sheet extent.}

\section{Antarctic biota and glacial history - inextricably linked}

Given the extremes of Antarctica today, it is difficult to imagine that ca. 500 Myr ago it was ecologically similar to contemporary temperate and subtropical latitudes. With complete isolation of the continent by ca. 45-30 Myr, followed by continental cooling and widespread glaciation (Lear et al., 2000; Zachos, et al., 2001; Miller et al., 2005), the terrestrial biota were reduced to a tundra-like community analogous to that of modern southernmost S. America, before largely being driven to extinction due to the development of hyperarid, polar-desert conditions at 14 Myr ago (Lewis et al., 2008). Molecular studies of the modern micro-invertebrate biota indicate that remaining communities became fragmented (e.g., Stevens et al., 2006) and distinct, with apparently little successful immigration from northerly landmasses.
Today's terrestrial and freshwater fauna are restricted to the ca. $0.3 \%$ of ice-free land currently found on the coast and on inland, higher-altitude mountain ranges (nunataks). They are dominated by small ( $200 \mu \mathrm{m}-5 \mathrm{~mm})$ and inconspicuous invertebrates and are usually associated with simple vegetation (lichens, mosses, algae). Within the scope of their coarse spatial resolution, model reconstructions of past ice-sheet extent suggest that most of the presently ice-free regions would have been completely ice covered during previous glacial maxima (Huybrechts, 2002; DeConto and Pollard, 2003). This notion has historically placed large constraints on our understanding of the antiquity of the Antarctic fauna, implicitly inferring recolonization of the continent after each glacial maximum. However, recent studies of Antarctic terrestrial and freshwater biota indicate ancient origins for many of them, suggesting survival in isolation for up to tens of millions of years (Fig. 1; Bayly et al., 2003; Cromer et al., 2006; Convey and Stevens, 2007; Gibson and Bayly, 2007; Convey et al., 2008).

\section{Terrestrial evidence}

On land, several lines of evidence point to this conclusion and, indeed, to a more complex picture of intra-Antarctic biological isolation and species radiation over considerable timescales. Recent biogeographical studies identify striking levels of species endemism within the current invertebrate fauna and lichen flora, both at continental and regional scale (Maslen and Convey, 2006; Convey et al., 2008; Pugh and Convey, 2008) - the latter also highlighting that the continent cannot be treated as a single entity when considering biological refugia; each region has its own distinct history. The strength of the

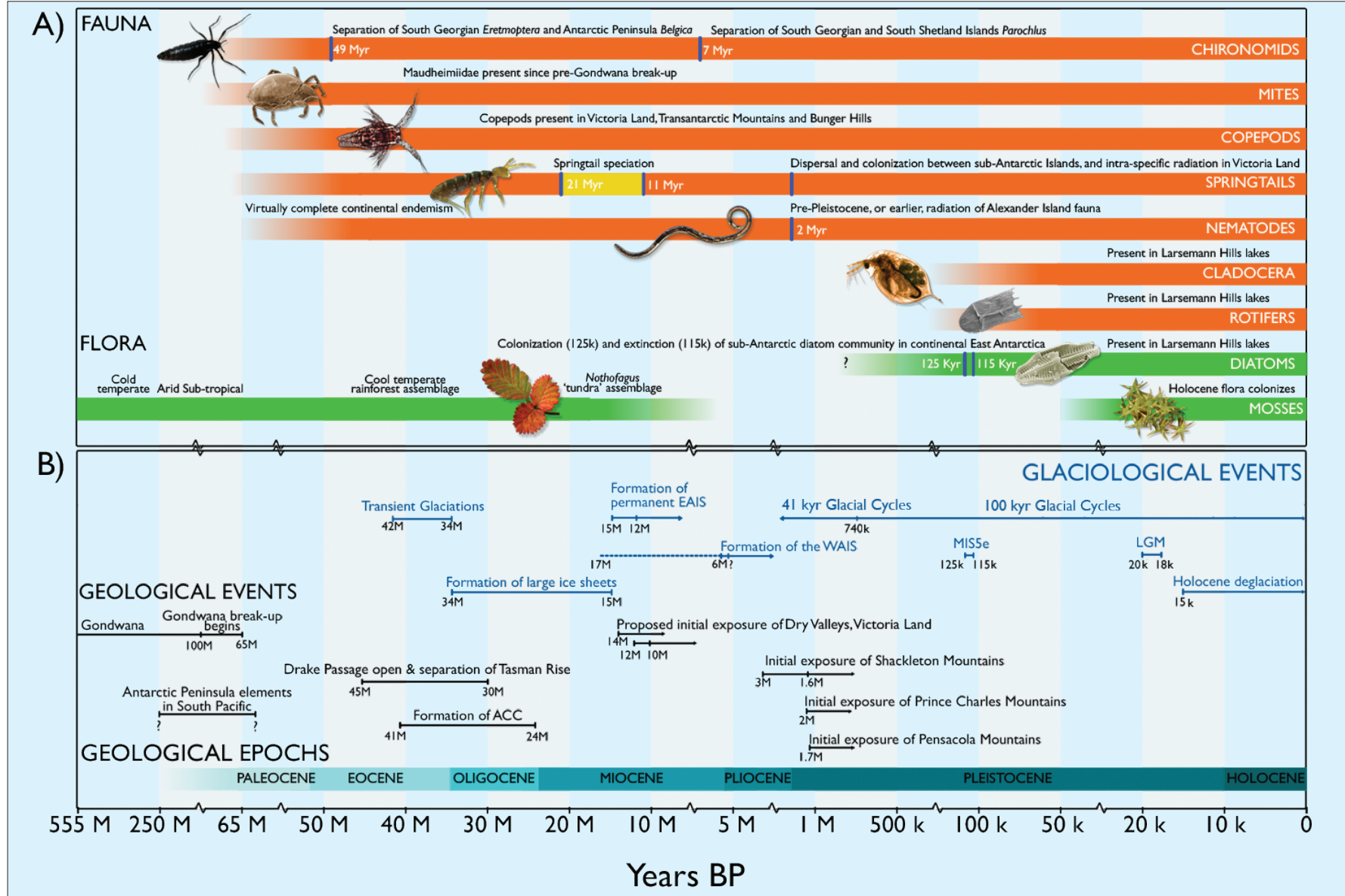

Figure 1: Molecular, phylogenetic and fossil evidence for the timing of biological colonizations and extinctions in Antarctica since the break-up of Gondwana. A) Schematic timelines for the survival of different flora and fauna on the continent; $B$ ) Key geological and glaciological episodes in the evolution of Antarctica that will have influenced flora and fauna. WAIS = West Antarctic Ice Sheet, EAIS = East Antarctic Ice Sheet, ACC = Antarctic Circumpolar Current, LGM = Last Glacial Maximum. Note that the geological timescale is non-linear and that most microorganisms are excluded from this schematic diagram. Modified from Convey et al. (2008). 


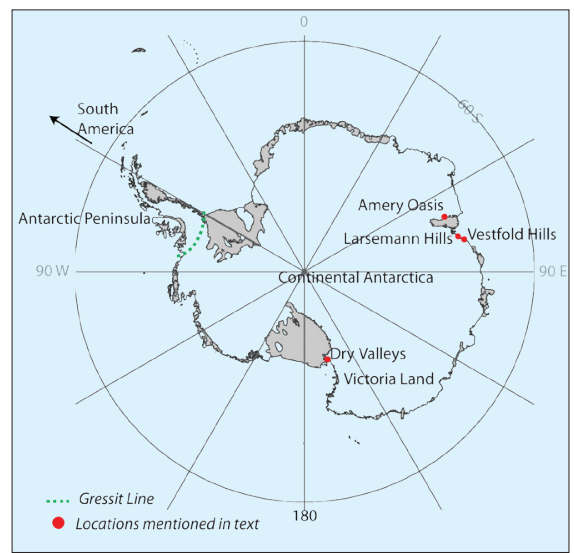

Figure 2: Map of Antarctica showing the location of places mentioned in the text.

boundary between faunal communities of the Antarctic Peninsula and continental Antarctica, across which no species are shared in many of the groups present, has led to the naming of the "Gressitt Line" (Fig. 2), a biogeographical boundary of similar significance to the Wallace Line of SE Asia (Chown and Convey, 2007). Moreover, molecular biological approaches, including phylogeography and estimations based on molecular clocks, have provided strong evidence of ancient colonization and divergence events on timescales of millions to tens of millions of years (e.g., Allegrucci et al., 2006; Stevens et al., 2006; Jansen van Vuuren et al., 2007).

\section{Lacustrine evidence}

Analogous evidence of an ancient fauna is available from Antarctic freshwater lakes. An essential requirement for the long-term survival of freshwater fauna on the continent is the continued existence of lakes. If ice-free areas were limited during glacial maxima, rock-based lakes were likely far scarcer. However, ice-based systems occur that can harbor a diverse fauna (Vincent et al., 2000; Christner et al., 2003). Due to this necessity for habitat persistence, direct evidence provided by lakes is generally on a shorter timescale (i.e., Pleistocene) than for terrestrial studies, although indirect approaches (i.e., biogeographical) suggest longer-term survival for some species. For example, the copepod Gladioferens antarcticus has a distribution suggesting an ancient association with Antarctica (Bayly et al., 2003). This species, which is a member of a genus that otherwise occurs along the south coast of Australia and New Zealand, is the most primitive of its sub-genus, and therefore cannot have been derived recently from other species. It is concluded that it has been associated with the Antarctic continent since the separation of Antarctica and Australia some 30 Myr ago (Bayly et al., 2003).
More direct evidence for long-term survival of fauna (over shorter but still preLast Glacial Maximum (LGM) timescales) comes from the study of faunal remains in lake sediments. Some lakes, notably Lake Reid (Larsemann Hills), have existed since MIS 5 (i.e., were not overrun and scoured by ice during the LGM). Faunal remains in Lake Reid sediments indicate that the cladoceran Daphniopsis studeri and the rotifer Notholca sp. have occurred in the lake throughout its existence (Cromer et al., 2006). Sediment cores from younger lakes also support the continued existence of animal populations on the continent. In most cases, the species currently present in a lake arrived soon after its formation, suggesting a local source (Cromer et al., 2005, 2006; Gibson and Zale, 2006). Furthermore, diversity has not increased markedly over time, which is inconsistent with continual colonization from extracontinental sources.

\section{Marine evidence}

In the marine realm, the historical view that the Antarctic shelf fauna was wiped out during glacial maxima and recolonized after ice-sheet retreat is currently changing. Clarke and Crame (1992) defined the term "Antarctic diversity pump" for the process that caused speciation events (development of a new species) in marine taxa, initiated by repeated glacial and interglacial cycles. Molecular phylogenetic studies on several marine groups have revealed successful radiation events (increases in diversity or morphological varaibility due to adaptation to environmental change) in several taxa since the onset of the Antarctic Circumpolar Current (ACC) 30 Myr ago, e.g., amphipods (Lörz and Held, 2004), isopods (Held, 2000; Raupach et al., 2007; Brökeland and Raupach, 2008) and octopods (Allcock and Piertney, 2002). Studies on the bivalve Limatula in the Southern Ocean have shown that species of this genus were able to cross the ACC (Page and Linse, 2002).

Dayton and Oliver's (1977) idea of refugia on the Antarctic shelf, which enable species with good dispersal abilities to recolonize the shelf after glaciation events or move between refugia during events (Thatje et al., 2005), is being tested with molecular population genetics. First results from recent studies on the crinoid Promachocrinus kerguelensis (Wilson et al., 2007) show that radiation events occurred after the onset of the ACC but before the LGM, suggesting that $P$. kerguelensis survived the LGM on the Antarctic shelf. As many Antarctic marine species have wide water-depth distribution levels, often ranging from the shelf to the continental slope, more studies specifically on species with restricted shelf-depth range are needed to confirm the existence of shelf refugia and, hence, whether this raises analogous questions in the marine environment to those outlined for land; e.g., are there ancient components of the current marine fauna of Antarctica that survived glaciations in refugia?

\section{Conclusions}

The general conclusion from these studies is that for different evolutionary lines to have remained in Antarctica over these timescales, the Antarctic shelf must have been at least partially free of grounded ice, and there must have been seasonally ice-free habitats available on land. For some biotas, such as those of the Victoria Land Dry Valleys and certain inland mountain ranges, this does not challenge current understanding of previous ice extent and thickness, as these regions are known to have maintained ice-free areas during more recent glacial maxima. However, no such explanation currently exists for other elements of the Antarctic biota that occupy low altitude and often coastal habitats today, with no possibility of nunatak or higher altitude refugia for survival through glacial maxima. It must be concluded that many of the coastal icefree areas present today were at least partially ice-free throughout repeated glacial maxima, which puts a significant restraint on the extent of the Antarctic ice sheet during these times. A different model of glaciation has to be developed, possibly involving the formation of ice shelves associated with major outlet glaciers but limited expansion elsewhere. This conclusion is consistent with the marine data, which support asymmetrical circumAntarctic expansion of the ice sheet.

In summary, numerous paleobiological approaches now indicate greater antiquity in the Antarctic terrestrial, marine and freshwater biota than previously thought. Moreover, ancient biogeographical boundaries are still evident in modern species distribution. The survival of ancient components of the Antarctic biota has significance beyond the purely biological realm, by providing a novel biological constraint on past ice sheet extent and thickness. The biological evidence indicates that model reconstructions currently overestimate past ice coverage. 


\section{Note}

Distributional data for the terrestrial and aquatic fauna is available via the Evolution and Biodiveristy in the Antarctic (EBA) dataportal (www. eba.aq/), while marine data is available in the SCAR Marine Biodiversity Information Network (SCAR-MarBIN) database (www.scarmarbin. be/).

\section{References}

Convey, P. and Stevens, M.I., 2007: Antarctic biodiversity, Science, 317 1877-1878.

Convey, P., Gibson, J.A. Hellenbrand, C, Hodgson, D. A, Pugh, PJ.A. Smellie, J.L. and Stevens, M.I., 2008: Antarctic terrestrial life challenging the history of the frozen continent? Biological Reviews, 83: 103-117.

Cromer, L., Gibson, J.A.E., Swadling, K.M. and Hodgson, D., 2006: Evidence for a lacustrine faunal refuge in the Larsemann Hills, East Antarctica, during the Last Glacial Maximum, Journal of Biogeography, 33: 1314-1323
Gibson, J.A.E. and Bayly, I.A.E., 2007: New insights into the origins of crustaceans of Antarctic lakes, Antarctic Science, 19: 157-164.

Page, T. and Linse, K., 2002: More evidence of speciation and dispersa across the Antarctic Polar Front through molecular systematic of Southern Ocean Limatula (Bivalvia: Limidae), Polar Biology, 25: $818-826$.

For full references please consult:

www.pages-igbp.org/products/newsletters/ref2009_1.html

\section{Sea-ice proxies in Antarctic ice cores}

Regine Röthlisberger and Nerilie Abram

British Antarctic Survey, Cambridge, UK; rro@bas.ac.uk

\section{Chemical parameters routinely analyzed in ice cores hold information on past changes in sea ice extent around Antarctica, providing a long-term perspective on sea ice.}

Sea ice plays a crucial role in the Earth System: Apart from its direct influence on radiative balance via its albedo, it also has a large influence on ocean-atmosphere exchange processes, ocean stratification and atmospheric circulation. Furthermore, sea ice is instrumental in the formation of deepwater masses and thus influences the global thermohaline circulation. Despite its importance, sea ice remains a poorly constrained component in model simulations of past and ongoing climate change. Much of this uncertainty is due to the paucity of information about past sea ice conditions.

Various methods have been applied to derive past sea ice extent. For the most

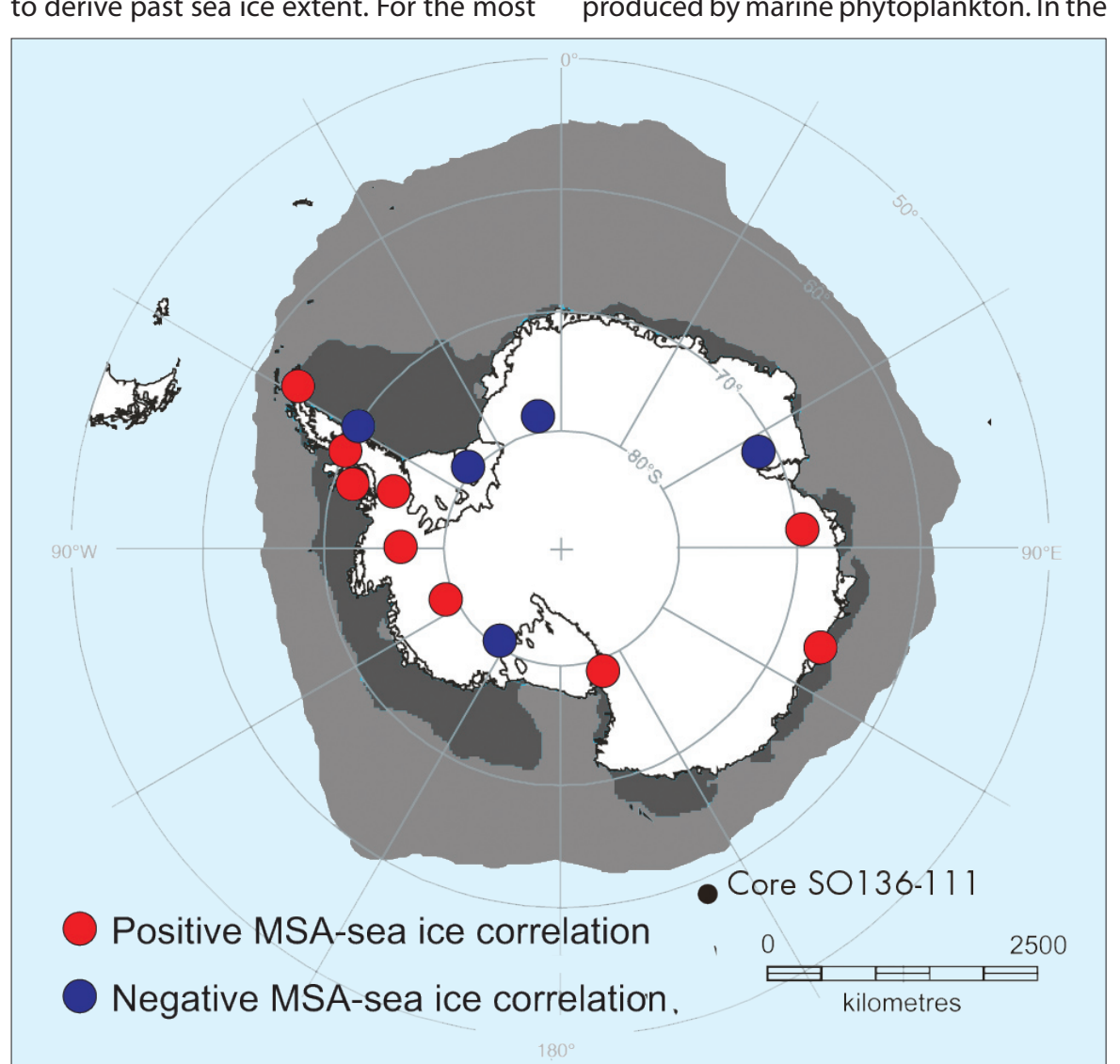

Figure 1: Spatial pattern of the correlation between methanesulfonic acid (MSA) for different coastal Antarctic ice core sites, and the winter maximum sea ice extent for the longitudinal sector considered to be the relevant source (Welch et al., 1993; Sun et al., 2002; Curran et al., 2003; Foster et al., 2006; Abram et al., 2007; Abram, unpublished data). Light and dark gray shading denotes mean winter and summer sea ice extent, respectively.
Southern Ocean, large amounts of DMS are produced by algae in the sea-ice zone (Curran and Jones, 2000). More extensive winter sea ice promotes increased phytoplankton activity during seasonal sea ice melt, and the associated increased release of DMS is reflected by greater amounts of MSA deposited in nearby snow layers.

A pioneering paper by Curran et al. (2003) showed remarkable agreement between the MSA record from Law Dome, a coastal ice dome in East Antarctica, and the satellite-derived sea ice maximum. The MSA record clearly traced the decadal-scale variability found in the satellite record of maximum sea ice extent. Using MSA as a proxy for regional sea ice extent allowed the satellite record to be put into a century-scale context, from which Curran et al. (2003) inferred a $20 \%$ decline in sea ice since 1950 for the $80-140^{\circ} \mathrm{E}$ sector.

Ice core MSA records from a number of other coastal sites also show a positive relationship between MSA and winter sea ice extent (Welch et al., 1993; Foster et al., 2006; Abram, unpublished data), making this a promising proxy for reconstructing regional patterns of sea ice change around Antarctica (Fig. 1). However, there are some limitations in using MSA as a sea ice proxy. Recent work in the Weddell Sea region has found that in some locations the MSA signal in ice cores is more strongly influenced by atmospheric transport strength and direction (Fundel et al., 2006; Abram et al., 2007). There is also evidence that the MSA sea ice proxy is not reliable at some sites around the Ross Sea and Lambert Glacier (Sun et al., 2002), suggesting that embayed coastal locations may not be suitable for sea ice reconstructions, due to geographical constraints on wind-driven transport. Work is currently underway to develop additional MSA records from near-coastal ice core sites, to help define the characteristics of sites where this proxy is reliable, in order to build a regional-scale 


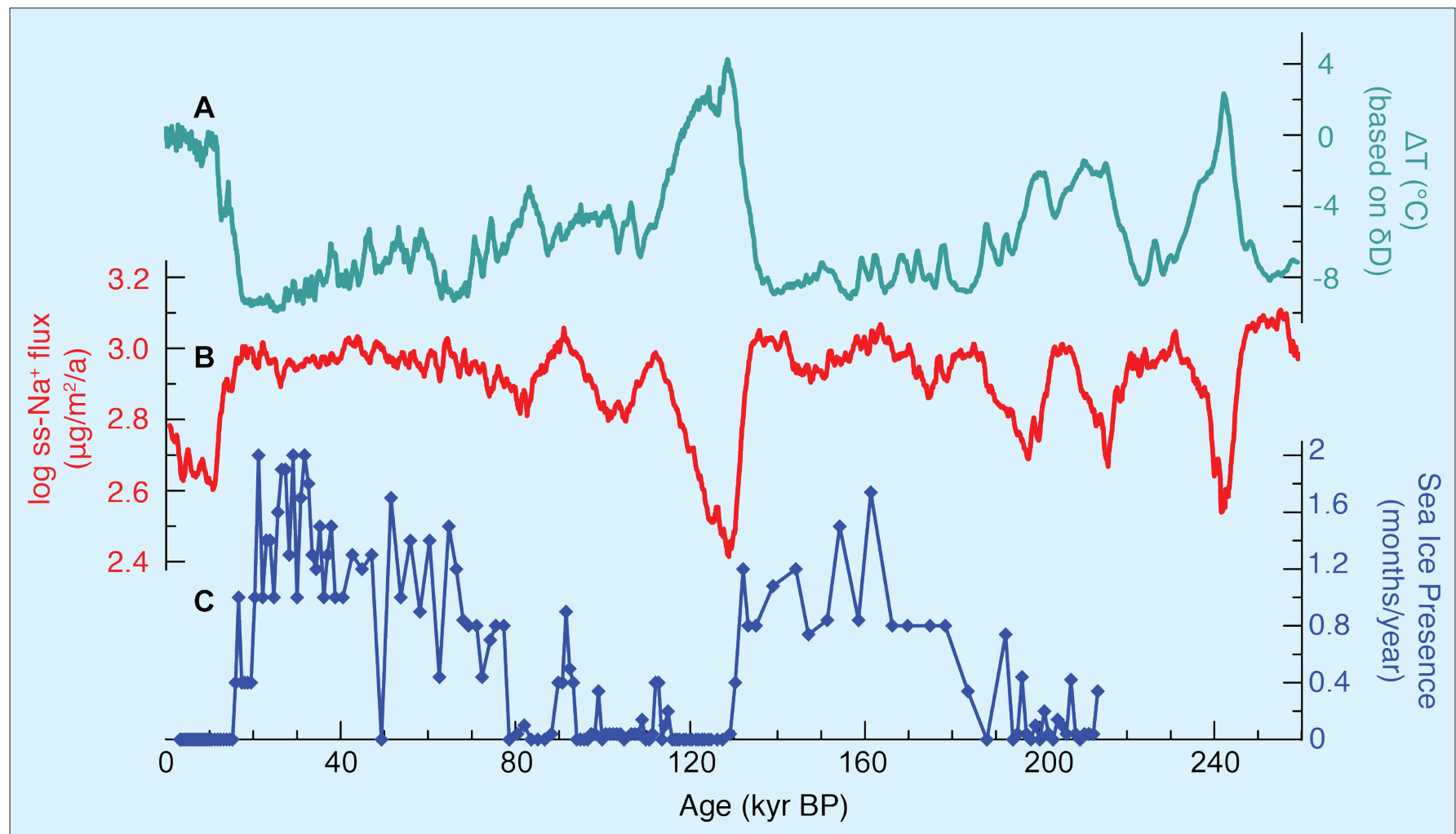

Figure 2: Comparison between ice and marine proxy records of sea ice over the last 2 glacial-interglacial cycles. A) Antarctic temperature anomaly at Dome C relative to modern (Jouzel et al., 2007). B) Sea ice extent proxy (ss Na+ flux) from Dome C (Wolff et al., 2006). C) Sea ice presence derived from diatom assemblages in marine record SO136-111 (Crosta et al., 2004).

synthesis of the history of Antarctic sea ice change (Abram et al., 2008). Conceivably, such reconstructions could be extended over thousands of years. However, on glacial-interglacial timescales, the MSA record in ice cores is likely to be susceptible to changes in the oxidative capacity of the atmosphere (Castebrunet et al., 2006), and to chemical influences on the preservation of MSA, particularly at inland sites with low snow-accumulation rates (Wagnon et al., 1999).

\section{Sea salt}

Sea salt aerosol is generally derived from small air bubbles bursting over open ocean. However, for Antarctica, sea ice surfaces rather than open water have been suggested as the dominant source of sea salt aerosol. Based on this premise, sea salt sodium ( $\left(\mathrm{ss} \mathrm{Na}^{+}\right.$) flux has been used as a qualitative proxy for sea ice extent around Antarctica (Wolff et al., 2003; 2006).

Fresh sea ice is covered by saline brine and it has been shown that blowing snow and small ice crystals growing on these salty surfaces represent effective sources of sea salt aerosol in coastal and inland Antarctica (Rankin et al., 2000; Yang et al., 2008). Two characteristic features of Antarctic sea salt aerosol records support the view that the sea ice surface is a primary source of sea salt aerosol in Antarctica. Firstly, sea salt aerosol concentrations peak in winter, when the open water source is many hundreds of kilometers seaward due to extensive sea ice cover- age. Secondly, sea salt aerosol in Antarctica exhibits marked sulfate depletion, which is incompatible with an open ocean source. Frost flowers and brine on sea ice surfaces, however, are depleted in sulfate due to sodium sulfate being precipitated out while residing on the sea ice surface. Although this strongly supports a link between $\mathrm{ss} \mathrm{Na}^{+}$and sea ice, it is also clear that meteorological conditions responsible for uplift and transport of sea salt aerosol from the sea ice surface to the ice sheet have a large influence on the $s \mathrm{Na}^{+}$flux at any particular site. Nevertheless, average changes in sea ice over relatively long periods (several centuries) and on relatively large spatial scales will leave an imprint on $s s \mathrm{Na}^{+}$flux that stands out against the background of meteorological variability.

The overall pattern of the $s \mathrm{Na}^{+}$record from Dome C, Antarctica, shows general agreement with a sea ice reconstruction based on a marine sediment core from the Indian Ocean sector offshore of Dome C (Fig. 2). Low levels linked to low sea ice extent in the Indian Ocean sector around Antarctica are observed during interglacial periods. A gradual increase in ss $\mathrm{Na}^{+}$flux over the glacial inception and the early part of the glacial period leads to their maximum levels being reached during glacial maxima. However, distinct differences in details of each of these records point toward thresholds in the response of both the sediment core and ice core proxies (Röthlisberger et al., in prep.). A recent study has shown that the response of $s \mathrm{Na}^{+}$flux to a change in sea ice extent, and therefore its use as a sea ice proxy, is greatest for interglacial and moderate glacial climates and decreases with increasing sea ice extent (Röthlisberger et al., 2008), complicating the quantitative interpretation of $s \mathrm{Na}^{+}$. The decrease in sensitivity during glacial periods can be explained by the increasing distance between the aerosol source and the Antarctic ice sheet. Sea salt aerosol concentration is rapidly depleted during transport (Minikin et al., 1994), so that only a small fraction of the sea salt aerosol from the northernmost sea ice areas contributes to the $s \mathrm{sa}^{+}$flux at a particular ice core site. Current efforts in sea salt aerosol modeling will improve the quantitative understanding of the ss $\mathrm{Na}^{+}$ice core records.

\section{Conclusions}

Two ice core parameters, MSA and ss $\mathrm{Na}^{+}$, can be linked to sea ice extent around Antarctica. The two proxies operate on different temporal scales: MSA is linked to the winter maximum in sea ice extent and offers high-resolution records over the past few centuries to millennia. Sea salt sodium, on the other hand, only relates to sea ice changes averaged over several centuries but at a qualitative level, ss $\mathrm{Na}+$ records change over several glacial-interglacial cycles. However, for both proxies, site-specific conditions may influence the response to sea ice changes and need to be taken into account on a case-by-case basis. 


\section{Note}

Data include previously published diatomderived sea-ice reconstruction (Crosta et al., 2004; www.sciencedirect.com/science/journal/03778398) and EPICA Dome C ssNa+ flux and D data (NOAA Paleoclimatology website www.ncdc.noaa.gov/paleo/paleo.html).

\section{References}

Abram, N., McConnell, J.R., Thomas, E.R., Mulvaney, R., Aristarain, A.J. 2008: Ice core records of 20th century sea ice decline in the Bellingshausen Sea, Geophysical Research Letters, submitted.

Abram, N., Mulvaney, R., Wolff, E.W., and Mudelsee, M., 2007: Ice core records as sea ice proxies: an evaluation from the Weddell Sea region of Antarctica, Journal Geophysical Research, 112: D15101, doi:15110.11029/12006JD008139.

Röthlisberger, R. et al., 2008: The southern hemisphere at glacial terminations: insights from the Dome C ice core, Climate of the Past:
Open Discussion, 4: 345-356. www.clim-past.net/4/345/2008/ cp-4-345-2008.html

Wolff, E.W. et al., 2006: Southern ocean sea-ice extent, productivity and iron flux over the past eight glacial cycles, Nature, 440: 491-496.

Wolff, E.W., Rankin, A.M., and Röthlisberger, R., 2003: An ice core indicator of Antarctic sea ice production?, Geophysical Research Letters, 30(22): 2158. doi:10.1029/2003GLL18454.

For full references please consult:

www.pages-igbp.org/products/newsletters/ref2009_1.html

\section{Accurate chronology for Antarctic ice cores on orbital}

\section{timescales}

Kenju Kawamura

National Institute of Polar Research, Research Organization of Information and Systems, Tokyo, Japan; kawamura@nipr.ac.jp

An accurate chronology of Dome Fuji and Vostok ice core records, with dating accuracy better than 2 kyr, has been established for the past $\mathbf{4 0 0} \mathrm{kyr}$ and is consistent with the Milankovitch theory for the sequence of 100-kyr climatic cycles.

Deep ice cores from Antarctica have provided key records of past climate, including local temperature, atmospheric greenhouse gases and aerosols (e.g., Petit et al., 1999; Kawamura et al., 2007; Lüthi et al., 2008), over several glacial-interglacial cycles. In particular, the records have revealed a strong correlation between Antarctic temperature and greenhouse gas concentrations. In order to understand further the roles of both orbital and greenhouse gas forcings on climate changes, and to test Milankovitch forcing as the driver for the 100-kyr cycles seen in the ice core proxies, one would need paleoclimate chronologies with accuracy better than $\sim 2 \mathrm{kyr}(\sim 10 \%$ of a precession cycle). A brief review is presented here on recent progress in improving the chronology of Antarctic ice cores for $\sim 80$ kyr BP and older, by orbital tuning of the record of oxygen-to-nitrogen concentration ratio $\left(\mathrm{O}_{2} / \mathrm{N}_{2}\right)$ in trapped air with the local summertime insolation (Kawamura et al., 2007; Suwa and Bender, 2008). The implications for our understanding of the mechanisms of glacial cycles is also discussed.

\section{Orbital tuning using $\mathrm{O}_{2} / \mathrm{N}_{2}$}

Dating of the Antarctic deep ice cores involves models of past snow accumulation rates and ice flow (to account for thinning) whose parameters are constrained by depth-age control points with associated uncertainties (typically 2-6 kyr for MIS 5 and older periods). The error of the glaciological chronology may be large (>10 kyr) especially deeper in cores (> 2000 m, e.g., GT4 of Vostok and EDC2 of Dome C chronologies) because the real ice flow and/ or accumulation histories do not follow the models' simple assumptions. Orbital tuning utilizes the known relationship between a measured parameter in the ice and an insolation curve to correct the gla- ciological chronology. Conventional orbital tuning uses global climate proxies, such as atmospheric $\mathrm{CH}_{4}$ or $\delta^{18} \mathrm{O}$ of $\mathrm{O}_{2}$, which are matched to proximal insolation forcing (Dreyfus et al., 2007; Ruddiman and Raymo, 2003). This has brought great improvement over the glaciological chronology (e.g., EDC3 over EDC2 for the Dome C core; Parrenin et al., 2007) but the error is still up to $\sim 6 \mathrm{kyr}$ because the actual phasing between these gas proxies and orbital variations is variable.

New orbital tuning using $\mathrm{O}_{2} / \mathrm{N}_{2}$ has been developed for the Dome Fuji and Vostok cores covering 80-400 kyr BP (Kawamura et al., 2007; Suwa and Bender, 2008) (Fig. 1, A-C). $\mathrm{O}_{2} / \mathrm{N}_{2}$ in these cores is depleted relative to the atmospheric ratio because of physical fractionation during air-bubble formation at $\sim 100 \mathrm{~m}$ depth (Severinghaus and Battle, 2006). The magnitude of this depletion is controlled by the magnitude of snow metamorphism, driven by local summer insolation when the layer was originally at the surface (Bender, 2002).Although the exact mechanisms are currently not well understood, empirical evidence indicates that the $\mathrm{O}_{2} / \mathrm{N}_{2}$ variation is probably phaselocked to the local summer solstice insolation, with negligible climatic influences (Kawamura et al., 2007). The independent Dome Fuji and Vostok $\mathrm{O}_{2} / \mathrm{N}_{2}$ chronologies agree within $1 \mathrm{kyr}$, indicating robustness of the method. The accuracy of the chronology (and thus the assumption of using the solstice insolation as the target) is validated through comparison with several age markers (a volcanic ash layer and $\mathrm{CH}_{4} /$ monsoon abrupt events) whose radiometric ages are accurate to within $\sim 2 \mathrm{kyr}$ for the last $200 \mathrm{kyr}$, and which agree within $2 \mathrm{kyr}$ (Kawamura et al., 2007; Suwa and Bender, 2008; Wang et al., 2008). Suwa and Bender (2008) developed a nearly identical $\mathrm{O}_{2} / \mathrm{N}_{2}$ tuned chronology for the Vostok core (100-
$400 \mathrm{kyr}$ BP), with the addition of new $\mathrm{O}_{2} / \mathrm{N}_{2}$ data and using a slightly different method for the matching. Another local insolation proxy is air content (used for EDC3), although it gives less accurate age control (with an error of $\pm 4 \mathrm{kyr}$ ) partly because of climatic influences (Raynaud et al., 2007).

\section{Climatic implications}

The new chronology permits comparisons between parameters measured in Antarctic ice cores (such as temperature and atmospheric greenhouse gases) and orbital variations, thus providing the possibility to separate the respective contributions to past global climate and sea level changes. The 340-kyr-long Dome Fuji temperature record on the new chronology closely follows boreal summer insolation, possibly with a slight lag behind solstice insolation (Fig. 1D). Thus, the previous arguments of early Antarctic warming following the southern summer insolation to trigger northern deglaciation is not supported by the new chronology. Further, the onset of the last four Antarctic terminations are found to lag behind the minima of insolation by 2-7 kyr, and the entire duration of the warming events fit within the rising phase of June solstice insolation at $65^{\circ} \mathrm{N}$. For the last three glacial inceptions, Antarctica cooled in phase with the decrease in northern summer insolation and before significant decreases seen in $\mathrm{CO}_{2}$ and sea level (Fig. 1, D-F) curves.

The above timings are fully consistent with the view that high northern latitude summer insolation drives the 100-kyr glacial cycles by changing summertime temperature and thus long-term glacial mass balance (Raymo, 1997; Denton et al., 2006), with large amplification by albedo and $\mathrm{CO}_{2}$ feedbacks. This view is supported by the recent analysis of marine sediment data by Bintanja and van de Wal (2008), which 


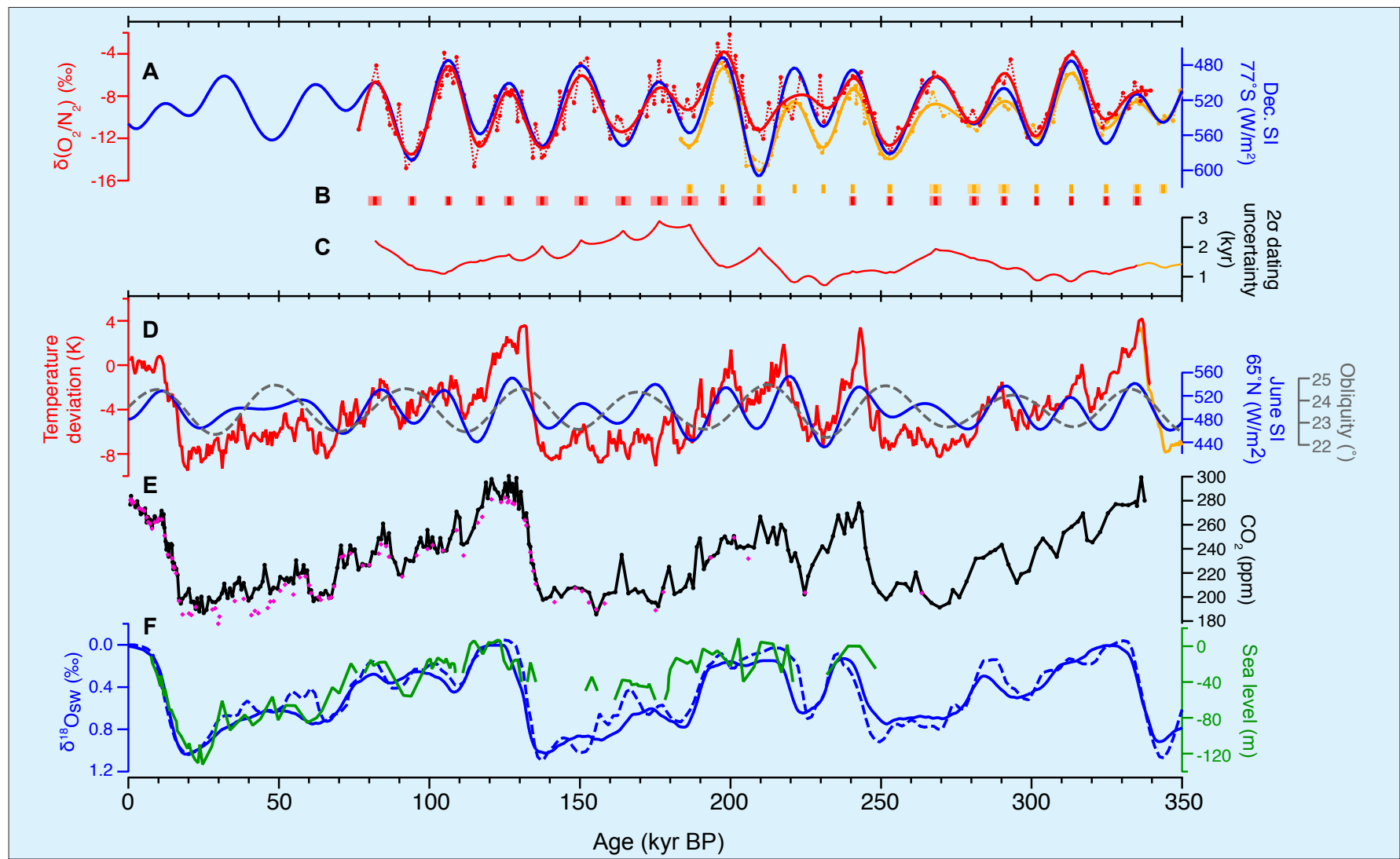

Figure 1: Accurately dated Antarctic ice core records and comparison with sea level proxies (Kawamura et al., 2007). A) Orbital tuning of O,/ $\mathrm{N}_{2}$ in the Dome Fuji (red) and Vostok (orange) cores with local summer insolation (Sl; blue). B) Tuning tie points with $2 \sigma$ error bars due to $\mathrm{O}_{2} / \mathrm{N}_{2}$ data noise. C) $2 \sigma$ dating uncertainty by combining those of the tie points and interpolation procedure. D) Dome Fuji temperature (red), Vostok temperature (orange), northern hemisphere summer insolation (Sl; blue) and obliquity (gray). E) Dome Fuji $\mathrm{CO}_{2}$ concentration by wet (black) and dry (purple) extraction. Note: wet values are too high at LGM and dry values too low in MIS 3, due to artifacts during extractions. F) Sea level reconstructions using radiometrically dated corals (green; Thompson and Goldstein, 2005) and orbitally tuned $\delta^{18} \mathrm{O}$ of seawater, based on marine sediment records through ice sheet modeling (blue solid line; Bintanja et al., 2005) and regression analyses (blue dashed line; Waelbroeck et al., 2002). Records are plotted on their own chronologies.

shows that the decrease in ice volume did not lag behind the increase of air temperature at the 100-kyr terminations after $\sim 700$ kyr BP. This suggests that the huge northern hemisphere ice sheets were actively involved in terminating the 100-kyr glacial periods.

For the last termination, the onset of sea level rise (at $19 \mathrm{kyr}$ BP) may have triggered the Antarctic warming (and $\mathrm{CO}_{2}$ rise, which is in phase with the Antarctic temperature within $1 \mathrm{kyr}$ ) through the bipolar seesaw mechanism (Clark et al., 2004). Assuming that the same mechanism worked during the older terminations, the onset of sea level rise for the older terminations is predicted to be slightly earlier than the onset of the Antarctic warming. There is an alternative view that Antarctic temperature is independent of northern climate and is controlled by the duration of the Antarctic summer, which shows a nearly identical pattern to the northern summer insolation (intensity) (Huybers and Denton, 2008). However, the tight bipolar coupling seems to apply also to orbitally driven warming events (A4 and A7 events in Blunier and Brook, 2001; see also EPICA, 2006). Thus the contribution of the local (Antarctic) orbital forcing could actually be small. A global climate modeling approach would be required to quantitatively estimate the contributions of local and distant orbital forcings to the Antarctic temperature (and $\mathrm{CO}_{2}$ ) changes.

Summer insolation intensity (June solstice, mid July, mean July, JJA average, etc.) is dominated by the precession signal, whose amplitude is modulated by eccentricity. However, the obliquity signal becomes stronger if longer periods (e.g., half-year average) or summer energy (timeintegrated insolation over the days where daily insolation exceeds a certain threshold) (Huybers, 2006) is taken into consideration. The last four terminations actually started when obliquity was relatively large (Huybers and Wunsch, 2005; Suwa and Bender, 2008). With regard to the relative importance of precession and obliquity, termination III ( 245 kyr BP) is interesting because the precession (as in northern summer insolation) and obliquity were out of phase just before the termination. Here, the pattern of temperature evolution from the termination to the next glacial inception is similar to northern summer insolation, while obliquity is decreasing from the previous peak. A longer ice core record with the $\mathrm{O}_{2} / \mathrm{N}_{2}$ chronology is certainly needed to investigate further terminations before this problem can be resolved.

\section{Outlook}

It is very important to extend the $\mathrm{O}_{2} / \mathrm{N}_{2}$ chronology further back in time. The sec- ond drilling at Dome Fuji reached $3035 \mathrm{~m}$ in depth ( 720 kyr BP according to EDC3 chronology; Motoyama, 2007) and the measurement of gas records is underway. The extended chronology will permit statistical testing of the phase stability of terminations with respect to both precession and obliquity (Huybers and Wunsch, 2005). It will also help clarify the true duration of Marine Isotope Stage 11 and how the climate evolution around this interglacial period might serve as an analog to the Holocene and future climate.

\section{Note}

Data used in this article are available from the World Data Center at www.ncdc.noaa.gov/paleo/icecore/antarctica/domefuji/domefuji.html

\section{References}

Bintanja, R. and Van De Wal, R.S.W., 2008: North American ice-sheet dynamics and the onset of 100,000-year glacial cycles, Nature, 454(7206): 869-872.

Clark, P.U., McCabe, A.M., Mix, A.C. and Weaver, A.J., 2004: Rapid rise of sea level 19,000 years ago and its global implications, Science, 304(5674): 1141-1144.

Dreyfus, G.B., et al., 2007: Anomalous flow below $2700 \mathrm{~m}$ in the EPICA Dome C ice core detected using $\delta^{18} 0$ of atmospheric oxygen measurements, Climate of the Past, 3(2): 341-353.

Kawamura, K., et al., 2007: Northern Hemisphere forcing of climatic cycles in Antarctica over the past 360,000 years, Nature, 448(7156): 912-916.

Suwa, M. and Bender, M.L., 2008: Chronology of the Vostok ice core constrained by $0 / \mathrm{N}$ ratios of occluded air, and its implication for the Vostok climate records, Quaternary Science Reviews, 27 1093-1106.

For full references please consult:

www.pages-igbp.org/products/newsletters/ref2009_1.html 


\section{Antarctic Ice Sheet and climate history since the Last Glacial Maximum}

Michael J. Bentley ${ }^{1,2}$ and Dominic A. Hodgson ${ }^{2}$

'Department of Geography, University of Durham, UK; m.j.bentley@durham.ac.uk; ²British Antarctic Survey, Cambridge, UK

Reconstructing the former dimensions and deglacial history of the Antarctic Ice Sheet (Fig. 1) along with Antarctic paleoclimate is important for understanding forcing mechanisms of ice sheet change. Here, we review briefly a number of recent research highlights that have advanced our understanding of the retreat history of the ice sheet and the changes in paleoclimate since the LGM.

\section{Ice sheet history}

The configuration of the Antarctic ice sheet at the Last Glacial Maximum (LGM) is now much better known than a decade ago, largely due to the use of swath bathymetric surveying techniques on the continental shelf (Fig. 2). Detailed surveys have mapped grounding-zone wedges and similar features marking the maximum position and retreat history of the ice sheet (Fig. 2) in areas such as the Antarctic Peninsula (Anderson, 1999; Canals et al., 2000; Ó Cofaigh et al., 2008), Pine Island Bay (Lowe and Anderson, 2002), Ross Sea, sub-Antarctic islands (Graham et al., 2008), Prydz Bay, and some other areas of the East Antarctic margin. Onshore glacial geomorphological studies have identified the maximum elevation of the ice sheet where it intersects interior nunataks (ice free mountain peaks or ridges surrounded by ice sheets or glaciers), and these limits have been dated using cosmogenic isotopes (Stone et al., 2003; Bentley et al., 2006; Mackintosh et al., 2007).Marine geophysical and geological studies have inferred the retreat history of the ice sheet across the continental shelf. For example, Heroy and Anderson (2007) showed that initial retreat of the Antarctic Peninsula Ice Sheet began from the outer continental shelf at $\sim 18 \mathrm{kyr}$, reaching the middle shelf several thousand years later. They suggested that retreat began first in the north and progressively later in the southern Antarctic Peninsula but that by the time the grounding line had reached the inner shelf, different basins were responding in different ways, probably due to different topographic configurations.

Similarly, the onshore studies using exposure dating have shown different behavior in different sectors of the ice sheet. Stone et al. (2003) demonstrated continuous thinning of the West Antarctic lce Sheet in the eastern Ross Sea for at least the last $10 \mathrm{kyr}$ and continuing today, whereas on the Antarctic Peninsula Bentley et al. (2006) showed that the ice thinned and retreated close to its present limits by $9.6 \mathrm{kyr}$. A similar result was noted for the Framnes Mountains in East Antarctica, where the ice was close to its present elevation by $6 \mathrm{kyr}$ (Mackintosh et al., 2007).

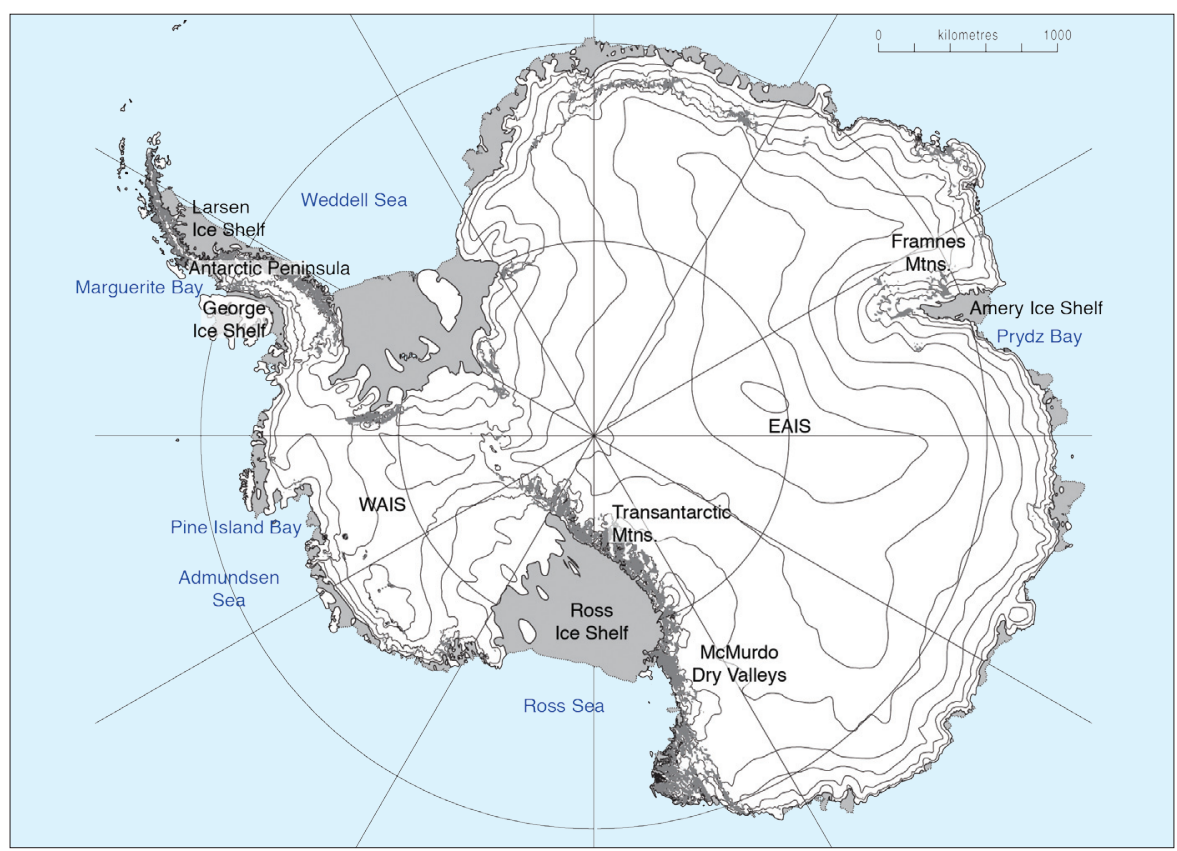

Figure 1: Map of Antarctica showing locations mentioned in the text

There have been other approaches to determining the deglacial history of the ice sheet. Dating of organic remains (shells, penguin bones, guano, sealskin) in raised beaches and of sediment cores from isolation basins (marine inlets now uplifted to form freshwater lakes) has been used to establish relative sea level curves to provide independent constraints on ice sheet volume and deglacial history (e.g., Hall et al., 2004; Bassett et al., 2007). New biological constraints on ice sheet history are also emerging from genetic studies of faunal communities on nunataks and ice-free coastal regions that have apparently been present since before the LGM, requiring the presence of ice-free areas at both high and low elevation even at peak glaciation (Convey et al., 2008; see also Newman et al., this issue).

Long-term ice shelf history has been used to place recent ice shelf collapses in context and a number of groups have used paleo-records to identify past (in)stability of Holocene ice shelves, including early Holocene collapse of the George VI Ice Shelf, mid-Holocene collapse of the Larsen-A/Prince Gustav Channel ice shelf complex, and apparent stability of LarsenB since the LGM (see Hodgson et al., 2006 for review), as well as a major retreat of the Amery lce Shelf to at least $80 \mathrm{~km}$ landward of its present location during the mid-Holocene climatic optimum (Hemer and Harris, 2003).

\section{Antarctic paleoclimate}

Antarctic paleoclimate records come primarily from proxies in ice cores or marine

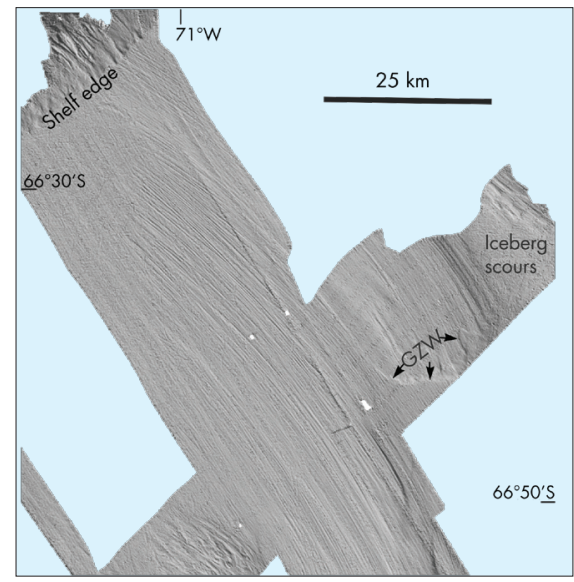

Figure 2: Shaded relief image of mega-scale glacial lineations produced beneath the Marguerite Trough ice stream, Antarctic Peninsula continental shelf. The lineations are formed in soft sediment in water depths of 500-700 m. They extend to the shelf edge, beyond which a well-developed series of gullies are incised into the upper continental slope. The lineations are replaced in shallower water by iceberg plough-marks. The position of a prominent sediment scarp formed in till, which marks a former grounding-zone position of the ice stream, is also indicated (GZW). The data were collected using a multibeam (swath) echo sounder. Grid cell size in the image is $50 \times 50 \mathrm{~m}$ (Modified from Ó Cofaigh et al., 2008). 
and lake sediment cores. The'paleoclimate' information contained in each of these records is often very different. Ice cores contain a mixture of global signals (e.g., concentrations of $\mathrm{CO}_{2}$ and $\mathrm{CH}_{4}$ ); regional signals (e.g., average sea-ice extent from sea salts and methanesulfonic acid), and local signals (e.g., precipitation/snow accumulation rate). Lake sediment cores record some global phenomena (e.g., long range transport of pollutants) but more commonly are used to identify regional signals such as temperature and relative sea level change, and local changes such as the advance and retreat of catchment glaciers and ice shelves. Marine sediment cores are similarly versatile, providing information on major oceanographic changes such as changes in currents or distribution of water masses, regional changes in parameters such as sea-ice extent and surface water productivity, and local changes such as the extent of ice shelves and glaciers.

Collectively these records offer a great wealth of information but also present a similarly great challenge for those attempting to assimilate the data into meaningful syntheses or identify mechanisms of change at a resolution that is of use for understanding climate forcing and constraining future climate scenarios. Following a workshop in Cambridge, one group recently attempted a synthesis of paleoclimate datasets across disciplines focusing on the Antarctic Peninsula region (Bentley et al., in press). The aim was to identify Holocene warm periods and to determine the underlying mechanisms causing them. Results showed that there are two warm periods recorded in most of the proxy records-a period of early Holocene warmth, and a Mid-Holocene Hypsithermal (Fig. 3).

For both of these, shifts in the Southern Westerlies may have been an important forcing mechanism, possibly superimposed on slower insolation changes. Notably, during the mid-Holocene the marine and terrestrial proxies do not all agree. Most terrestrial proxies show warming in this period, whereas the Palmer Deep-a key offshore record west of the Antarctic Peninsula-shows relatively cool conditions. There are various possible explanations, including differences in seasonal insolation forcing (e.g., Renssen et al., 2005) or albedo feedbacks that served to amplify changes in certain proxies close to the coast (Bentley et al., in press).

The differences among proxy records carry an important implication: it is unwise to rely on any individual type of paleoclimate record, even to identify when past warm periods occurred. Two other warm periods are less well recorded in those

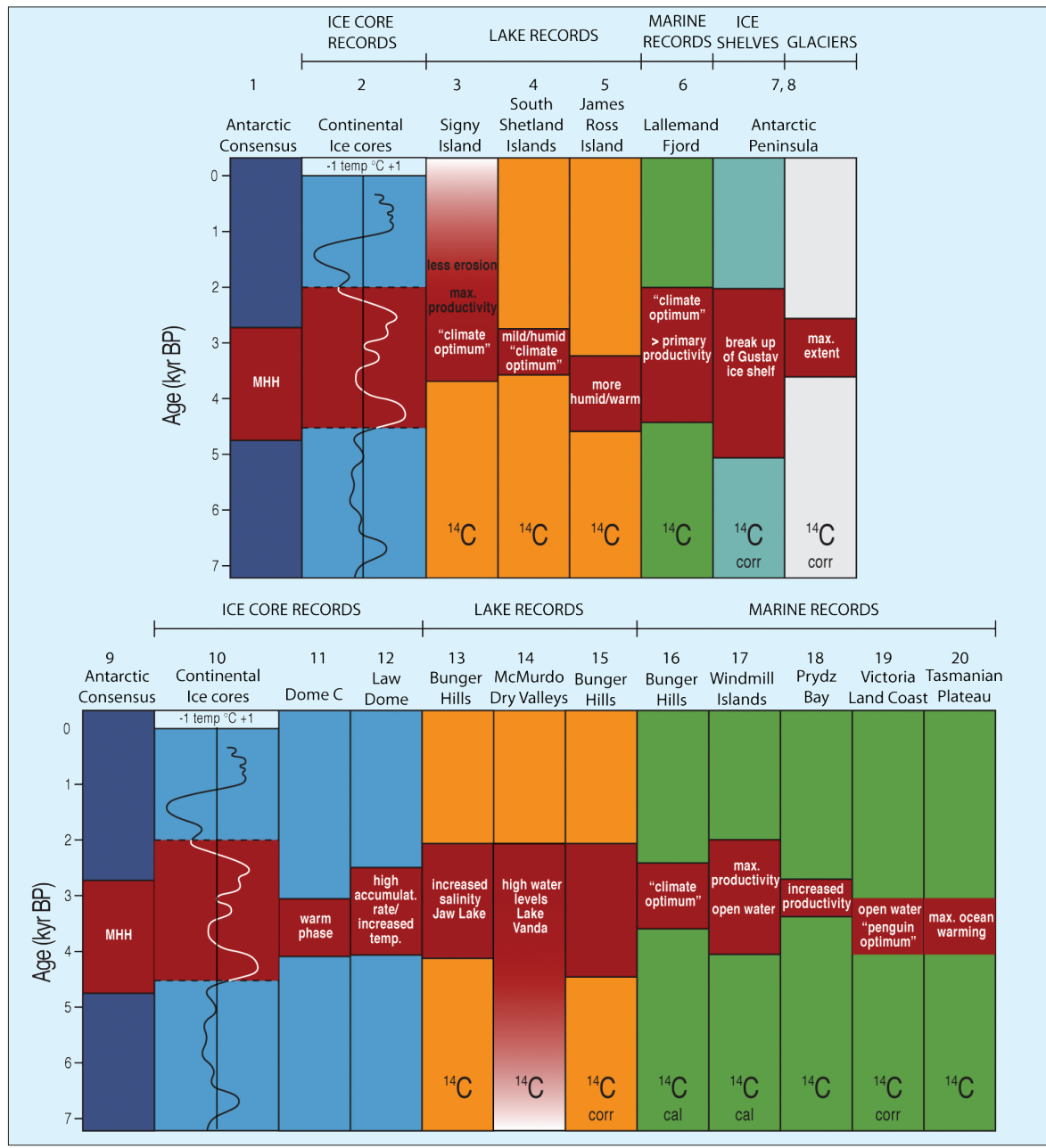

Figure 3: Summary of selected records showing the Mid-Holocene Hypsithermal (MHH). Top panel: Maritime Antarctic and Antarctic Peninsula. Bottom panel: Continental Antarctica. Red shading indicates periods of relative warmth inferred from proxy records. ${ }^{14} \mathrm{C}$ and ${ }^{14} \mathrm{C}$ corr. differentiates whether uncorrected or corrected radiocarbon dates were applied in the original studies. The 'Antarctic consensus' is based on some of the best radiocarbon dated records, which place the hypsithermal between either 4 and $2.7^{14} \mathrm{C} \mathrm{kyr} B P(4.5$ and $2.8 \mathrm{cal}$. kyr BP) in the Antarctic Peninsula region (Björcket al., 1991) or 3.8 and 1.4 cal. kyr BP in the maritime Antarctic (Jones et al., 2000; Hodgson and Convey, 2005). Continental ice core plots are measured as average temperature curve from 6 ice cores. Temperature is expressed as the departure from the mean of the past $5 \mathrm{kyr}$. Modified from Hodgson et al., 2004. Numbers above plots match references listed online at www.pages-igbp.org/products/newsletters/ref2009_1.html

proxies studied and require greater focus, namely the Medieval Warm Period and the Recent Rapid Regional Warming (robustly known from instrumental records). This exercise has also exposed other key gaps in knowledge. There is a need for a regional ice core spanning the Holocene (in this case we are looking forward to the first results from James Ross Island, drilled in 2008) and for better understanding of the Holocene history of oceanic water masses such as Circumpolar Deep Water, as well as a need to extend the network of marine and terrestrial (lake) geological records.

\section{Future priorities}

The establishment of improved linkages between glacial geologists, paleoclimatologists and modelers will aid our understanding of ice sheet history and past patterns of climate change in all regions of Antarctica. In turn, this will inform a new generation of models that are regionally sensitive, and stimulate field programs to collect data to constrain such models. Some such models already exist: e.g., the model simulations of Renssen et al. (2005) have already been used to explain some of the contrasts between marine and terrestrial records during the mid-Holocene warm period in the Antarctic Peninsula region (Bentley et al., in press).

\section{References}

Bentley, M.J., et al., in press: Mechanisms of Holocene palaeoenvironmental change in the Antarctic Peninsula region, The Holocene.

Graham, A.G.C., Fretwell, P.T., Larter, R.D., Hodgson, D.A., Wilson, C.K. Tate, A.J. and Morris,P., 2008: A new bathymetric compilation highlighting extensive paleo-ice sheet drainage on the continental shelf, South Georgia, sub-Antarctica, Geochemistry Geophysics Geosystems, 9(7): doi:10.1029/2008GC001993.

Hodgson, D.A., Doran, P.T., Roberts, D. and McMinn, A., 2004: Paleolimnological studies from the Antarctic and sub-Antarctic islands, In: Pienitz, R., et al., (Eds), Developments in paleoenvironmental research volume 8, Long-term environmental change in Arctic and Antarctic Lakes, Springer, 419-74.

Renssen, H., Goosse, H., Fichefet, T., Masson-Delmotte, V. and Koç, N., 2005: Holocene climate evolution in the high-latitude Southern Hemisphere simulated by a coupled atmospheric-sea-iceocean-vegetation model, The Holocene, 15: 951-64.

Stone, J.0., Balco, G.A., Sugden, D.E., Caffee, M.W., Sass, L.C., Cowdery, S.G. and Siddoway, C., 2003: Holocene Deglaciation of Marie Byrd Land, West Antarctica, Science, 299: 99-102. doi: 10.1126/ science. 1077998 .

For full references please consult:

www.pages-igbp.org/products/newsletters/ref2009_1.html 


\section{Change in the Southern Ocean: Responding to Antarctica}

Lionel Carter ${ }^{1}$ and Giuseppe Cortese ${ }^{2}$

'Antarctic Research Centre, Victoria University, Wellington, New Zealand; lionel.carter@vuw.ac.nz

${ }^{2}$ Geological and Nuclear Sciences, Lower Hutt, New Zealand; g.cortese@gns.cri.nz

Antarctica exerts a strong influence on the Southern Ocean, where sea surface temperatures, ocean frontal systems and icebergs respond directly to glacial/interglacial- to millennial-scale changes. These responses, however, can differ between ocean basins, due to differences in basin morphology, circulation and climate.

Precisely fifty years ago, in a 3-page letter to Deep-Sea Research, Henry Stommel (1958) highlighted the role played by Antarctica in driving the oceans' abyssal circulation. Since then, many studies of the present and past ocean have redefined the close links between Antarctica and the Southern Ocean, and their influence on the global ocean and climate. To highlight those links, we briefly review Antarctica's impact on the surface of the Southern Ocean at glacial-interglacial (G-I) and millennial timescales.

The Southern Ocean is a sea of superlatives. It is dominated by the longest (24,000 km), largest (transport of $\sim 13710^{6}$ $\mathrm{m}^{3} \mathrm{~s}^{-1}$ ) and only current to link the major oceans-the Antarctic Circumpolar Current (ACC) (Fig. 1). This complex system of flows is driven mainly by the westerly zonal winds. Much of its flow today is concentrated along several ocean fronts that also define the distribution of surface waters and include, from north to south, the Subantarctic, Polar, Southern, and Boundary Fronts (e.g., Orsi et al., 1995).

\section{Riding the G-I Cycle}

A wide range of proxies for sea surface temperature (SST) reveal strong glacial cooling at orbital frequencies (e.g., Barrows et al., 2007; Cortese et al., 2007; Gersonde et al., 2005; Howard and Prell, 1992; Pahnke and Sachs, 2006). Ocean cooling was most pronounced around $40-46^{\circ} \mathrm{S}$ during major glaciations of Marine Isotope Stages (MIS) $2,6,8,10$ and 12 , when SSTs were $4-6^{\circ} \mathrm{C}$ lower than present. Such temperature differences were reduced southwards. By comparison, the peak interglacial periods of MIS $5 \mathrm{e}$ and 11 had SSTs up to $3^{\circ} \mathrm{C}$ warmer than present.

The variability in SSTs between these periods and the present is associated with meridional shifts of ocean fronts coincident with the growth and decay of the cryosphere, and the migration of westerly winds. Glacial periods witnessed major expansions of ice sheets and winter sea ice, which extended $3-8^{\circ}$ of latitude northward into the Atlantic, $7-10^{\circ}$ into the Indian Ocean and possibly $\sim 2-5^{\circ}$ into the Pacific Ocean. This expansion was accompanied by an equatorward displacement of the westerly winds and ocean fronts. In

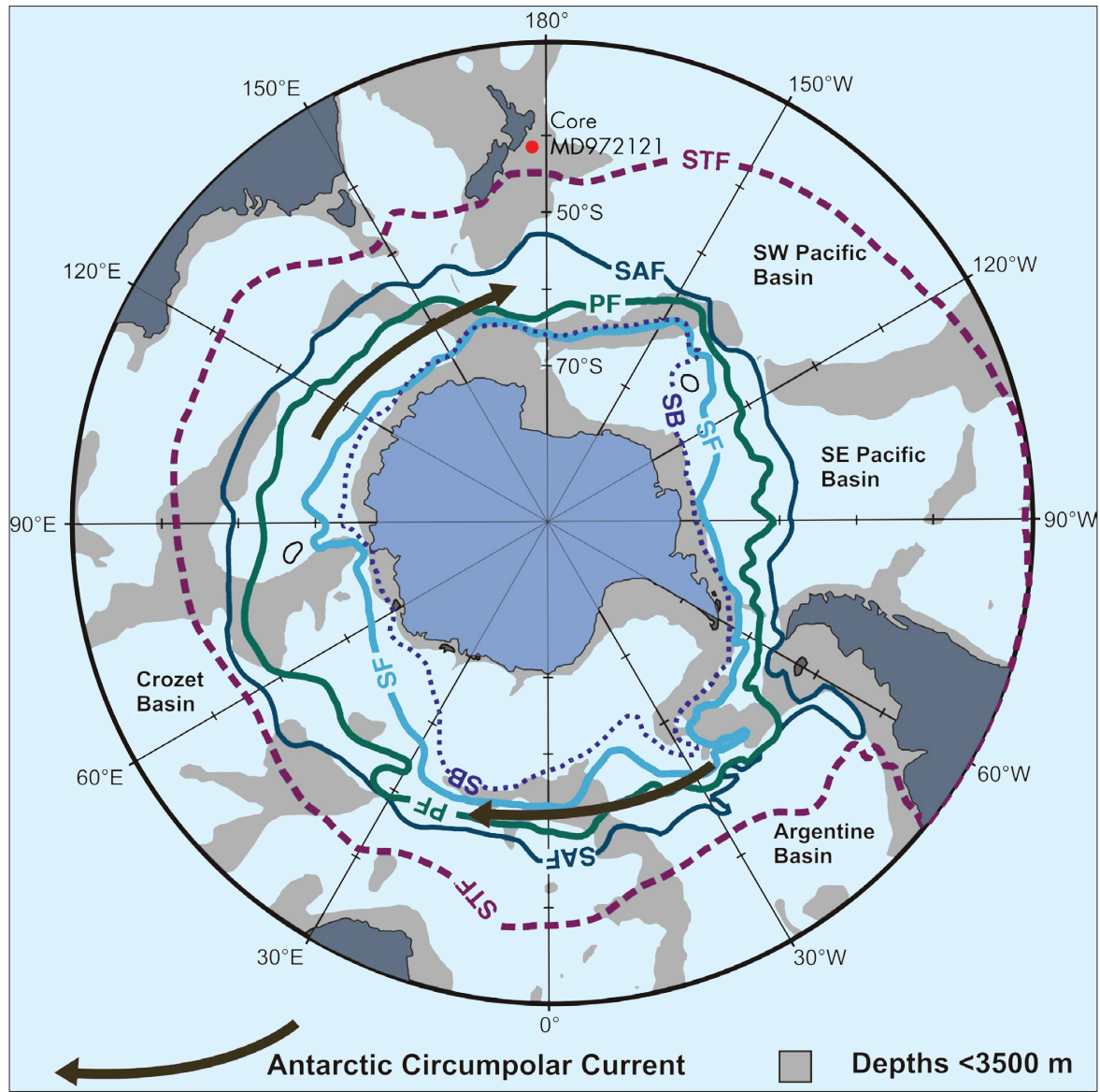

Figure 1: The Southern Ocean and its frontal systems that include the Subtropical (STF; purple dashed line) and Subantarctic (SAF; dark blue line), Polar (PF; green line), Southern (SF; light blue line) and Southern Boundary (SB; purple dotted line) Fronts, with the Antarctic Circumpolar Current (black arrows) constrained between the SAF and SB. Red dot indicates location of core MD97 2121.

the open Southern Ocean, away from shallow bathymetry, the Polar Front moved $4^{\circ}$, 5-10 and $2-3^{\circ}$ into the Atlantic, Indian and Pacific sectors, respectively, during the LGM. At the same time, the Subantarctic Front shifted $4-5^{\circ}$ and $5-10^{\circ}$ into the Atlantic and Indian oceans. In contrast, the Subtropical Front displayed smaller, $\sim 2-5^{\circ}$ shifts, possibly the result of blocking by the subtropical gyres in the main ocean basins. This could compress and intensify oceanographic gradients at the northern limit of the Southern Ocean (Gersonde et al., 2005).

These frontal migrations, as best identified from the scatter of SST data, imply a shift in the ACC. However, any such shift poses a problem because the path of the modern current is steered by the abyssal bathymetry (e.g., Rintoul et al., 2001). Thus, at the LGM it was only the surface waters of the ACC that responded to the shift of the westerly winds and expanded northwards. Overall, the ACC would have slowed down in the LGM compared to modern circulation, which has narrowed and intensified as zonal winds migrate south to reside almost directly above the ACC (e.g., Toggweiler and Russell, 2008). Nevertheless, the glacial ACC may have accelerated locally where its path was restricted by shallow bathymetry (as it is today), to block and compress the advancing fronts (e.g., Pudsey and Howe, 1998).

\section{Responding to millennial change}

Ice cores reveal frequent abrupt changes in temperature (e.g., EPICA, 2004). Of these, the Antarctic Cold Reversal (ACR; 14.2-12.4 kyr) has received recent attention (e.g., Carter et al., 2008). In Antarctica, the ACR is represented by an abrupt cooling of $\sim 3^{\circ} \mathrm{C}$, accompanied by an expansion of ice shelves and sea ice, and a modest intensification of winds (Fig. 2). The response of the surface ocean was variable. South of the Subtropical Front, SSTs cooled in phase with the ACR. This change reflects 


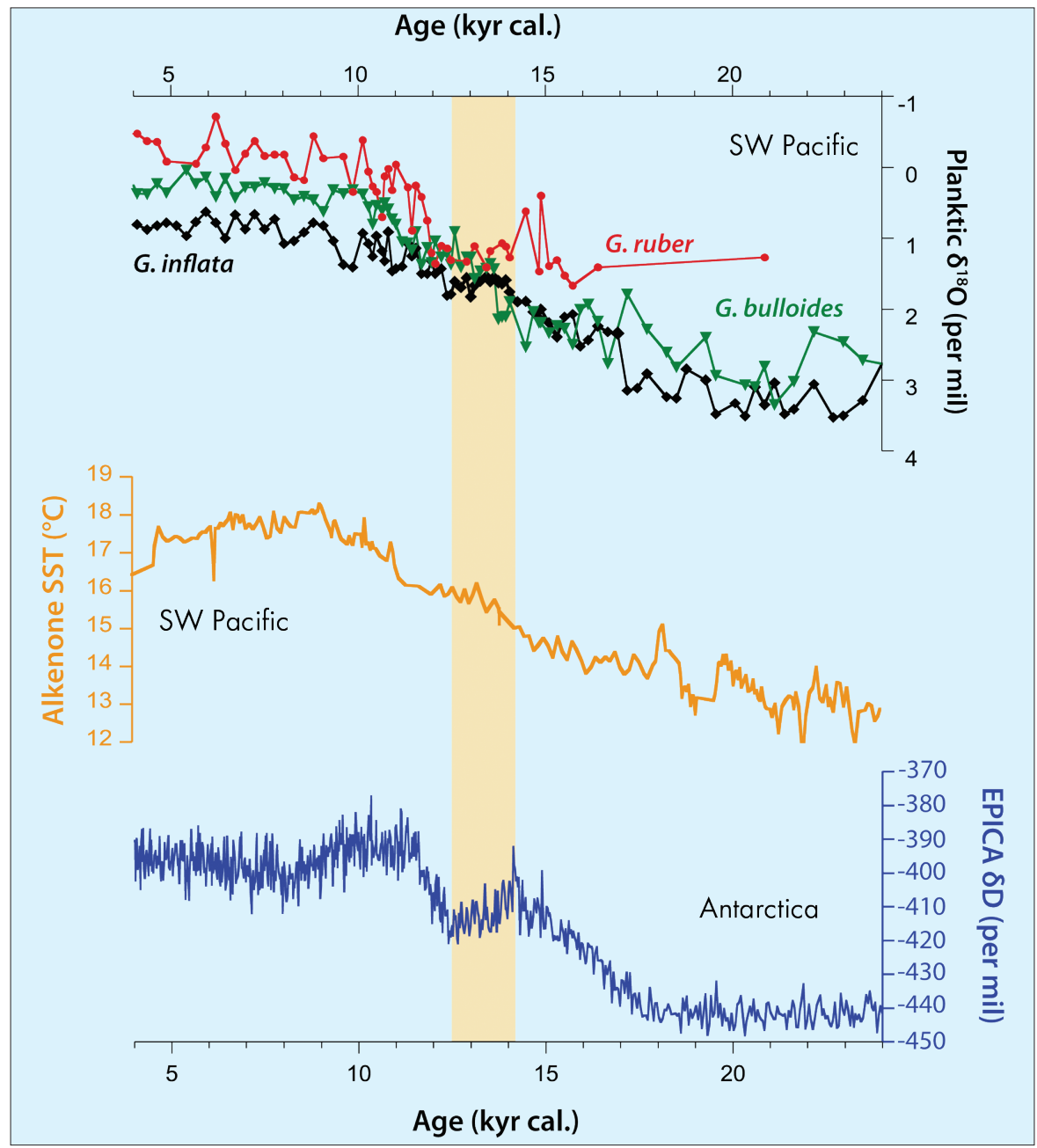

Figure 2: Oxygen isotope profiles from 3 planktic foraminifers (Carter et al., 2008) and an alkenone-based SST curve (Pahnke and Sachs, 2006) spanning the last termination, as recorded in the SW Pacific core, MD97 2121 (see Fig. 1). Yellow shading indicates the Antarctic Cold Reversal (ACR), as identified in the EPICA Dome C ice core deuterium record (EPICA, 2004). The ACR leads any response in the SW Pacific Ocean, where surface waters appear to become better mixed or subject to cooler summers (as suggested by merging of the planktic $\delta^{18} \mathrm{O}$ profiles), and the SST warming trend becomes less pronounced midway through the ACR.

the direct atmospheric and oceanic links with Antarctica, especially during glacial periods when winds and polar waters migrated north. In contrast, waters just north of the Subtropical Front, had a delayed and muted response. Off eastern New Zealand, there was no clear reaction until

$\sim 13.5 \mathrm{kyr}$, when the ACR was at its coldest (Fig. 2). SSTs reduced, marine fertility declined and the uppermost ocean was either more mixed or the thermocline more shallow. Like the SW Pacific Ocean, the S. Indian Ocean also cooled out of phase; SSTs reduced by $0.8^{\circ} \mathrm{C}$ between $13.2-12$

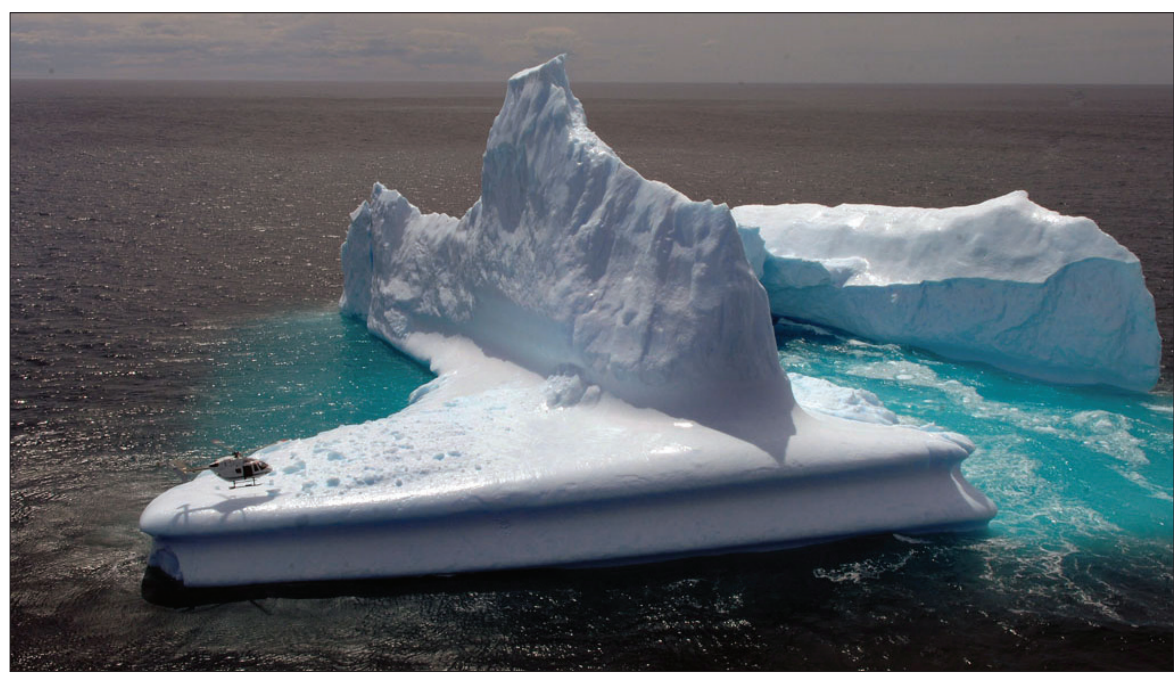

Figure 3: An iceberg sails close to New Zealand in 2006. Whereas the media heralded this as a precursor of global warming, iceberg incursions to this region have occurred throughout recorded history and, of course, during G-I cycles. Image: Stephen Jaquiery, permission for use kindly given by Helicopters Otago (www.helicoptersotago. co.nz/air_transport_ops.html) kyr, about 1 kyr after the ACR began (Stenni et al., 2001). Such reactions suggest distinct regional responses to the ACR. It also seems that reversal events such as the ACR are a feature of glacial terminations (transitions from glacial to interglacial state) around the Southern Ocean, as they appear at several times in the past implying a two-step termination process (Cortese et al., 2007; Bianchi and Gersonde, 2002).

Rapid warm events, recorded by ice cores, are also expressed in SSTs. Antarctic warm events A1-4, between 60-38 kyr, were accompanied by concomitant SST increases of $2-3^{\circ} \mathrm{C}$ (Barrows et al., 2007). Of note is the timing of these warm periods. They appear to immediately precede Dansgaard-Oeschger events 8, 12, 14 and 17 as identified in the Greenland GISP 2 ice core. A north-south connection is also suggested by phases of algal productivity off eastern New Zealand that occurred within 1-2 kyr of iceberg influxes in the N. Atlantic Ocean associated with Heinrich Events 1-6 (Sachs and Anderson, 2005). Therefore, in addition to strong Antarctic influences on the Southern Ocean, there also appear to be links with the northern hemisphere, although the driving mechanism(s) and precise timing of these changes are still being resolved.

\section{The icebergs cometh}

The most dramatic manifestation of Antarctica in the Southern Ocean are icebergs-a point highlighted by the media interest in an iceberg grounded off New Zealand in 2006 (Fig. 3). However, this event was not unusual. Ships have recorded icebergs in mid-southern latitudes since the $19^{\text {th }}$ century. Likewise, sediment cores document pulses of ice rafted debris (IRD) throughout the Quaternary (e.g., Cowan, 2002). A 300 kyr-long record from the Weddell Sea (a prominent source of icebergs) shows IRD deposition was highest in interglacial periods (Grobe and Mackensen, 1992). Further afield, late Quaternary IRD profiles from New Zealand resemble the Weddell Sea records (Carter et al., 2003), which is not surprising as New Zealand intercepts the ACC; the main transporter of icebergs. However, the interglacial IRD pulses in distal records off New Zealand are more subdued than those from the Weddell Sea; a feature attributed to iceberg melting in warm interglacial seas. In contrast, glacial records from the two regions are more closely related, indicating better preservation of icebergs on account of cold ocean temperatures. Superimposed on the G-I cycles are IRD pulses of millennial frequency, which may be traced through much of the Southern Ocean, at least for the past 
70 kyr. Kanfoush et al. (2000) noted that IRD pulses in the S. Atlantic Ocean coincided with warm periods when production of North Atlantic Deep Water (NADW) was enhanced in the northern hemisphere and sea level rose; both processes leading to destabilization of Antarctic ice shelves and the promotion of icebergs.

This brief synthesis of Southern Ocean research highlights the interactions of the atmosphere, ocean and cryosphere of the two hemispheres as they vie for control of the climate machine. It is an exciting challenge to clarify these inter-relationships in order to understand how the planet "ticks" and so to better gauge its responses to a rapidly changing climate.

\section{Note}

The majority of data presented in this article comes from existing datasets available in the World Ocean Circulation Experiment Southern Ocean Atlas (http://wocesoatlas.tamu.edu/)

\section{References}

Barrows, T.T., Juggins, S., de Deckker, P., Calvo, E. and Pelejero, C., 2007: Long-term sea surface temperature and climate change in the Australian-New Zealand region, Paleoceanography, 22: PA2215, doi.10.1029/2006PA001328.

Carter, L., Manighetti, B., Ganssen, G. and Northcote, L., 2008: SW Pacific modulation of abrupt climate change during the Antarctic Cold
Reversal -Younger Dryas, Palaeogeography, Palaeoclimatology, Palaeoecology, 260: 284-298.

Cortese, G., Abelmann, A. and Gersonde, R., 2007: The last five glacialinterglacial transitions: a high-resolution 450,000 year record from the subantarctic Atlantic, Paleoceanography, 22: PA4203, doi:10.1029/2007PA001457.

Gersonde, R., Crosta, X., Abelmann, A. and Armand, L., 2005: Sea surface temperature and sea ice distribution of the Southern Ocean at the EPILOG Last Glacial Maximum - a circum-Antarctic view based on siliceous microfossil records, Quaternary Science Reviews, 24 : 869-896.

Howard, W.R. and Prell, W.L., 1992: Late Quaternary surface circulation of the Southern Indian 0cean and its relationship to orbital variations, Paleoceanography, 7: 79-117.

For full references please consult:

www.pages-igbp.org/products/newsletters/ref2009_1.html

\section{New records of the role of Antarctic ice sheets in late Cenozoic climate}

\section{Ross Powell ${ }^{1}$, T. Naish ${ }^{2}$, R. LeVY ${ }^{3}$ and the MIS Science Team ${ }^{3}$}

'Department of Geology and Environmental Geosciences, Northern Illinois University, DeKalb, USA; ross@geol.niu.edu

${ }^{2}$ Antarctic Research Centre, Victoria University of Wellington, New Zealand, and Geological and Nuclear Sciences, Lower Hutt, New Zealand; ${ }^{3}$ ANDRILL Science Management Office, University of Nebraska at Lincoln, USA

\section{New drill core records of Plio-Pleistocene age from Antarctica include evidence of significant changes in ice sheet regime younger than $14 \mathrm{Myr}$ and an obliquity-driven dynamic marine-based ice sheet prior to 800 kyr.}

Although Antarctica's ice sheets contain the world's largest terrestrial water reservoir, their influence on Late Cenozoic (14 Myr ago) sea level and climate remains poorly known from proximal records. Consequently, the role of Antarctica's ice sheets in global sea level and climate relies heavily upon inferences from oxygen isotope records from deep-sea cores. Although these isotopic records have revolutionized our understanding of climate-ice-ocean interactions, questions remain about the specific contribution of Antarctica's ice sheets.

Various lines of evidence, including geomorphic studies from the Transantarctic Mountains (TAM), suggest that the East Antarctic Ice Sheet (EAIS) has been quite stable for the past $14 \mathrm{Myr}$ (Sugden et al., 1993). However, oxygen isotope records indicate moderate oscillations of global ice volume capable of producing sea level fluctuations of $<25 \mathrm{~m}$ above present, prior to the development of northern hemisphere ice sheets about 3 Myr ago. These ice volume changes must have involved a Greenland ice cap, the West Antarctic Ice Sheet (WAIS), and margins of EAIS. A more dynamic view of the late Cenozoic EAIS has been proposed from a number of on-land geological studies, with evidence (from marine diatoms in glacial sediments) of marine incursions into the continental East Antarctica during the Pliocene (5.3-1.8 Myr ago) requiring a significant deglaciation of the interior of EAIS (Webb et al., 1984; Har- wood et al., 2000). However, the origin of the diatoms has been called into question (e.g., McKay et al., 2008), and uncertainty remains over the scale of Antarctic ice sheet dynamism. While this debate continues, the Early and middle Pliocene (5-3 Myr ago) is generally regarded as a time of global warmth and is, therefore, an important window into Earth's future climate in the context of anthropogenic warming.

During the austral summer of 20062007, a new Antarctic geological drilling program (ANDRILL) recovered a 1285-mlong record of climate and ice sheet variability spanning the past $14 \mathrm{Myr}$. This AND$1 \mathrm{~B}$ core came from beneath the 85 -m-thick McMurdo Ice Shelf (MIS), within an 850-mdeep sedimentary basin surrounding Ross Island (Fig. 1). The core provides the best direct evidence of past Antarctic Ice Sheet (AIS) and climate fluctuations for this time interval, enabling comparison with deepsea isotope records, low-latitude continental margin sea level records, and numerical climate and ice sheet models, especially for times of past global warmth. A synopsis of the initial results from AND-1B (Naish et al., $2007 ; 2008$ ) is presented here, focusing on their potential to improve our knowledge of Antarctica's influence on, and response to, global climate change.

\section{Glacial-Interglacial cycles from the MIS Project}

Strata of AND-1B core accumulated in deep water (200-1000 m), $100 \mathrm{~km}$ from the
Victoria Land coastline, western Ross Sea. The diverse range of rock types represent particular past environments that included open marine diatomites (rock made from siliceous diatom remains), mudstones and turbidites (deposits formed by instantaneous downslope movement of sediment) deposited during interglacials from local sources, ice-proximal massive and stratified diamictites (poorly sorted conglomerate), and conglomerates and sandstones representing glacial periods. During glacial periods, the ice sheet had an extensive marine terminus perhaps hundreds of km north of the drill site in the Ross Sea. During interglacials, the drill site was either covered by an ice shelf (similar to present day) or lay in open or sea-ice-covered seas, while the ice sheet had retreated onto the continent with deposition of marine diatoms or terrigenous mud from local streams, and occasional debris from icebergs.

A preliminary age model for the upper $700 \mathrm{~m}$ of drill core constructed from diatom biostratigraphy and radiometric ages on volcanic material allows a unique correlation between about $40 \%$ of the magnetic polarity stratigraphy and the geomagnetic polarity timescale. The age model provides several well-constrained intervals displaying relatively rapid $(<1 \mathrm{~m} / \mathrm{kyr}$ ) and continuous accumulation of sediment, punctuated by several 0.5-1 Myr stratal hiatuses representing more than half of the past $7 \mathrm{Myr}$. Thus, the AND-1B record provides several highly resolved "windows" into late Ceno- 


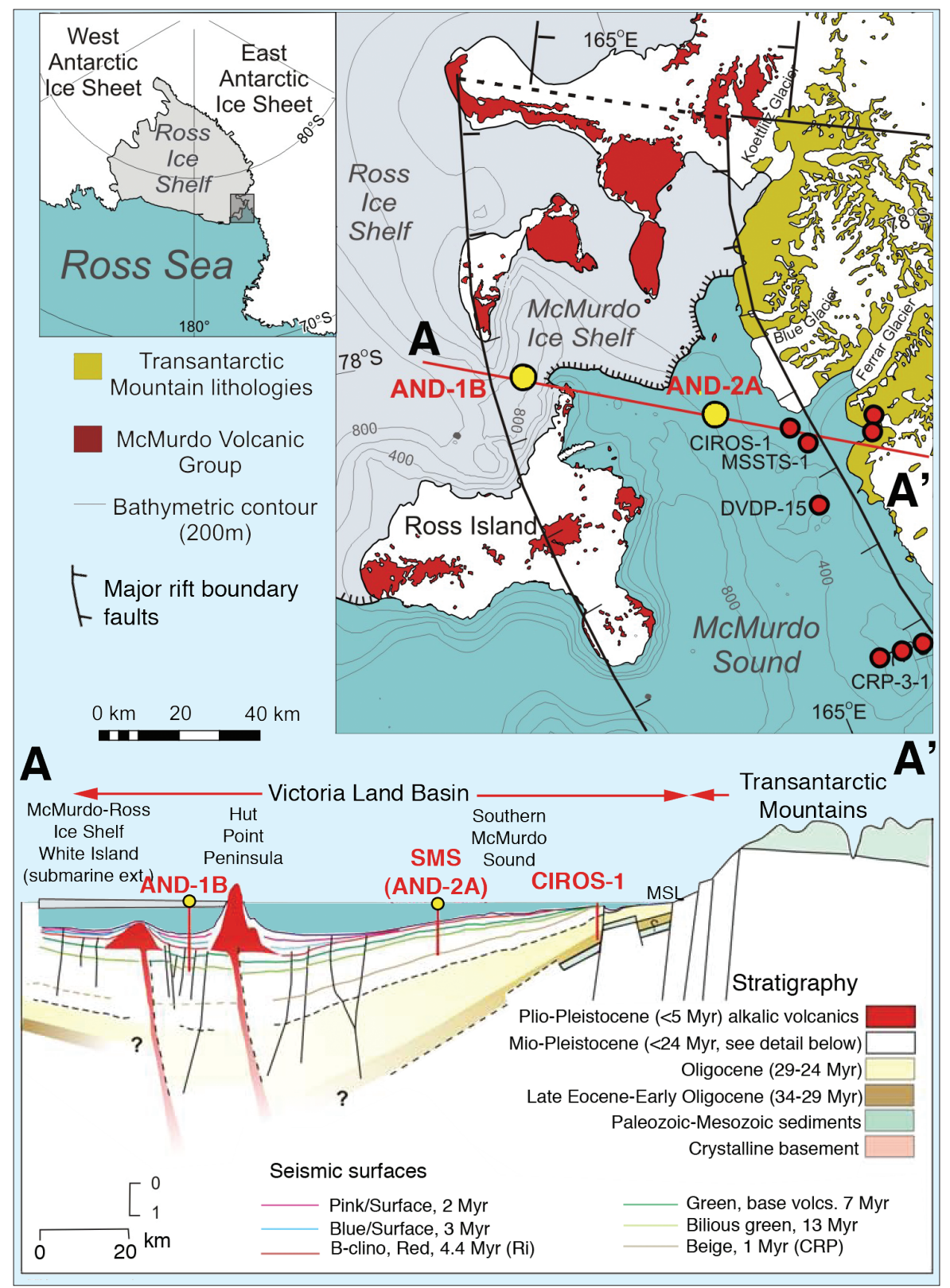

Figure 1: Top diagrams show the location of key geographical, geological and tectonic features in southern McMurdo Sound, with ANDRILL's two new drill sites shown as yellow circles. Boundary faults of the southern extension of Terror Rift are also shown as black hatched lines. Bottom diagram is a schematic structural-stratigraphic cross-section across the Victoria Land Basin $\left(A-A^{\prime}\right)$, and shows the stratigraphic context of the MIS and Southern MCMurdo Sound (SMS) drill sites with respect to previous drill cores (CIROS-1, MSSTS-1, DVDP and CRP) and interpreted seismic reflection data.

zoic development of Antarctic ice sheets. Strata below $\sim 700 \mathrm{~m}$ core depth are late Miocene in age (5-13 Myr ago).

The $>60$ cycles of grounded ice sheet advance and retreat record the evolution of the AIS since a profound global cooling step in deep-sea oxygen isotope records $\sim 14$ Myr ago. Each cycle begins with a glacial erosion surface created by the sole of the advancing ice sheet on the seabed. Above this, coarse-grained, ice-proximal sediments pass upward into a sequence reflecting retreat of the grounding line, sometimes with rapid transitions into open-ocean environments during interglacial times. These retreat sequences may pass back into ice re-advance deposits before being overridden by the ice sheet, creating another glacial erosion surface. Till composition indicates that the depositing

\section{Late Cenozoic Antarctic climate and global implications}

The glacimarine sedimentary cycles reflect orbitally influenced, glacial-interglacial oscillations of the ice sheets during four different phases of late Cenozoic climate evolution.
1. A colder period of polar ice sheets dominated the early-late Miocene, 13.5-10 Myr ago, consistent with inferred cooling from the oxygen isotope record. These cycles are almost entirely glacial diamictites with minor interglacial glacimarine mudstones.

2. An increase in submarine outwash deposits indicates a significantly warmer period of subpolar ice sheets during latest Miocene, 9-6 Myr ago. Open-water, ice distal conditions occur during interglacials, with ice grounded at the site during glacial maxima implying important changes in ice sheet volume.

3. Cyclic variations in deposition units (facies) and chronostratigraphic constraints link ice sheet extent to orbitalscale climate cycles that appear to be $\sim 40$ kyr duration during the Pliocene (5.3-1.8 Myr ago) (Naish et al., 2008). Our data provide the first direct evidence of orbitally controlled oscillations of a marine-based ice sheet (cf., Raymo and Huybers, 2008) in Ross Embayment, which periodically contracted onto terrestrial Antarctica when planetary temperatures were up to $\sim 3^{\circ} \mathrm{C}$ warmer than today and atmospheric $\mathrm{pCO}_{2}$ may have been $400 \mathrm{ppm}$. A feature of particular interest is an $\sim 60 \mathrm{~m}$-thick interval of diatomite deposited during part of the warm Pliocene, representing an extended period ( $200 \mathrm{kyr}$ ) of locally open water, high phytoplankton productivity and retreat of the glaciers on land.

A significant change in thermal regime of the ice sheet is coincident with a global cooling trend between 3-2.5 Myr ago, evident in global oxygen isotope records, associated with onset of northern hemisphere glaciations. During this time, the WAIS and the coastal margins of the EAIS cooled towards their present polar state, expanding and developing more permanent marine termini and ice shelves. Further expansion of the WAIS occurred across the Mid-Pleistocene Climate Transition ( 900-600 kyr ago).

4. A return to cold polar glaciation dominated by extensive ice sheets during the past $800 \mathrm{kyr}$ is represented in the upper $83 \mathrm{~m}$ of core (Fig. 2). Thin units of sandstone, mudstone, and volcaniclastic sediment (reworked volcanic deposits) occur in the upper parts of the cycles, and these units may indicate that the ice shelf location was similar to present interglacial conditions, with the calvingline remaining near the drill site.

Preliminary paleoenvironmental reconstructions imply changes in Antarctic ice volume have contributed significantly to sea level and ocean circulation on Milankovitch timescales, and that the AIS has played an active, dynamic role in global changes over the past 13 Myr. 


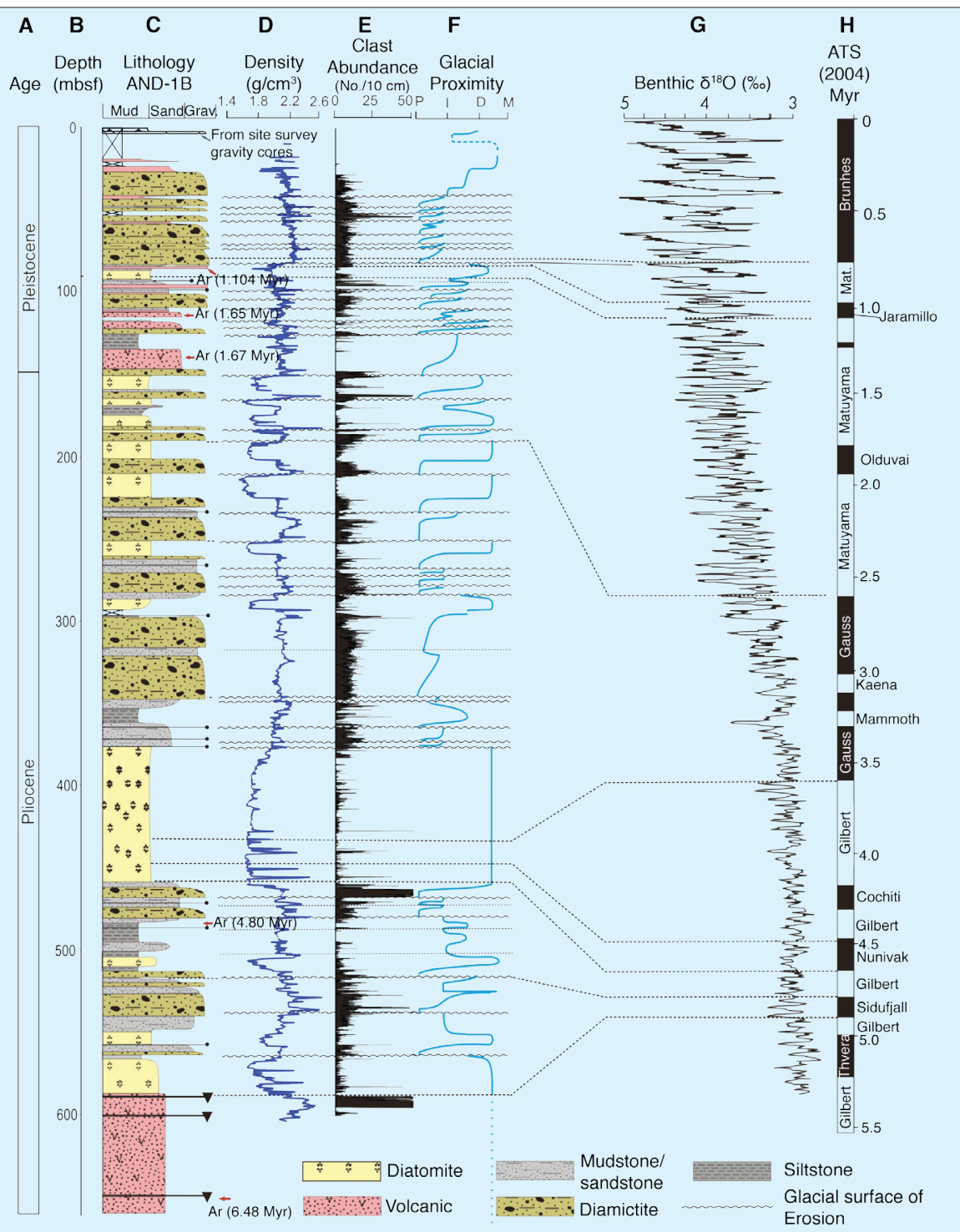

Figure 2: Lithological column of the upper 600 m of the AND-1B drill core recovered by the ANDRILL MCMurdo Ice Shelf Project. Columns from left to right: $\boldsymbol{A}$ ) geological age; $\boldsymbol{B}$ ) depth in $m$ below sea floor (mbsf); $\boldsymbol{C}$ ) lithological log with main rock types detailed below and column width scaled to sediment particle size; $\boldsymbol{D}$ ) rock density log $\left(\mathrm{g} / \mathrm{cm}^{3}\right)$; $\left.\boldsymbol{E}\right)$ gravel-size clast abundance (clast number $/ 10 \mathrm{~cm}$ length); $\boldsymbol{F}$ ) glacial proximity curve based on facies where $p=$ proximal, $i=$ intermediate,$d=$ distal, $m=$ open marine; $\boldsymbol{G})$ benthic oxygen isotope $\left(\delta^{18} \mathrm{O}\right.$ in ppt) deepsea record (Lisiecki and Raymo, 2005) for comparison of ice sheet events; $\boldsymbol{H}$ ) paleomagnetic reversal stratigraphy and the 2004 astronomical time scale (ATS) in Myr. Black lines with inverted triangle = thin conglomerate beds; black lines with circles $=$ thin diamictite beds; red arrows $={ }^{40} \mathrm{Ar} /{ }^{\beta 9} \mathrm{Ar}$ dates on volcanic material; dashed horizontal lines represent paleomagnetic constraints on the correlation of the AND-1B cycles with the deep-marine oxygen isotope curve (see Naish et al., in prep., for detailed correlations).

\section{Note}

Updates on ANDRILL science results, planning documents, background information, and education and outreach resources are available at www.andrill.org. At the time of writing, ANDRILLMIS data remain in moratorium; databases and samples may be requested and accessed after June 2009 through information available on the ANDRILL website.

\section{Acknowledgements}

The ANDRILL project is a multinational collaboration between the Antarctic Programs of Germany, Italy, New Zealand and the USA. The US National Science Foundation, NZ Foundation for Research, Italian Antarctic Research Program, German Science Foundation and AlfredWegener-Institute jointly supported scientific studies; the Science Management Office is at the University of Nebraska, Lincoln. Antarctica New Zealand is the project operator, and has developed the drilling system in collaboration with Alex Pyne at Victoria University of Welling ton and Webster Drilling and Enterprises Ltd. New Zealand.

\section{References}

Lisiecki, L.E. and Raymo, M.E. 2005: A Pliocene-Pleistocene stack of 57 globally distributed benthic $\delta^{180} 0$ records, Paleoceanography, 20 PA1003; doi:10.1029/2004PA001071.

Naish, T.R., et al., 2008: Late Cenozoic climate history of the Ross Embayment from the AND-1B drill hole: Culmination of three decades of Antarctic margin drilling. In Cooper, A.K. et al. (Eds), Antarctica: A Keystone in a Changing World. Proceedings of the 10th International Symposium on Antarctic Earth Sciences: 150pp. Washington, DC, The National Academies Press: 71-82.

Raymo, M.E. and Huybers, P. 2008. Unlocking the mysteries of the ice ages, Nature, 415: 284-285.

Sugden, D.E., Marchant, D.R. and Denton, G.H. (Eds.), 1993: The case for the stable East Antarctic lce Sheet: The background, Geografiska Annaler Series A, Physical Geography, 75: 151-155.

Webb, P.N. Harwood, D.M. McKelvey, B.C. Mercer, J.H. and Stott, LD, 1984: Cenozoic marine sedimentation and ice-vol ume variation on the East Antarctic craton, Geology, 12: 287-291.

For full references please consult:

www.pages-igbp.org/products/newsletters/ref2009_1.htm

\section{PAGES Arctic2k Metadatabase}

\section{}

Future progress in understanding climate history will depend increasingly on the provision of welldocumented data. Towards this goal, PAGES has developed a number of regional metadatabases (www. pages-igbp.org/science/databases).

The Arctic 2k Metadatabase is a collection of proxy datasets from the Arctic, with focus on the last 2000 years. It provides meta-information on proxy sites of different natural and human archives that might be suitable for climate reconstructions of high temporal resolution. The focus is, therefore, on data with at least decadal resolution. Some of the datasets are freely accessible, others can be provided on request from the corresponding contributor.

For more information, please visit the Arctic2k Working Group website: www.pages-igbp.org/science/arctic $2 \mathrm{k} /$ 


\section{Cenozoic bi-polar connections over millennia}

\section{Session and town meeting at 33rd International Geological Congress Oslo, Norway, August 2008}

\section{Julie Brigham-Grette ${ }^{1}$ and Ross D. Powell ${ }^{2}$}

'Department of Geosciences, University of Massachusetts, Amherst, USA; juliebg@geo.umass.edu

${ }^{2}$ Department of Geology and Environmental Geosciences and Analytical Center for Climate and Environmental Change, Northern Illinois University, DeKalb, USA

Several innovative geological drilling projects (e.g., Arctic Coring Expedition (ACEX), Lake El'gygytgyn, ANDRILL (Antarctic Drilling Project), SHALDRIL (Shallow Drilling on the Antarctic Continental Margin) in the polar regions are in the process of recovering long sedimentary records of climate and environmental change for the past hundreds to millions of years. Syntheses and inter-comparative assessments of these records are required for better understanding of polar climate drivers and linkages, and science plans need to be established in order to evaluate conflicting interpretations of those comparative syntheses. The focus of this session at the $33^{\text {rd }}$ IGC was to assess the initial results of these drilling projects and place them in a global context. The session was advertised and solicited as an International Polar Year contribution to the Bipolar Climate Machinery (BIPOMAC) and Antarctic Climate Evolution (ACE) programs.

Lively presentations and discussions emphasized the global nature of late Cenozoic (ca. 40 Myr ago) change, espe-

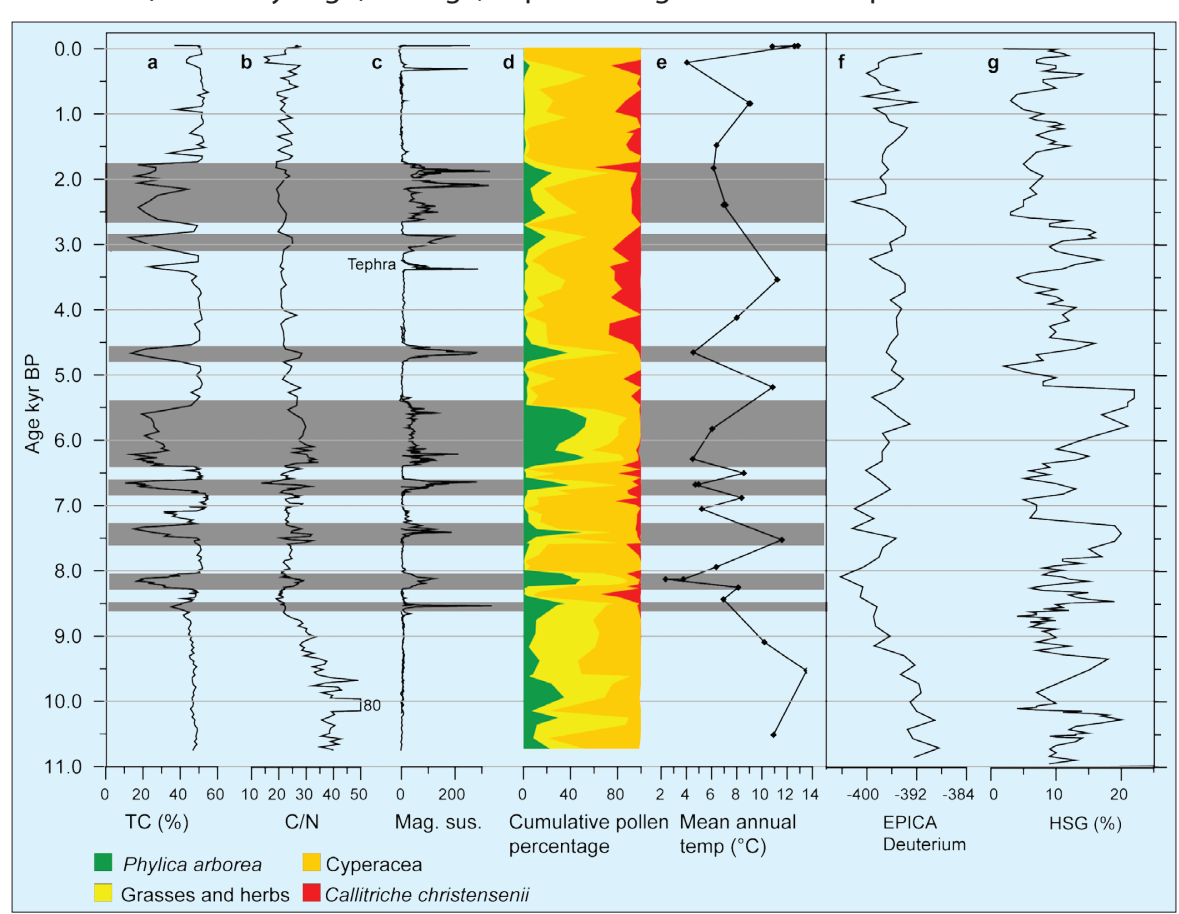

Figure 1: $\boldsymbol{a}$-d) Total carbon, carbon-nitrogen ratio, magnetic susceptibility, cumulative pollen percentages (Ljung and Björck, 2007) and e) mean annual temperatures (unpublished data) from a lake on Nightingale Island (37 $\left.{ }^{\circ} \mathrm{S}\right)$ in the central South Atlantic. The temperature reconstructions are inferred from the methylation index of branched tetraethers (MBT) using the calibration of Weijers et al. (2007). f) Deuterium from the EPICA ice core as an indicator of temperature (Epica Community Members, 2004), and $\boldsymbol{g}$ ) percentage of hematite stained grains (HSG) from marine cores in the North Atlantic, as an indicator of ice rafting (Bond et al., 2001). Gray bars denote periods with increased erosion caused by increased precipitation on Nightingale Island. The Nightingale proxy data reveal a variable Holocene climate, with temperature and precipitation changes probably caused by variations of the southern hemisphere Westerlies and South Atlantic sea surface temperatures.

cially the timing and magnitude of past climatic events on orbital and millennial both poles. Provocative assessments were made on the role the polar regions play in driving and amplifying global variability, and in interpreting the co-evolution of polar paleoenvironments.

Keynote talks introduced and summarized each of the major completed and planned polar drilling projects; there were five presentations each for Antarctic and Arctic science, and one relating South Atcords included papers led by Moran, Stickley, Sangiorgi and Krupskaya, focusing on results from the ACEX drilling project. These presentations included a general overview of a dynamic Arctic Ocean, bio-
genic silica productivity in the Middle Eocene (ca. 40 Myr ago), surface water temperature estimates from Tex86 that differ from iceberg rafting inferences made from sedimentology, and Arctic weathering regimes inferred from clay mineralogy. Brigham-Grette explained the conflict in

(a) 


\section{over Antarctica

\author{
International Trans-Antarctic Scientific Expedition (ITASE) Synthesis Workshop \\ Castine, USA, 2-5 September 2008
}

Recent change in the climate and atmospheric chemistry

Daniel Dixon', M. Frezzotti ${ }^{2}$, E. Isaksson ${ }^{3}$ and T. Meloth ${ }^{4}$

${ }^{1}$ Climate Change Institute, University of Maine, Orono, USA; '2aboratory of Climate Observations, National Agency for New Technologies, Energy and the Environment, Rome, Italy; ${ }^{3}$ Norwegian Polar Institute, Troms $\varnothing$, Norway; elisabeth.isaksson@npolar.no; ${ }^{4}$ National Centre For Antarctic and

Ocean Research, Vasco-da-Gama, India

Changing global climate is forcing scientists to vigorously test existing paradigms and find improved evidence of how the climate system really works at various timescales. Since polar regions are the pacemakers of climate change, it is imperative to gain critical knowledge on the role and response of the cryospheric system in a warming scenario. However, due to the lack of long-term instrumental climate records in remote places like Antarctica, scientists are focusing on ice core proxy climate records buried in the vast ice sheets of Antarctica, which provide valuable information on climate change on interannual to millennial timescales. One such multinational effort to obtain climate archives from Antarctica is the International TransAntarctic Scientific Expedition (ITASE). Operating since 1990, 21 countries are now involved in ITASE programs that aim to understand the impact of global change on the Antarctic continent, and the influence of Antarctica on global change during the last $\sim 200$ to over 1000 years. By combining available meteorological data from the Antarctic and Southern Ocean with firn/ice core proxies for a variety of climate parameters (e.g., moisture balance, atmospheric circulation and temperature), ITASE is actively working to extend the Antarctic climate and atmospheric chemistry records back at least $\sim 200$ years. This offers the temporal perspective needed to assess the multi-decadal variability of natural Antarctic climate.

At the idyllic coastal Maine village of Castine, Paul Mayewski and his group from the Climate Change Institute at the University of Maine invited 32 glaciologists, geophysicists and climate modelers to discuss and synthesize the results obtained thus far from the ITASE programs.

The main focus for this workshop was to obtain an updated overview of newly collected firn/ice cores and available datasets. A large effort is planned to make the data available online, in order to facilitate a number of synthesis products. In addition, there were a number of presentations on both syntheses of previously collected data and new developments from the many participating countries. One

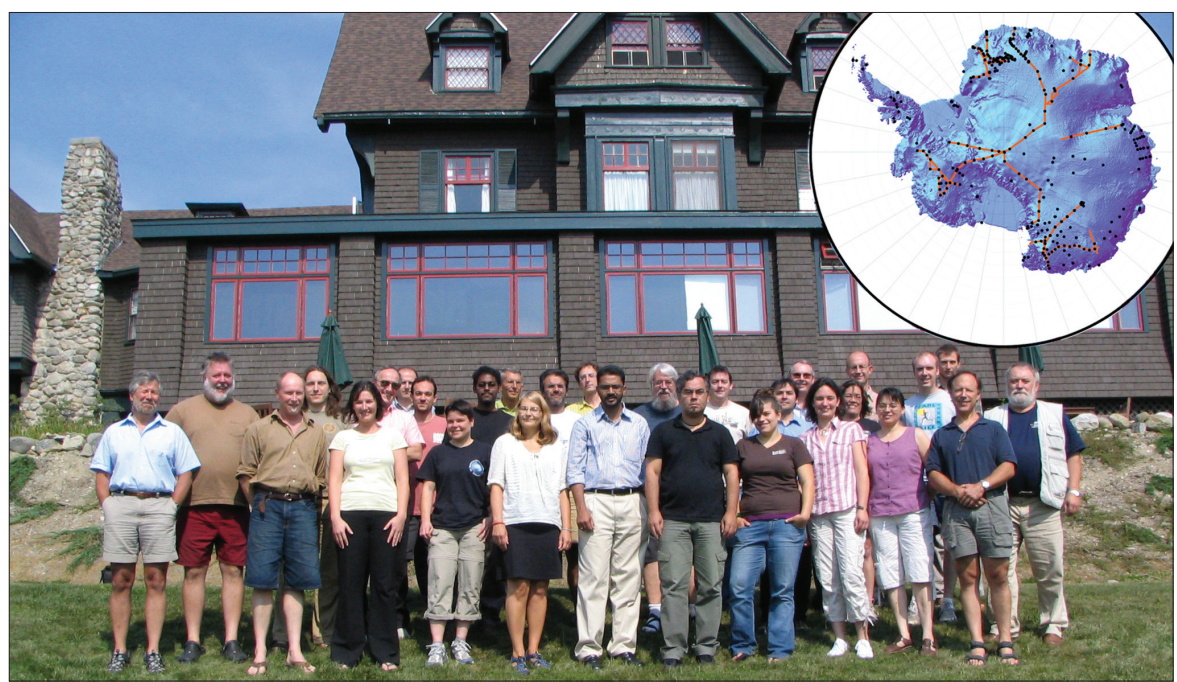

Figure 1: ITASE Synthesis Workshop participants. Inset: The Ice Reader shaded relief map of Antarctica showing ITASE core locations (black dots) and Ground Penetrating Radar transects (orange lines).

important new result discovered by members of the ITASE group is that the climate of W. Antarctica appears to have warmed during the last several decades.

Other interesting aspects discussed were the importance of the Southern Annular Mode (SAM) in Antarctic climate change, and climate teleconnections related to extra-tropical systems like the EI Niño Southern Oscillation (ENSO). It was also concluded that firn/ice core records should be interpreted in combination with snow Ground Penetrating Radar (GPR) surveys to ensure continuous chronology and climate data from the cores.

Based on the available data and our current state of knowledge, the ITASE community agreed that the following synthesis products would be created in the near future:

1. Temporal variability of snow accumulation, using well-dated firn/ice cores with reference horizons such as sulfur peaks from the eruptions of Tambora AD 1815 and the atomic bomb tests of AD 1964/65.

2. Sea ice proxy reconstruction using a combination of sea salt and methanesulfonic acid (MSA) records from coastal ice cores around Antarctica.

3. Proxy Atmospheric Reanalysis of AnTarctica (PARAT).

4. Temperature reconstruction during the past 200 years using ice core proxy data.
In addition to the interesting talks and discussions, we also enjoyed an afternoon of sailing in Penobscot Bay on the polar-class schooner Bowdoin that has sailed many times to Greenland.

ITASE is jointly sponsored by the Scientific Committee on Antarctic Research (SCAR; www.scar.org/) and PAGES. The next workshop is planned in conjunction with the next SCAR Open Science Conference in Buenos Aires, Argentina in July 2010. 


\section{Fairbanks, USA, 29 June-3 July 2008}

\section{Jerry Brown ${ }^{1}$, H.-W. Hubberten ${ }^{2}$ and V. Romanovsky ${ }^{3}$}

IInternational Permafrost Association, Woods Hole, USA; jerrybrown@igc.org

${ }^{2}$ Alfred Wegener Institute for Polar and Marine Research, Potsdam, Germany; ${ }^{3}$ Geophysical Institute, University of Alaska, Fairbanks, USA

The Ninth International Conference on Permafrost (NICOP) was held at the University of Alaska and attended by 685 individuals, of whom 158 were members of the Permafrost Young Researchers Network (PYRN). A total of 27 countries were represented, with the largest delegations from the United States (337), Canada (91), Russia (57), Germany (31), Switzerland (20), Norway (18) and China (18), and Japan (17). The Conference marked the $25^{\text {th }}$ anniversaries of the formation of the International Permafrost Association (IPA) and the Fourth ICOP, both having occurred in Fairbanks in the summer of 1983. The Conference was also an important activity of the Fourth International Polar Year (IPY).

Several plenary reports and sessions dealt with the past, present and future

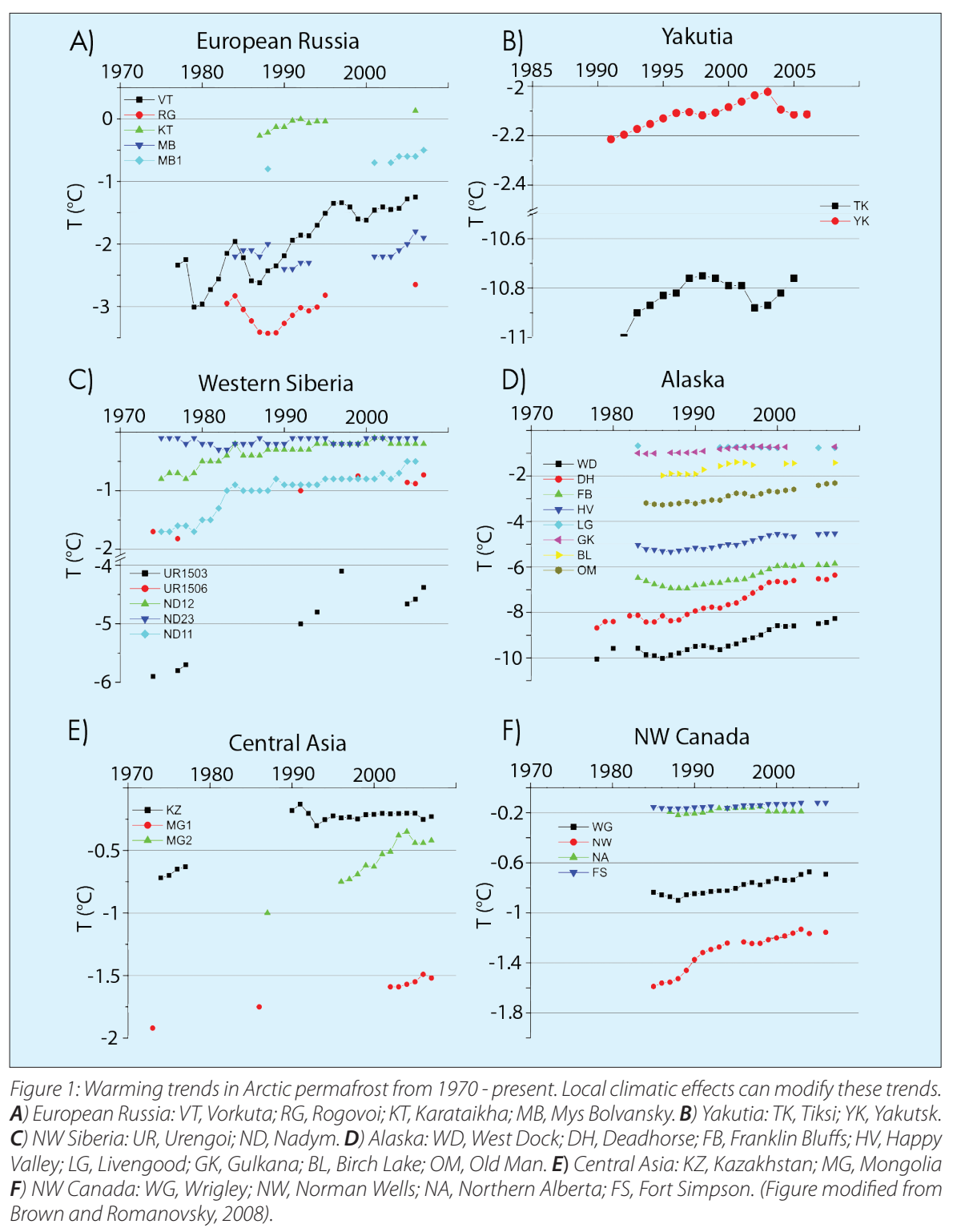

Figure 1: Warming trends in Arctic permafrost from 1970 - present. Local climatic effects can modify these trends, A) European Russia:VT, Vorkuta; RG, Rogovoi; KT, Karataikha; MB, Mys Bolvansky. B) Yakutia: TK, Tiksi; YK, Yakutsk. C) NW Siberia: UR, Urengoi; ND, Nadym. D) Alaska: WD, West Dock; DH, Deadhorse; FB, Franklin Bluffs; HV, Happy Valley; LG, Livengood; GK, Gulkana; BL, Birch Lake; OM, Old Man. E) Central Asia: KZ, Kazakhstan; MG, Mongolia F) NW Canada: WG, Wrigley; NW, Norman Wells; NA, Northern Alberta; FS, Fort Simpson. (Figure modified from Brown and Romanovsky, 2008). state of permafrost. Sessions dealing with modern permafrost dynamics reported that ground temperatures are being measured in approximately 400 existing and newly drilled boreholes in both hemispheres. Most of the boreholes observatories show a substantial warming during the last 20 years (Fig. 1). The magnitude of warming varied with location but was typically from $0.5-2^{\circ} \mathrm{C}$ at the depth of zero seasonal temperature variations in the permafrost. Figure 1 presents characteristic regional trends in permafrost temperatures for the northern hemisphere, based principally on the long-term borehole observations.

The thermal responses of permafrost terrains to climate change occur at different timescales. For example, changes in active layer thickness are responsive to seasonal events, whereas modification of thermal profiles below the depth of zero amplitude (depth of no discernable seasonal change in temperature) takes decades or centuries, and basal melting associated with progressive permafrost thinning requires millennial timescales. In the northern hemisphere, thawing of permafrost is currently observed within the southern limits of the permafrost zone. The consequences of thawing permafrost in the $21^{\text {st }}$ century pose serious societal and environmental impacts, some of which have global consequences.

Two oral sessions and one poster session on "Contemporary Climate Change and Paleoclimatic Reconstructions in Permafrost Regions" were co-organized by PAGES (represented by J. Brigham-Grette) and the WCRP Climate and Cryosphere (CLiC) program (represented by H.-W. Hubberten).

A wide spectrum of topics dealing with the formation of permafrost over the last 2 Myr was presented by authors from Europe, America and Russia. Seven papers reported on studies of the formation of ice-complex deposits on the Siberian lowlands and the surroundings of El'gygytgyn Lake in Chukotka. Others dealt with the formation and degradation of permafrost in Alaska, Canada and South America, and with the study of relicts of old permafrost in Europe.

A number of publications on permafrost are now available, including a twovolume proceeding consisting of 360 peer-reviewed papers, a companion $C D$, an abstract volume and 182 extended abstracts (see www.ipa-permafrost.org/ to order). A DVD containing the optically scanned proceedings of all nine permafrost conferences and a revised permafrost map of Alaska were also prepared and distributed. Additionally, a booklet on the history of the ICOPs and the 25-year history and accomplishments of the IPA was published. The newly published ASCE book by Siemon Muller Frozen in Time, was also unveiled during the conference. Preand post-conference field trips to parts of Alaska and the Colorado Rockies were prepared by the Alaska Division of Geological and Geophysical Surveys (www.dggs.dnr. state.ak.us/). 
Plans for future meetings were also discussed. The Tenth International Conference on Permafrost will be held in Tyumen, Russia in 2012. The Third European Conference on Permafrost will be held in June
2010 in Norway-Svalbard, following the Oslo IPY Conference. Additionally, Canada extended an invitation for participation in the Canadian Permafrost Conference in September 2010 in Calgary.

\section{References}

Brown, J. and Romanovsky, V., 2008: Report from the International Permafrost Association: State of Permafrost in the First Decade of the $21^{\text {t }}$ Century, Permafrost and Periglacial Processes, $19(2)$ : $255-260$

\title{
Arctic Paleoclimate Assessment Past Climate Variability and Change in the Arctic US Climate Change
Science Program www.climatescience.gov
}

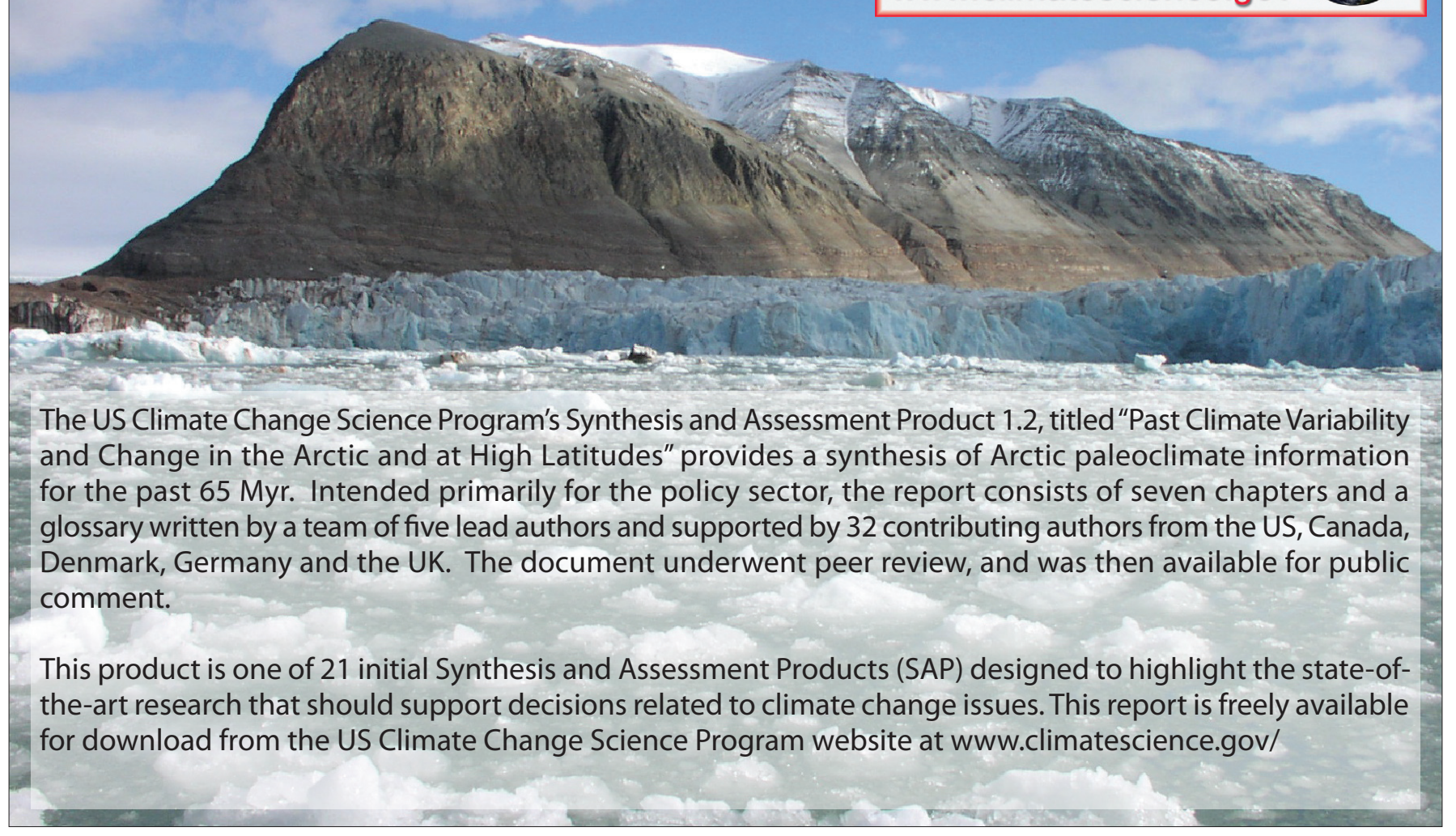

\section{New on the PAGES Bookshelf}

\section{Natural Climate Variability and Global Warning: A Holocene Perspective}

\author{
Editors: R.W. Battarbee \& H.A. Binney \\ Wiley-Blackwell, ISBN-13: 978-1-4051-5905-0
}

Predicting the course of future climate change requires an understanding of the natural variability of the climate system as well as the effects of human-induced change. This book is based on keynote lectures from the ESF-Holivar Open Science Meeting in London 2006. It covers our understanding of natural climate change, its variability on decadal-to-centennial timescales, the extent to which climate models of different kinds simulate past variability, and the role of past climate variability in explaining changes to natural ecosystems and human society over the later part of the Holocene.

\section{Contents}

1. Holocene climate variability and global warming; R.W. Battarbee

2. Holocene climate research - progress, paradigms, and problems; H.J.B. Birks

3. The role of people in the Holocene; F. Oldfield

4. Modeling the climate of the Holocene; M. Crucifix

5. The early to mid-Holocene thermal optimum in the N. Atlantic; E. Jansen et al.

6. Holocene climate change and evidence for solar and other forcings; J. Beer, B. van Geel

7. Climate of the past millennium - proxy data and model simulations; H. Goosse et al.

8. Latitudinal linkages in late-Holocene moisture-balance variation; D. Verschuren, D.J. Charman

9. Holocene rapid land-cover changes - evidence and theory; $M$. Claussen

10. Holocene perspectives on future climate change; $R$. Bradley

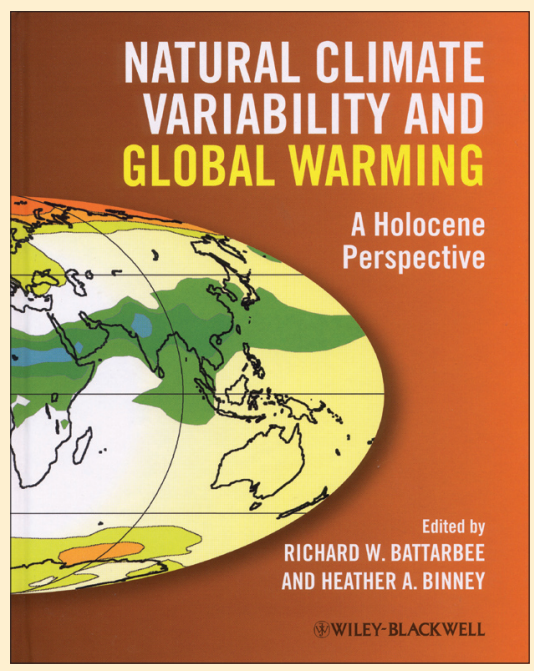




\section{What causes glacial-interglacial cycles?}

\section{Louvain-la-Neuve, Belgium, 26-29 May 2008}

\section{Michel Crucifix}

Georges Lemaître Institute of Astronomy and Geophysics, Catholic University of Louvain, Louvain-la-Neuve, Belgium; michel.crucifix@uclouvain.be

This question has been inspiring André Berger's research for over 35 years. André Berger became a key character in the world of past and future climate modeling with his 1978 publication on frequencies, phase and amplitudes of Earth's orbital elements over the Quaternary. This publication contained the famous 19, 23, 41, 100 and 412 kyr periods, known as the "Milankovitch" frequencies. Since then, he and his team in Louvain-la-Neuve, Belgium have continued to deliver world-leading research on the astronomical theory of paleoclimate. On the occasion of his recent retirement, a symposium entitled "Climate change: From the geologic past to the uncertain future" was organized to celebrate his life's work.

The first day of the meeting was devoted to key components of climate, with lectures on the carbon cycle (F. Joos), landsurface feedbacks (M. Claussen), ice-sheets (P. Huybrechts) and ocean sediment dynamics (G. Munhoven).

Presentations then covered the intricacies of the connections between these different components on geological timescales. For example, M. Sarnthein examined the consequences of the closure of Panama Seaway on the atmosphere, salinity in the Arctic Ocean and large-scale glaciation of the northern hemisphere, while Z. Guo discussed the possible effects of Tibetan plateau uplift on regional atmospheric circulation.

The meeting was also rich in thoughtprovoking ideas, such as E. Wolff's suggestion that Antarctic "warm events" (characteristic of glaciations) were in fact aborted terminations. The younger generation was also well represented. P. Langebroeck gave an excellent presentation on the response of the Antarctic Ice Sheet to orbital variations and atmospheric $\mathrm{CO}_{2}$ in the Middle Miocene, and Q. Yin suggested that moderate amounts of ice in Eurasia may have strengthened the East Asian summer monsoon during pre-stage-11 interglacials. P. Köhler proposed a "Southern Ocean decoupling hypothesis" for the mid-Pleistocene transition, while A. Antico covered the modulation of the astronomical forcing by sea-ice during the Early Pleistocene.

Some presentations also suggested that the strength of certain climate feedbacks might be less than currently believed. F. Joos, for example, showed simulations suggesting that changes in the carbon cycle might not be as sensitive to the strength

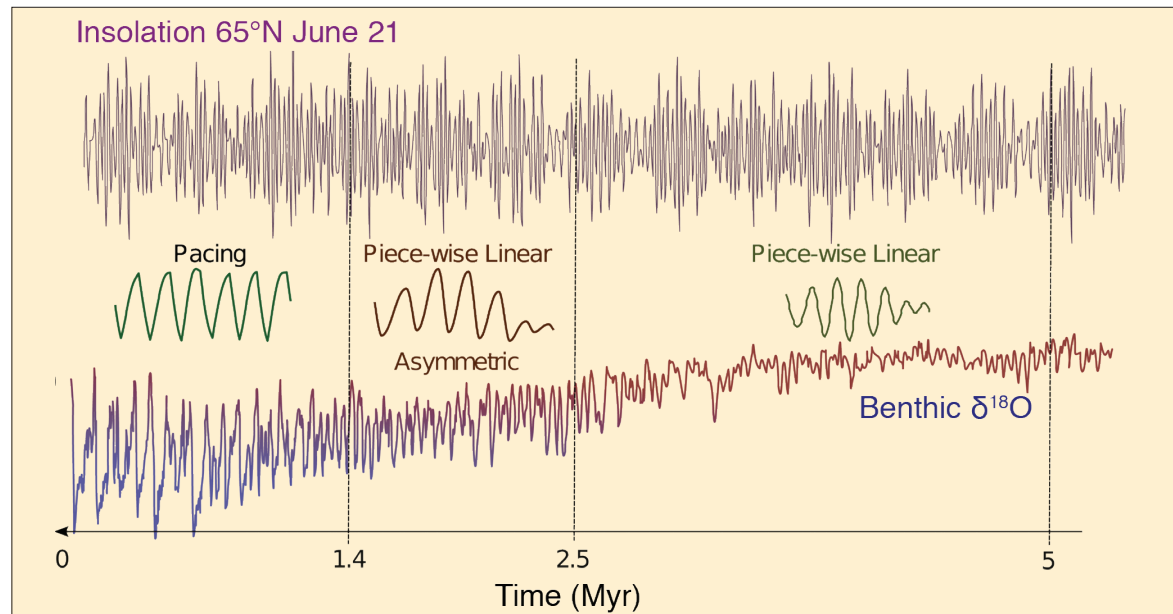

Figure 1: Lorraine Lisiecki discussed the 'LR04'5.3 Myr-long record obtained by lining up 57 records of benthic foraminifera $\delta^{18} \mathrm{O}$ (Lisiecki and Raymo, 2005). She showed evidence for 2 significant transitions in the climate response to the orbital forcing: one around 2.5 Myr ago, when the saw-toothed shape characteristic of glacial cycles first appeared, and one around 1.4 Myr when the response to obliquity shifted from linear response to non-linear pacing. Orbital forcing is represented here by summer solstice insolation obtained from the La04 model (Laskar et al., 2004). More details are available in Lisiecki and Raymo, 2007. Figure provided by L. Lisiecki.

and position of southern westerlies as previously thought. In fact, the links between southern temperature and $\mathrm{CO}_{2}$, so obvious in the ice-core records shown by D. Raynaud, are not easy to elucidate.

It was also evident that we still have much to learn about the effects of orbital forcing on climate. J.C. Duplessy presented a simulation based on data and model experiments, according to which high summer insolation in the northern hemisphere leads to an increase in southern ocean temperature, with potential effects on the West Antarctic Ice Sheet. P. Huybers presented the idea that the Southern Ocean essentially responds to changes in the duration of local summer. M.F. Loutre's review of insolation forcing theory helped clarify this difficult subject.

Notably, records were often described in terms of their frequency spectrum. P. Wang emphasized the presence of 400500-kyr oscillations in globally distributed $\delta^{13} \mathrm{C}$ marine records back to the Oligocene, L. Lisiecki analyzed the linear vs non-linear character of the climate's response to obliquity and identified a change in regime around 1.4 Myr (Fig. 1), while D. Verschuren presented evidence for a 11-kyr signal in the recurrence of so-called "African megadroughts". Additionally, P. Pestiaux reminded us that spectral analysis of paleoclimate data facilitates their interpretation in terms of complex system theory.

Finally, on the modeling side, A. Ganoposki presented his "megarun" project, which covers the last 1 Myr of the Pleistocene with the "CLIMBER" model, and A. Abe-Ouchi presented experiments cover- ing several glacial-interglacial cycles, executed with the MIROC general circulation model asynchronously coupled with an ice sheet model.

There was unanimous agreement that the identification of age uncertainties is one of the major hurdles in understanding climate dynamics. J. Hays summarized the CLIMAP and SPECMAP efforts that, more than 15 years ago, delivered synthetic descriptions of leads and lags between the orbital forcing and different aspects of climate's response. The question of whether the time had come for a SPECMAP-2 initiative was debated and it was decided that the answer was probably yes but that our needs had changed. Climate modelers increasingly focus on quantifying model uncertainty. Advanced statistical techniques are being developed to this end but their application requires accessible descriptions of the processes that cause data uncertainty. Thus, there may be a more pressing demand for meta-data (description of the data and how they were produced) than for data sensu stricto.

The symposium, was a true acknowledgment of the friendship that surrounds André Berger, who is now Professor Emeritus at the Catholic University of Louvain. Despite retirement, his commitment to science remains and we are sure to hear of him again.

\section{Acknowledgements}

The meeting was hosted by Université catholique de Louvain, Belgium and sponsored by the Belgian National Fund for Scientific Research, the Belgian Federal Science Policy Office, 
the French Commissariat à I'Energie Atomique, the French Institut National des Sciences de I'Univers, the European Geosciences Union, the Belgian Agency for Radioactive Waste and Enriched Fissile Materials, and the Belgian private company "Vincotte". Early career scientists and scientists from Eastern and developing countries were supported by PAGES and EGU.

\section{References}

Lisiecki, L.E. and Raymo, M.E. 2005: A Pliocene-Pleistocene stack of 57 globally distributed benthic $\delta^{18} 0$ records, Paleoceanography, 20 PA1003, doi:10.1029/2004PA001071
Lisiecki, LE and Raymo, ME 2007: Plio-Pleistocene climate evolution: trends and transitions in glacial cycle dynamics, Quaternary Science Reviews, 26: 56-69.

Laskar, J., Robutel1, P., Joutel1, F., Gastineau, M., Correia, A.C.M. and Levrard B., 2004: A long term numberical solution for the insolation quantities of the Earth, Astronomy and Astrophysics, 428 261-185.

\section{CLIVAR-PAGES-WCRP summer school on El Niño}

\section{Puna, USA, 14-24 June 2008}

\section{Axel Timmermann}

International Pacific Research Center, University of Hawaii, Honolulu; axel@hawaii.edu

The summer school "ENSO Dynamics and Predictability" took place in the lush jungle of Puna on the Big Island of Hawai'i. Sixteen graduate students in oceanography, meteorology and geology from 10 countries gathered to learn from lecturers on a broad range of ENSO-related topics: ENSO theory (Fei-Fei Jin, University of Hawai'i, USA), ENSO phenomenology (Michael McPhaden, NOAA, USA), ENSO predictability (Magdalena Balmaseda, European Centre for Medium-range Weather Forecasts, UK; Richard Kleeman, Courant Institute, USA), and ENSO's sensitivity to past and future climate change (Scott Power, Centre for Australian Weather and Climate Research Bureau of Meteorology/CSIRO, Australia; Axel Timmermann, University of Hawai'i, USA).

Energized by fresh goat milk kefir, exotic local fruit smoothies and island-style cuisine, the students conducted research projects in addition to the 3-4 hour daily lecture-marathon. In teams, they studied the effects of ENSO on the Antarctic Peninsula, the rapid termination of the 2008 La Niña event that was induced by easterly wind bursts, the geographical reaches of a tropical megadrought $\sim 4.2 \mathrm{kyr}$ ago, the effects of state-dependent noise on the predictability of ENSO, the dynamics of warm pool El Niño events, the effects of Atlantic multi-decadal SST variability on ENSO, and the role of equatorial waves in the ENSO recharge mechanism. In carrying out these research projects students applied the concepts taught during the lectures, such as the recharge oscillator paradigm, ENSO frequency entrainment, equatorial waves, basin modes, teleconnection patterns and multiplicative noise.

Understanding ENSO's past requires an in-depth understanding of the coupled instability mechanisms that underlie ENSO and the annual cycle in the eastern equatorial Pacific. Oversimplified concepts, such as the dynamical thermostat, can mislead paleo-proxy interpretations, and a thorough heat-budget analysis of corresponding model simulations is usually needed to understand ENSO changes that occurred with past climate forcings, such as orbitally induced variations in solar insolation. Numerous coupled general circulation model studies have demonstrated that for certain ENSO regimes a weaker (stronger) annual cycle corresponds to stronger (weaker) ENSO variability. Testing these model-derived relations with paleo-proxy data, such as corals, lake records, speleothems, mollusks, and tree rings, would be an important contribution towards a better understanding of ENSO forcing mechanisms in the past.

The summer school demonstrated the benefit for climate research of the CLI-
VAR/PAGES Interaction: Climate modelers need paleo-records to validate their models; paleoclimatologists benefit from the dynamical insights provided by climate modeling experiments. An example of a student team project that highlighted this was provided by Intan Nurhati (Georgia Institute of Technology, USA) and Gabriel Bayona (EAFIT University, Columbia). They studied the geographical extent of a 30 - to 50-year-long megadrought that occurred $\sim 4.2 \mathrm{kyr}$ ago and affected the civilizations of Egypt and Mesopotamia. By compiling and synthesizing paleo-data, from archives such as speleothems, lake sediments and ice cores, they derived a map showing the tropical-wide extent of the drought (Fig. 1). To determine what may have caused this drought, they analyzed cosmogenic isotope variations and temperature variability in the N. Atlantic. Results, however, are still inconclusive. Fostering such joint PAGES/CLIVAR activities could become an important legacy of both programs.

\section{Note}

Lectures are available from: http://iprc.soest.hawaii.edu/ axel/ENSOsummerschool.html

\section{Acknowledgements}

The summer school was supported by PAGES, CLIVAR, WCRP, NOAA, the Australian Government (ARCNESS) and the International Pacific Research Center.

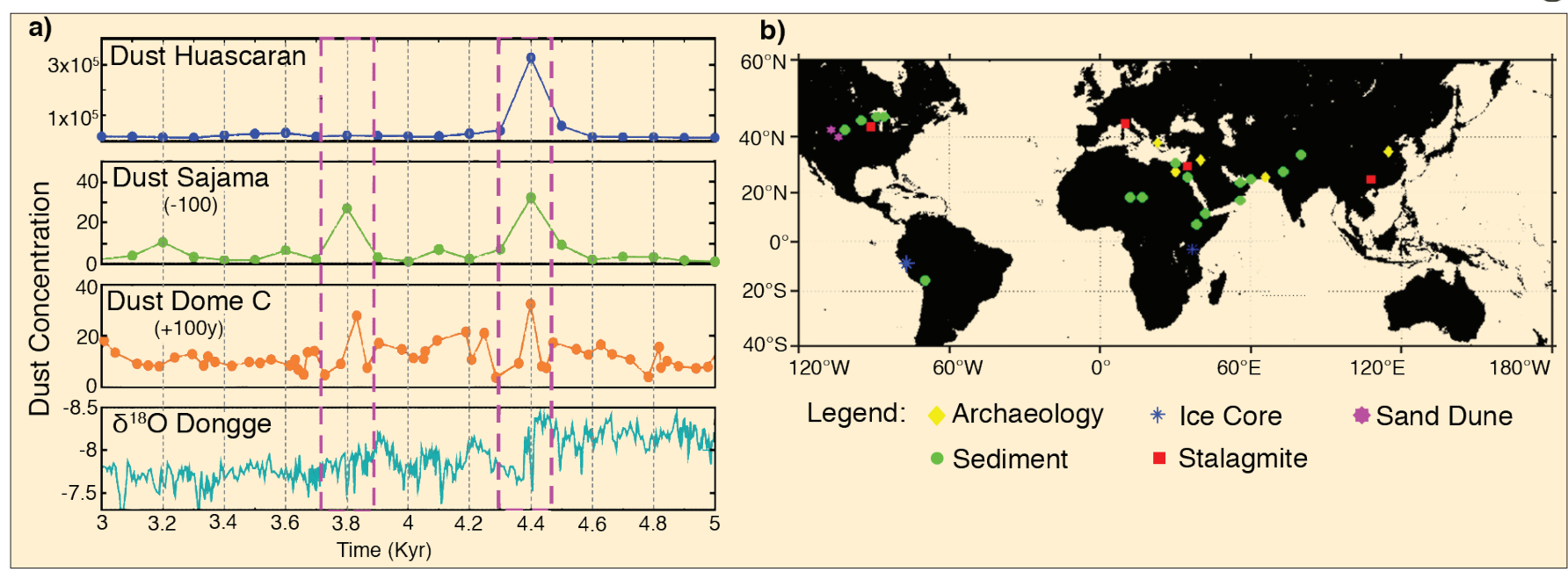

Figure 1: a) Time series of dust fluxes at Huascaran (Peru), Sajama (Bolivia) (timescale shifted by -100 years), EPICA Dome C (Antarctica) (timescale shifted by + 100 years) and Dongge Cave $\delta^{18} \mathrm{O}$ (China), indicating major drought periods around the tropics (purple boxes). Dust records indicate that in fact two major droughts occurred around 3.8 kyr 


\title{
PAGES Focus 4: Past Human-Climate-Ecosystem Interactions (PHAROS) Workshop
}

\section{London, UK, 7-8 July 2008}

\author{
John Dearing ${ }^{1}$ and Rick Battarbee ${ }^{2}$ \\ 'University of Southampton, UK; J.Dearing@soton.ac.uk \\ University College London, UK
}

Focus 4 (PHAROS) was formally adopted at the PAGES Scientific Steering Committee meeting in Atherton, Australia, August 2007. Its principal objective is to bring together existing and new research communities to examine how climate, natural ecosystems and human activity have interacted through time, both regionally and globally, and how these interactions help address key questions about future global environmental change.

The aims of this workshop were twofold: (1) To finalize the PHAROS Science and Implementation Plan and produce a work plan for the next five years, and (2) To coordinate the production of synthesis papers on the integration and upscaling of paleodata for key ecological processes (land cover, soil and sediment, and water), and for IPCC projected "Climate Change Hotspots". The intention was also to produce a position paper reviewing paleoperspectives on global environmental change that highlights the role of paleodata in Earth System science, current levels and coverage of reconstructed data, and future challenges for developing new methods and improving geographical representation.

35 scientists from Africa, Asia, Australasia, Europe and North America, representing the Focus 4 Working Groups of HITE, LUCIFS, and LIMPACS, and the PAGES International Project Office, met at the Royal Society to discuss how Focus 4 should progress. Following opening plenary talks from John Dearing, Marie-Jo Gaillard, Thomas Hoffmann, Peter Gell and Rick Battarbee, the meeting was structured around break-out sessions.

The first session addressed the following questions as the basis for the position paper:

- How can your scientific community best interact with or make a contribution to the research communities concerned with contemporary Earth System science?

- What are the key questions that the paleoscience community should pursue in future?

The second set of sessions dealt with regional-global syntheses, in particular:

- What can be done with current information to generate global syntheses?
- What kind of information can be upscaled?

- How can data be pooled and made available?

- How can temporal change be visualized on (global) maps?

- Are there good examples to use or follow?

- What are the priority syntheses for the future?

The second morning addressed how the different sub-disciplines could integrate results within regional landscapes, with discussion groups on four generic landscapes (monsoonal/low latitude, dryland, temperate zone, high latitude/high altitude) tasked with discussing the questions:

- How can LUCIFS, HITE and LIMPACS groups work together to provide an integrated assessment of modern global environmental change issues within a region? Which themes can be tackled by such integration?

- What were the human-ecosystem-climate interactions in the past that provide lessons for the future?

Synthesis papers were planned in the subsequent writing session. The final plenary session considered the progress made and PHAROS structure. The overwhelming view was to modify the struc-

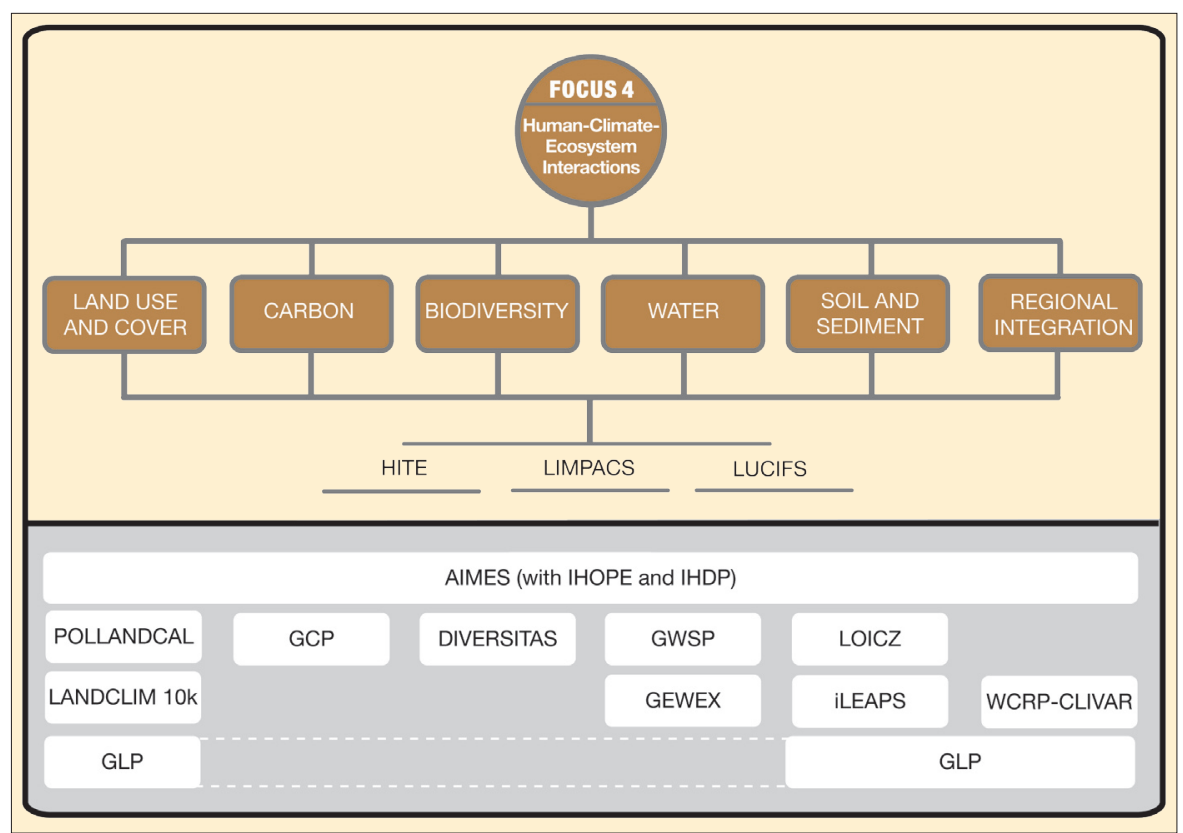

Figure 1: The new structure of PAGES FocUS 4 (PHAROS) showing how the science undertaken within HITE, LIMPACS and LUCIFS communities contributes to major landscape elements through the activities of integration and modeling, with explicit links to ESSP/IGBP projects and other PAGES Foci and Cross-Cutting Themes. ture in ways that allowed explicit links to be made with other ESSP/IGBP projects and other PAGES Foci. At the heart of the new structure (Fig. 1) lie the key activities of Regional-Global Integration, applied to five major landscape elements (Carbon, Water, Soil and Sediment, Land Use and Cover, Biodiversity) through the combined activities of the HITE, LUCIFS and LIMPACS communities. Regions designated as Climate Change Hotspots are a priority under the Regional-Global Integration banner. The new structure enables more direct engagement with the activities and objectives of ESSP DIVERSITAS, ESSP Joint Projects Carbon and Water, and IGBP Core Projects AIMES, GLP, iLEAPS and LOICZ, particularly in terms of providing a temporal perspective for model development and validation.

\section{Acknowledgements}

We were pleased that so many scientists participated in the meeting, and would like to pay particular thanks to three postgraduates for their skills as meeting reporters - Alex Dickson, Emily Foster and Katy Wilson. 


\section{Estes Park, USA, 15-19 September 2008}

\section{Bette L. Otto-Bliesner ${ }^{1}$, S. Joussaume ${ }^{2}$, S.P. Harrison ${ }^{3}$, A. Abe-Ouchi ${ }^{4}$ and P. Braconnot ${ }^{2}$}

'Climate and Global Dynamics Division, National Center for Atmospheric Research, Boulder,

\section{USA; ottobli@ucar.edu}

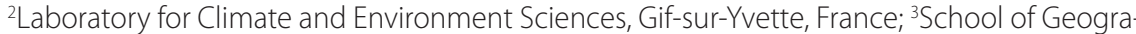
phical Sciences, University of Bristol, UK: ${ }^{4}$ Center for Climate System Research, University of Tokyo, Japan

The Palaeoclimate Modelling Intercomparison Project (PMIP) is a long-standing initiative endorsed by both WCRP/CLIVAR/ WGCM and PAGES. It has provided an efficient mechanism for coordinating paleoclimate modeling activities. These activities provide valuable information on the mechanisms of climate change, the identification of key feedbacks operating in the climate system and, through model evaluation, the capability of climate models to reproduce climates different from today. Thanks to the production of data syntheses and to rigorous model-data comparisons, the mid-Holocene climate (ca. $6 \mathrm{kyr}$ BP) and the Last Glacial Maximum (LGM; ca. 21 kyr BP) are now recognized as benchmark periods for climate models.

Drawing on its past experience, PMIP will continue to combine simulations made with climate models and paleoenvironmental data syntheses. At its recent workshop in Estes Park, USA, over 70 scientists, including atmospheric scientists, oceanographers, and paleoclimatologists from the data and modeling communities, met to review past successes and discuss future efforts. The first day of the workshop focused on the analyses by PMIP2 subprojects of the coupled atmosphereocean and atmosphere-ocean-vegetation model simulations for the LGM and midHolocene, and the evaluation of these results using new and existing data syntheses (Fig. 1).

The workshop participants then concentrated on the science and implementation plans for the four new priority themes of PMIP Phase 3: 1) Evaluation of Earth System Models for mid-Holocene and LGM, 2) Interglacials and warm periods, with emphasis on the last interglacial, the midPliocene, and last millennium, 3) Abrupt climate changes, particularly the last deglaciation and thresholds in the hydrologic cycle, and 4) Characterization and understanding of uncertainties. An outcome of the workshop was the identification of
B)

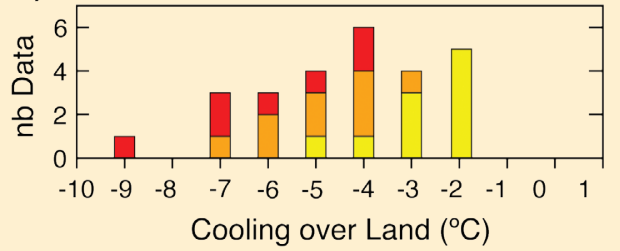

A)
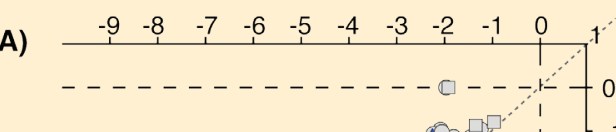

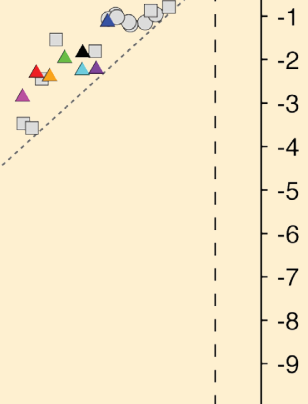

\section{Land - Pollen}

America $\left(90^{\circ} \mathrm{W}-40^{\circ} \mathrm{W}\right)$

$\square$ Africa $\left(2^{\circ} \mathrm{W}-50^{\circ} \mathrm{E}\right)$

$\square$ Indonesia, Pacific $\left(105^{\circ} \mathrm{E}-109^{\circ} \mathrm{W}\right)$

Ocean - all proxies

- MARGO Data

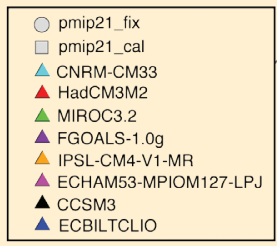

C)

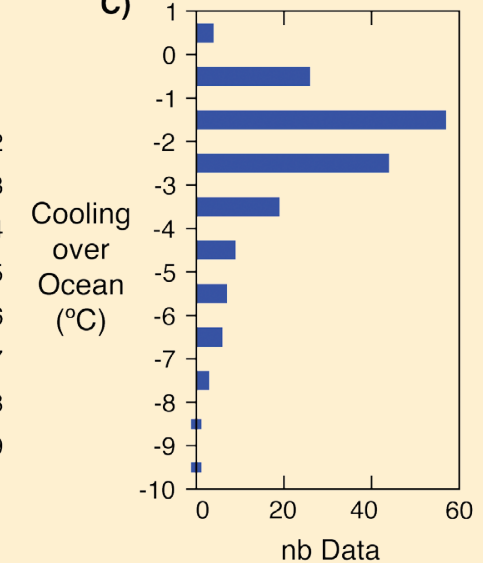

Figure 1: Comparison between model results and paleodata of annual mean tropical cooling $\left({ }^{\circ} \mathrm{C}\right)$ at the LGM. $\boldsymbol{A}$ Simulated surface air temperature changes over land, displayed as a function of surface air temperature change over the oceans, both averaged in the $30^{\circ} \mathrm{S}$ to $30^{\circ} \mathrm{N}$ latitudinal band, for the PMIPI simulations (gray) and all the PMIP2 OA simulations (color). In comparison to the PMIP1 models, the PMIP2 models include a fully predictive 3D ocean (for details on model abbreviations used see Braconnot et al., 2007). The comparison with paleodata uses two reconstructions: $\boldsymbol{B}$ ) Distribution of temperature change over land, estimated from various pollen data (Farrera et al., 1999); C) Distribution of sea surface temperature change estimated from Multiproxy Approach for the Reconstruction of the Glacial Ocean surface (MARGO; http://margo.pangaea.de/). Note, "nb data" is the number of data points for each temperature change. Figure courtesy of M. Kageyama.

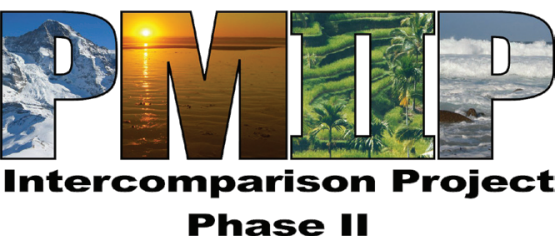

key climate targets for model simulations and data synthesis that could help reduce uncertainties in future climate projections. The workshop participants adopted a set of coordinated climate model experiments of past time periods that will become the basis for future internationally mandated assessments of climate science (e.g., the IPCC's AR5, scheduled to be published in early 2013).

It was proposed that a high priority for international modeling groups participating in the Coupled Model Intercomparison Project CMIP5 of the WCRP's Working Group on Coupled Modelling (WGCM) was to perform mid-Holocene and LGM simulations with the same model components and at the same resolution as the preindustrial and future projection simulations. The mid-Holocene experiment evaluates responses of the monsoons to vegetation feedbacks and patterns of ocean warming, as well as high latitude to poleward expansion of boreal forests. The LGM experiment considers the sensitivity of tropical oceans and continents to lowered $\mathrm{CO}_{2}$, and improves our understanding of feedbacks between sea ice and ocean thermohaline circulation.

The workshop participants identified several additional coordinated experiments of priority, though it was recognized that these might be run with different model components and resolutions than CMIP5. The experiments proposed are the last millennium, for detection and attribution studies of decadal to centennial climate variability; the mid-Pliocene, an equilibrium world of $400 \mathrm{ppm} \mathrm{CO}_{2}$ and reduced Greenland and Antarctic ice sheets; and the last interglacial, with Arctic summer warmth comparable to projections at the end of this century. The last interglacial experiment is also relevant for coupled climate-ice sheet models, to assess the stability of the polar ice sheets and sea level rise. PMIP3 will continue to provide a forum for modelers and observationalists to discuss experiments for other past time periods. Working groups have been established to study the transient behavior of the Earth System during deglaciation and the 8.2-kyr event. 
Subgroups have been organized to provide the model simulation design and identify the relevant datasets for the PMIP3 coordinated experiments. For further information, see http://pmip2.Isce.ipsl.fr/
The workshop was sponsored by PAGES and the U.S. National Science Foundation and National Oceanic and Atmospheric Administration.

\section{References}

Braconnot, P., et al., 2007: Results of PMIP2 Coupled Simulations of the Mid-Holocene and Last Glacial Maximum - Part 1: Experiments and Large-Scale Features, Climate of the Past, 3: 261-277.

Farrera, I., et al., 1999: Tropical climates at the Last Glacial Maximum: a new synthesis of terrestrial palaeoclimate data. I. Vegetation, lake-levels and geochemistry, Climate Dynamics, 15: 823-856.

\title{
Oxygen isotopes as tracers of Mediterranean climate variability: Linking past, present and future
}

\section{ESF MedCLIVAR Workshop, Pisa, Italy, 11-13 June 2008}

\author{
Neil Roberts ${ }^{1}$, G. Zanchetta ${ }^{2}$ and M. Jones ${ }^{3}$ \\ 'School of Geography, University of Plymouth, UK; cnroberts@plymouth.ac.uk \\ 2Department of Earth Sciences, University of Pisa, Italy; 3School of Geography, University of Nottingham, UK
}

Given predictions of future climate, changes in rainfall and water resources seem certain to have important socio-economic and political impacts in the Mediterranean region (Giorgi, 2006). Understanding the variability of hydro-climate over different timescales is therefore essential for predicting future climate change and its possible impact on society. Because they vary directly with the physical processes of the hydrological cycle, oxygen isotope ratios provide an important hydro-climatic tracer on all timescales-instrumental, historical and geological. This workshop provided a timely opportunity to bring together members of the scientific community engaged in different aspects of stable isotope research around the Mediterranean basin. The meeting was held over three days in the University of Pisa's Botanical Gardens, with oral and poster presentations by 56 participants.

Following introductory papers by $\mathrm{R}$. García Herrera, N. Roberts and A. Longinelli, the meeting was structured around 5 themes: Session 1 examined how water isotopes have been used as tracers in the monitoring and modeling of contemporary precipitation patterns over the Mediterranean (Fig. 1). L. Araguas outlined the IAEA water-isotope monitoring program, while S. Lykoudis described spatial interpolations of precipitation isotope data for the eastern Mediterranean region. Oxygen isotopes are one of few outputs of Global Circulation Models (GCMs) that can be measured directly by natural climate archives, and G. Hofmann discussed nested meso-scale GCM simulation experiments and their application to isotopes from tree ring cellulose.

Session 2 focused on surface waters, involving both contemporary and paleohydrology (see Roberts and Jones, 2002). M. Leng examined the isotopic record preserved in lake carbonates and silicates,

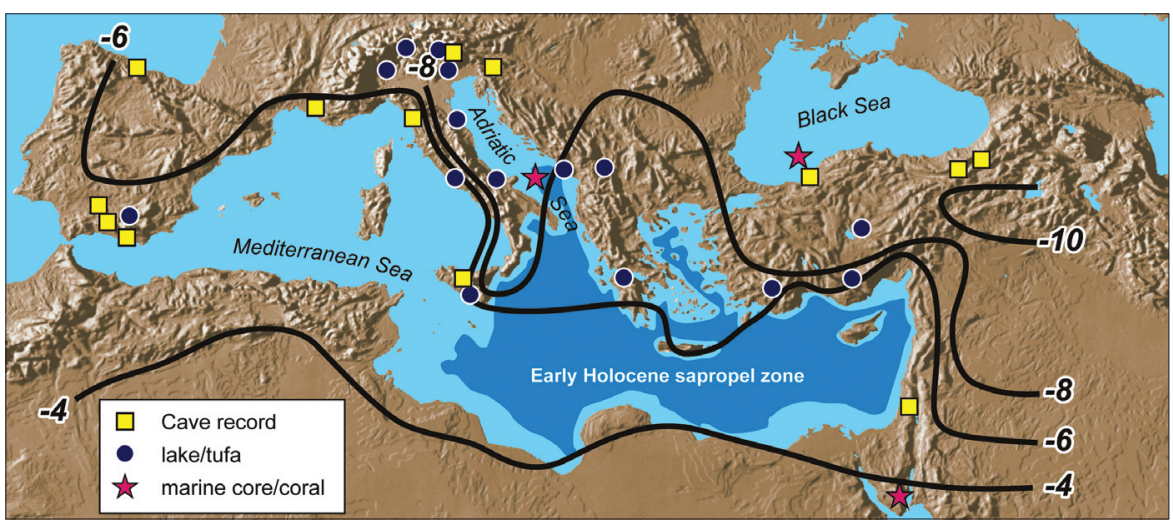

Figure 1: Map showing mean-weighted $\delta^{18} \mathrm{O}$ composition of Mediterranean precipitation and paleo-isotoperecords presented at the workshop

and U. von Grafenstein provided examples from northern Italy and the ancient Lake Ohrid. M. Jones presented a mass balance model of isotope response to climatic forcing for different lake types, while J. Andrews showed how laminated tufa deposits from Greece can potentially provide a signal of past climate seasonality.

Session 3 was devoted to karst hydrology and cave carbonates. A. Baker focused on the calibration of carbonate isotope records against instrumental climate data, and F. McDermott compared $\delta^{18} \mathrm{O}$ against other proxy-climate parameters from speleothems to highlight how no single proxy provides a "magic bullet" solution to climate reconstruction. D. Fleitmann used speleothem isotopes to show paleoclimatic gradients from south (Oman) to north (Turkey). H. Affek closed the session by outlining the new technique of clumped-isotope paleothermometry and its application to the well-known Soreq Cave record from Israel.

In session 4, the focus shifted to marine isotopes. E. Rohling provided an analysis of paleoceanographic conditions during sapropel formation when the eastern Mediterranean Sea became anoxic. This occurred most recently during the early Holocene when, as M. Fontugne showed, runoff from the Nile and North African wadi systems contributed to the creation of a freshwater lid. T. Felis presented highresolution isotopic analyses of northern Red Sea corals during different time windows of the late Holocene, with teleconnections to "centers of action" under climate modes such as the North Atlantic Oscillation.

In session 5 on intercomparison of isotope archives, G. Zanchetta evaluated data from lakes, caves and land snails in a review of Holocene isotope changes in Italy. The integrated multi-archive OLOAMBIENT project provided the basis of two linked papers; M. Letizia Filippi described the results of seasonal monitoring of Lake Lavarone, and A. Borsato outlined analyses of speleothems from three cave systems in northern Italy. The final presentation by A. Delgado-Huertas compared lake carbonate isotopes with those of bone phosphate from archaeological sites in Iberia.

The final session was a panel discussion of key issues relevant to different time periods and archives. Participants identified the following future objectives:

- Synthetic stable isotope databases for speleothem, coral and lake records for the last $2 \mathrm{kyr}$, of at least decadal-scale resolution, for comparison against data from historical observational records (e.g., Luterbacher et al., 2006). 
- Improved monitoring of modern hydroclimatic conditions in the same systems (e.g., individual caves or lakes) that preserve longer isotope-climate records in carbonate deposits.

- Harmonizing methods for numerically calibrating paleo-isotope data to derive quantitative values for past temperature, precipitation and relative humidity.

- Data-model comparisons, both for individual systems and at a Mediterraneanwide scale.
- Reconstruction of Mediterranean isotope gradients at important time periods in the past.

Abstracts and a longer version of this report are available at: www.geog.plymouth.ac.uk/research/groups/MedCLIVAR_ isotope_workshop.html

A selection of the papers will be published in a special issue of Global and Planetary Change.

\section{References}

Giorgi, F., 2006: Climate change hot spots, Geophysical Research Letters, 33: L08707, doi:10.1029/2006GL025734

Luterbacher, J. and 48 co-authors, 2006: Mediterranean climate variability over the last centuries. In: Lionello, P., et al. (Eds), The Mediterranean Climate: an overview of the main characteristics and issues, Elsevier, Amsterdam, 27-148.

Roberts, N. and Jones, M., 2002: Towards a regional synthesis of Mediterranean climatic change using lake stable isotope records, PAGES news, 10(2): 13-15.

\section{Past climate variability in the Altai}

\section{Barnaul, Russia, 1-6 June 2008}

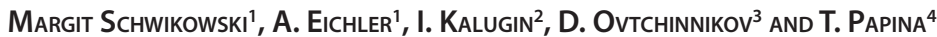

${ }^{1}$ Paul Scherrer Institute, Villigen, Switzerland; margit.schwikowski@psi.ch

${ }^{2}$ Institute of Geology and Mineralogy, Siberian Branch of the Russian Academy of Sciences (SB RAS), Novosibirsk, Russia; ${ }^{3}$ Institute of Forest, SB RAS, Krasnoyarsk, Russia; ${ }^{4}$ Institute for Water and Environmental Problems, SB RAS, Barnaul, Russia

The Altai mountain range in Central Asia has a NW to SE extension of about $2100 \mathrm{~km}$ and is located on the boundary between Russia, Kazakhstan, China, and Mongolia. It forms a climate divide between vast Siberian forests in the north and arid regions of Central Asia in the south (Fig. 1). The region has the highest degree of continentality in the world (Lydolph, 1977), resulting in cold winters and warm summers. In winter, due to the prevailing stable Siberian High, cold and dry arctic air masses predominate. In summer, humid air masses from the Atlantic Ocean and recycled moisture are the main sources of precipitation. The Altai mountain range has great potential for high-resolution, well-dated multiproxy reconstructions of past climate, since high-elevation glaciers, lakes with laminated sediments, and living trees and relict wood material can be found in close proximity to each other. Long meteorological records from Barnaul (1840-present) and glacier mass balance data from Malii Aktru (1961-present) are also available. These facts, together with the geographical setting, make the Altai particularly attractive for climate change research.

A Russian-Swiss workshop was held at the Institute for Water and Environmental Problems, Siberian Branch of the Russian Academy of Sciences, in Barnaul, Russia to discuss the status of paleoclimate research on the Altai, and the prospects and limitations of obtaining more high-resolution millennial-scale paleo-records from this region. The meeting brought together 12 Russian and 8 Swiss scientists working with the different kinds of natural archives (ice cores, lake sediments, peat bogs, tree

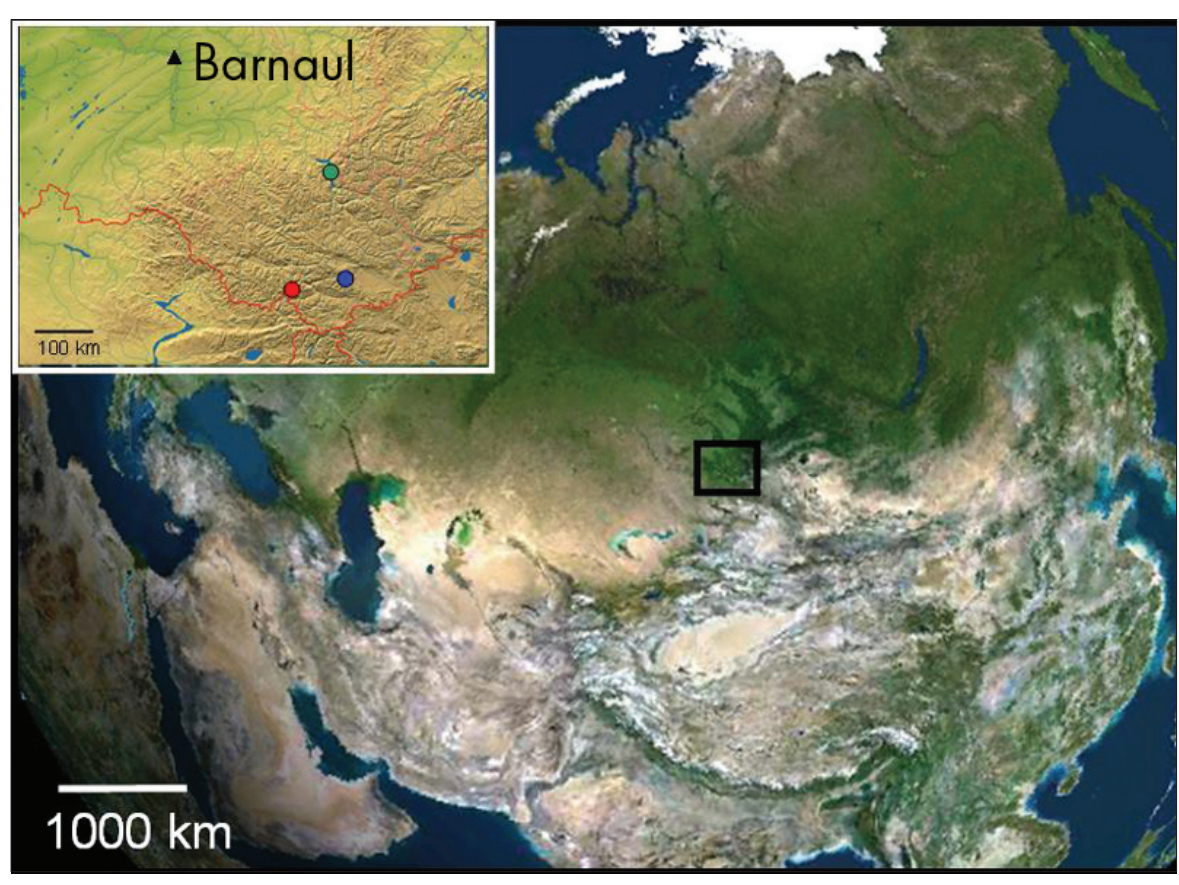

Figure 1: Satellite image showing the location of the Altai mountain range on the boundary between vast Siberian forests and arid regions of Central Asia. Insert gives locations of the different natural archives (green: Lake Teletskoye, red: Belukha glacier, blue: tree ring sites) and the city of Barnaul with an instrumental data set covering the period 1840-present (black triangle). Satellite images from DVD-ROM "Der Große 3D-Globus 4.0 Premium", () 2008 United Soft Media Verlag GmbH, Munich.

rings) in Siberia. The main objective was to discuss the strengths and weaknesses of existing paleo-records and to identify gaps in spatial/temporal data coverage.

One outcome of the workshop was a compilation of three annually resolved, millennial-scale temperature records-Belukha ice core, Teletskoye Lake sediments, and tree ring width chronologies for Larix Sibirica from the SE Altai (Fig. 2). Although the common proxy is temperature, the three archives represent different seasons (ice core $=$ March-November (Eichler et al., 1008); lake sediment = annual (Kalugin et al., 2007); tree ring width = JuneJuly (Ovtchinnikov et al., 2000)). This most likely explains the observed differences between each of the reconstructions. Nevertheless, a general feature of the three reconstructions is the pronounced longterm variation, along with a strong temperature increase of $2-3^{\circ} \mathrm{C}$ from the Little Ice Age minimum to the present. This is consistent with instrumental data and model simulations suggesting that warming is strongest at highly continental sites (e.g., Bradley et al., 2003). Furthermore, it is in agreement with reconstructions of the recent mass-balance history of the Sofiyskiy glacier (Altai Mountains; De Smedt and Pattyn, 2003). As indicated in Fig. 2, there is a strong correlation between ice core 


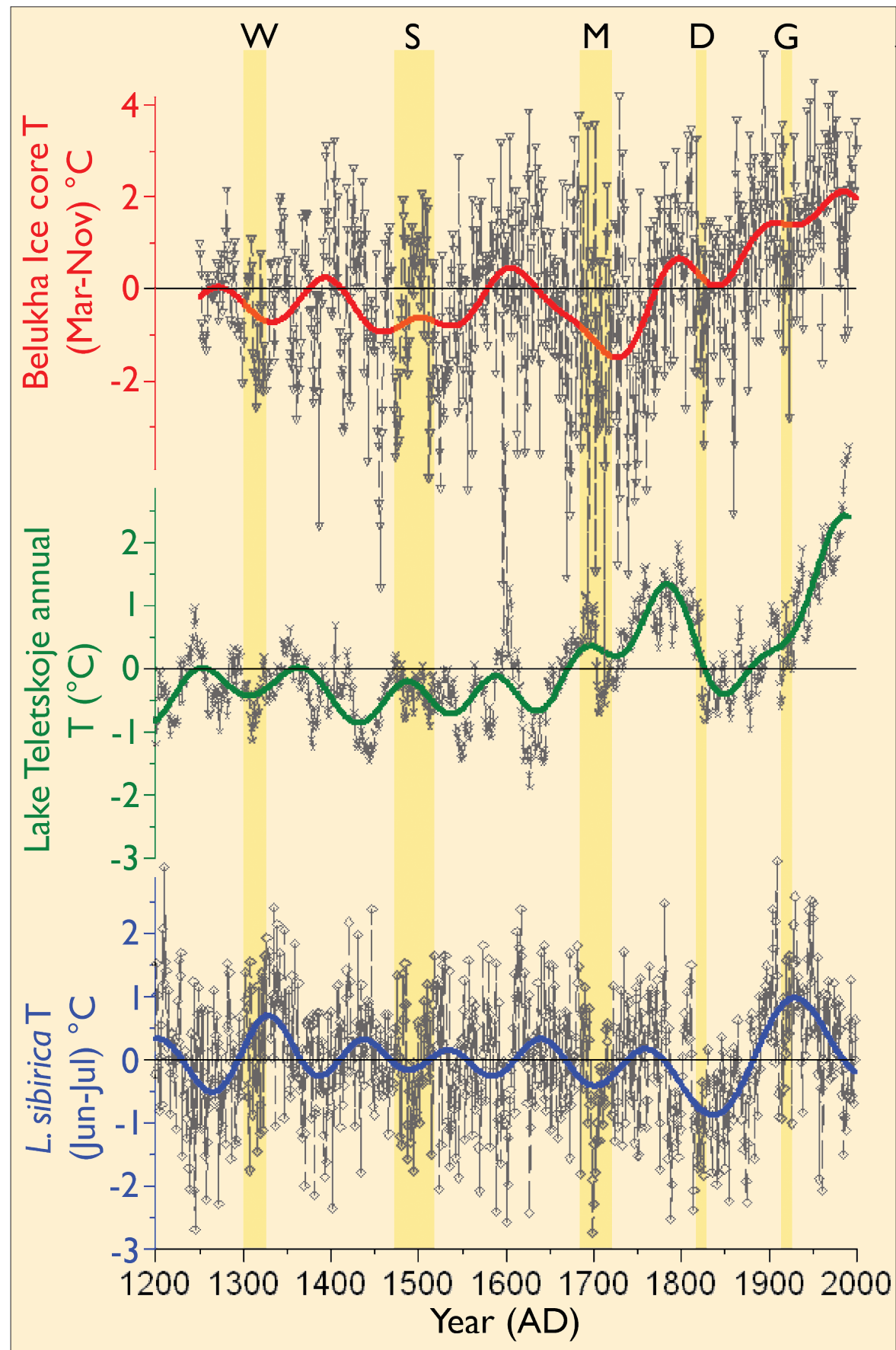

based temperature reconstructions and solar activity, suggesting solar forcing as an important driving force for temperature variations during the last 750 years in this region.

There was general consensus on the high potential of the Altai region for multiproxy climate reconstructions. Suggestions for future work included extending the existing records further back in time, combining results from different proxies, and incorporating reconstructions from other archives, like archeological data (e.g., from Plateau Ukok), documentary data, phenological data from Katun National Park, and geomorphologic studies for reconstructing glacier history.

\section{Acknowledgments}

The meeting was funded by the Russian Foundation for Basic Research and the Swiss National Science Foundation.

\section{References}

Bradley, R.S., Briffa, K.R., Cole, J., Hughes, M.K. and Osborn T.J., 2003 : The climate of the last millennium, In: Alverson, K., et al. (Eds), Paleoclimate, Global Change and the Future, Springer, 105-141.

De Smedt, B. and Pattyn, F., 2003: Numerical modelling of historical front variations and dynamic response of Sofiyskiy glacier, Altai mountains, Russia, Annals of Glaciology, 37: 143-149.

Eichler, A., Olivier, S., Hendersen, K., Laube, A., Beer, J., Papina, T., Gäggeler, H.W. and Schwikowski, M., 2008: Temperature response in the Altai region lags solar forcing, submitted to Geophysical Research Letters.

Kalugin, I., Daryin, A., Smolyaninova, L. Andreev, A. Diekmann, B. and Khlystov, 0., 2007: 800-yr-long records of annual air temperature and precipitation over southern Siberia inferred from Teletskoye Lake sediments, Quaternary Research, 67: 400-410.

Lydolph, P.E., 1977: Climates of the Soviet Union, World Survey of Climatology, 7: 1-115.

Ovtchinnikov, D., Adamenko, M. and Panushkina, I., 2000: A 1105-year tree-ring chronology in Altai region and its application for reconstruction of summer temperatures, Geolines, 11:121-122.

Figure 2: Annual values (gray lines) and 100-year lowpass filtered (colored lines) temperature anomalies reconstructed from the Belukha ice core $\delta^{18} \mathrm{O}$ record (March-November T; red; Eichler et al., submitted), the Lake Teletskoye sediment geochemistry (annual T; green; Kalugin et al., 2007), and the tree ring width chronology for Larix sibirica at the upper timberline in the SE Altai (June-July T; blue; Ovtchinnikov et al., 2000). Periods of low solar activity are indicated by yellow bars ( $W=$ Wolf, $S=$ Spörer, $M=$ Maunder, $D=$ Dalton and $G=$ Gleissberg minima).

\section{Climate extremes during recent millennia and their impact on Mediterranean societies}

\section{University of Athens, Greece, 13-16 September 2008}

\section{Jürg Luterbacher ${ }^{1}$, R. Garcia-Herrera ${ }^{2}$, P.D. Jones ${ }^{3}$, C.C. Raible ${ }^{4}$, E. Xoplaki ${ }^{1}$ and C.S. Zerefos ${ }^{5}$}

'Oeschger Centre for Climate Change Research and Institute of Geography, University of Bern, Switzerland; juerg@giub.unibe.ch

${ }^{2}$ Complutense University of Madrid, Spain; ${ }^{3}$ Climatic Research Unit, School of Environmental Sciences, University of East Anglia, Norwich, UK; ${ }^{4}$ Oeschger Centre for Climate Change Research and Institute of Physics, University of Bern, Switzerland; ${ }^{5}$ National and Kapodistrian University of Athens, National Observatory of Athens, Greece

The complexity of the Mediterranean climate makes the reconstruction of its past variability a challenging task. There is, therefore, a strong need for more high quality and high temporally resolved paleo-records from the region. Currently, spatial coverage is lopsided with little information available from northern Africa. The increase in research conducted on natural proxies in the Eastern Mediterra- nean, especially in Turkey, could help to compensate the scarcity of documentary records in that area. This interdisciplinary Symposium aimed to bring together researchers from natural and human sci- 
ences working in the Greater Mediterranean Region, to identify the datasets available, the spatial and temporal gaps in our knowledge as well as climate extremes during recent millennia and their impact on Mediterranean societies. This Symposium builds on the achievements of the 2006 ESF-MedCLIVAR/PAGES workshop "Reconstruction of Past Mediterranean climate" (PAGES news, 2006(2)). A number of topical sessions were held, covering a broad range of archives and methods.

An important conclusion drawn from a number of the presentations is that it is mainly single years of extremes in growing-season precipitation that are reflected in human history. Other periods of extreme spatial variability, such as shifts from regional to local precipitation patterns, did not have a clear impact on societal behavior. The need for a multi-proxy approach was also discussed. Every natural proxy has limitations and uncertainties, and responses of proxies to changes in the environment are often non-linear. Additionally, anthropogenic impacts on the environment are seen to limit the reliability of certain proxies, and there may also be subtle and non-obvious effects on even apparently "objective" proxies like isotopes from speleothems. A multi-proxy approach will also help to bridge the large communication gap between the scientists producing paleorecords, and those from the modeling/dynamical community.

The impact of volcanoes on climate was addressed through both instrumental data and proxy reconstructions. Documentary sources can be used to describe volcanic effects on climate and society. Paintings created by artists, representing sunsets (measured red/green ratios) can provide proxy information on the aerosol optical depth following major volcanic eruptions. The seasonal impacts of tropical and extratropical volcanic eruptions over the last centuries on Mediterranean climate were also examined. Generally, GCM experiments support proxy reconstructions and seem logically consistent with the circulation reaction to the global re-distribution of heat following tropical eruptions.

The symposium ended with a session devoted to the impacts of climate extremes on Mediterranean societies. It covered the impacts of and adaptation to climatic events of the last millennia to today. In particular, the events of 8.2, 5.2, and $4.2 \mathrm{kyr}$ BP were discussed. Such events had severe impacts on the Neolithic Mediterranean societies, including changes in mo-

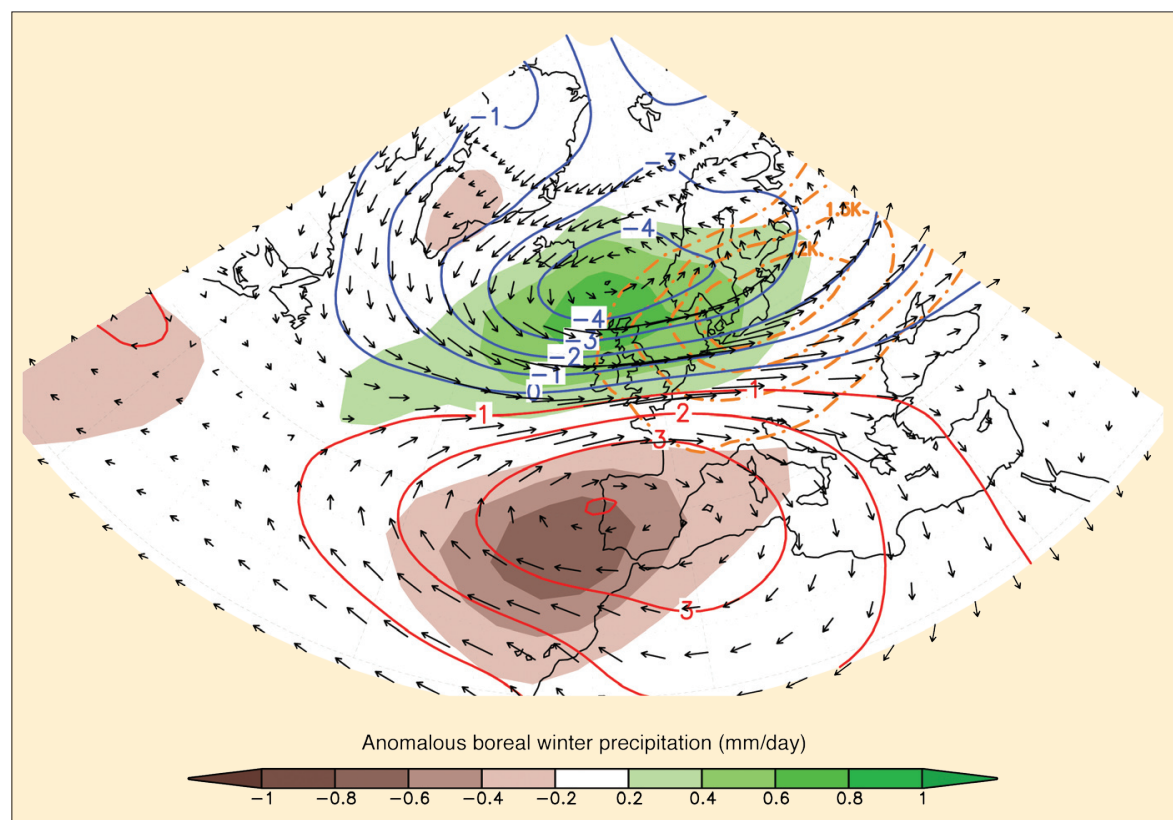

Figure 1: Estimated composite of anomalous boreal winter precipitation ( $\mathrm{mm} /$ day), temperature (dashed orange line, in ${ }^{\circ} \mathrm{C}$ ), sea-level pressure (blue (-) and red (+) contours in $\mathrm{hPa}$ ) and near surface geostropic wind anomalies (arrows) during Medieval times. The composite was produced using Proxy Surrogate Reconstruction (PSR, Graham et al., 2007) in which the temporal order of coupled model output is constrained by the agreement between climate proxy data (Morocco drought severity reconstruction, Austrian Alps speleothem-based winter temperature reconstruction and northern Scotland speleothem-based reconstruction of the temperature / precipitation (T/P) ratio) and corresponding data drawn from the coupled model from a 1150-year radiatively forced simulation with NCAR Community Climate System Model (Ammann et al., 2007). The composite map shown here is the difference between the average of the PSR reconstruction for AD 1049-1298 and the average for AD 1449-1923, thus it depicts an estimate of anomalies during Medieval times. The results indicate that Medieval winters were dominated by a positive NAO-like pattern bringing wetter conditions to NW Europe (up to 115\% of post-Medieval times precipitation, $\mathrm{mm} /$ day), drier conditions in Iberia and Morocco (about $60 \%$ of post-Medieval times values), and warmer conditions in central and northern Europe. The maximum changes depicted in near-surface westerlies across western Europe are approximately $1.4 \mathrm{~m} / \mathrm{s}$ compared with typical mean values of $9-10 \mathrm{~m} / \mathrm{s}$.

bility patterns and reduced demographic status due to reduced food supplies.

A discussion forum followed each session and culminating from these are several issues that were identified to improve research on past Mediterranean climate extremes:

- More high quality and high-resolution records - this task will take years to resolve, thus we suggest a "location sensitivity analysis" in conjunction with the climate system dynamical/modeling community to identify areas of particular sensitivity. - Development of new proxies - currently employed proxies are of great use, however, we urge the development of new proxies, such as trace elements and fluid inclusion analysis of speleothems.

- Calibration of proxy data against instrumental data - it is vital that the calibration period be as long as possible. Initiatives towards this goal are being undertaken in the MEDARE project (www.omm.urv. cat/MEDARE/index.html).

- Synthesis of these pre-existing records this will aid understanding of the spatial distribution (especially inhomogeneities) and magnitude of abrupt climate events. Such data interchange will be enhanced by the MedCLIVAR metadatabase (www.medclivar.eu).

- Integration and exchange between paleo-researchers and dynamicists/modelers - paleo-scientists can provide results that serve to validate model results, or provide initial and/or boundary conditions for forcing models. In turn, dynamicists/modelers can provide insight into understanding and interpreting the signals seen in paleorecords (see Fig. 1 as an example).

- Concentration on different time slices and/or scales - to provide information on the variability and contributions of different mechanisms at differing frequencies.

\section{References}

Graham, N.E., Hughes, M.K., Ammann, C.M., Cobb, K.M., Hoerling, M.P., Kennett, D.J., Kennett, J.P., Rein, B., Stott, L., Wigand, P.E. and Xu, T., 2007: Tropical Pacific - Mid-latitude Teleconnections in Medieval Times, Climatic Change, 83: 241-285 doi:10.1007/ s10584-007-09239-2.

Ammann, C.M., Joos, F., Schimel, D.S., Otto-Bliesner, B.L. and Tomas, R.A., 2007: Solar influence on climate during the past millennium: Results from transient simulations with the NCAR Climate System Model, Proceedings of the National Academy of Sciences, 104: 3713-3718; doi:10.1073/pnas.0605064103 


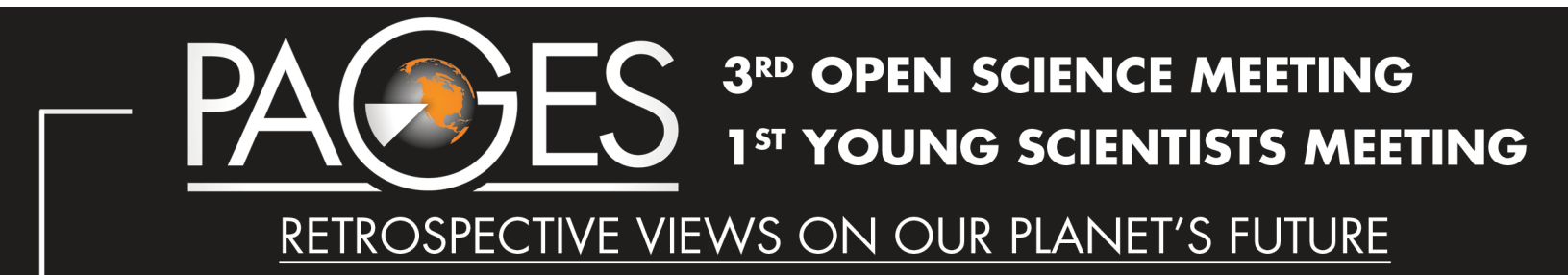

YSM 6 - 7 July, OSM 8 - 11 July at Oregon State University in Corvallis, USA

****ABSTRACT SUBMISSION \& OSM REGISTRATION IS NOW OPEN****

YSM SCIENTIFIC PROGRAM

\author{
MON $06 \mathrm{JUL}$ \\ Keynote Lecture \\ Case studies of paleoscience \\ informing future projections \\ Session 1 \& 2 \\ - Climate Modeling \\ - Regional Climate Dynamics \\ Poster Session 1 \\ Session 3 - 5 \\ - Chronlogy \\ - Proxies \\ - Modeling \\ Poster Session 2
}

Breakout-Discussion

How to improve support for YS
TUE 07 JUL

Breakout-Report

Session $6 \& 7$

- Earth System Dynamics

- Human-Climate-Ecosystem Interactions

Poster Session 3

Plenary \& Discussion

Grants and funding: Tips from funders (NSF, START)

Publishing your work: Tips from editors

(Nature Geoscience, Climate of the Past)

Data management

(NOAA World Data Center)

Communicating science to the public

(reaclimate.org, media)

YS Awards

\section{OSM SCIENTIFIC PROGRAM}

$\begin{array}{cc}\text { WED 08 JUL } & \text { THU 09 JUL } \\ \text { Session } 1 & \text { Session } 4 \\ \text { Hydrological Cycle } & \text { Biogeochemistry } \\ \text { Session } 2 & \text { Session } 5 \\ \text { Climate Modes } & \begin{array}{c}\text { Land Cover, Water, } \\ \text { Sediment }\end{array} \\ \text { Session 3 } & \text { Session 6 } \\ \text { Chronology } & \text { Proxies }\end{array}$

YSM Awardee Talk

Poster Session 1

- Climate Forcings

- Chronology

Hof Topic 1

Paleoscience \& IPCC
YSM Awardee Talk

\author{
Poster Session 2 \\ - Regional Climate \\ - Proxies
}

Hof Topic 2

Ocean Acidification
FRI $10 \mathrm{JUL}$

Session 7

Regional Climate

Session 8

Human-Environment

Interactions

Session 9

Modeling

YSM Awardee Talk

Poster Session 3

- ES Dynamics

- Modeling

Hof Topic 3

Drying of the Sahara
SAT $11 \mathrm{JUL}$

Session 10

Interglacials

Session 11

Ice Sheets \&

Sea Level

Plenary Discussion

Future Paleo \& PAGES

YSM Awardee Talk

Poster Session 4

- Human-Climate-Ecosystem

- Data Management

Hot Topic 4

Sea Level Rise

Confirmed speakers to date: A. Abe-Ouchi, R. Alley, C. Ammann, L. Beaufort, J. Carriquiry, E. Cook, B. Damnati, R. D'Arrigo, M-J. Gaillard-Lemdahl, A. Gupta, R. Hall, B. Hönisch, P. Huybrechts, C. Jones, A. Korhola, A. Landais, S. van der Leeuw, A. LeGrande, C. Le Quesne, Z. Liu, J. Luterbacher, R. Marchant, J. Marlon, J. McManus, D. Montgomery, R. Mulvaney, B. Otto-Bliesner, E. Piovano, D. Pollard, M. Prange, M. Siddall, T. Stocker, J. Stoner, A. Timmermann, M. Vuille, Y. Wang, H. Wanner, R. Wasson, K. Willis 
- Editorial: Change at the Poles: A Paleoscience Perspective

- PAGES calendar

- Inside PAGES

- New on the PAGES Bookshelf

- PAGES OSM and YSM announcement

PAGES International Project Office Zähringerstrasse 25

3012 Bern - Switzerland

Tel.: +41316315611

Fax: +41316315606

pages@pages.unibe.ch www.pages-igbp.org/

- Data portal for transient paleoclimate simulations covering the last $21 \mathrm{kyr}$

O. Timm, A. Timmermann and S.H. DeCarlo

- Teleconnections during glacial terminations associated with ENSO-like variability

L.D. Pena and I. Cacho

- Accurate dating of Gallipoli Terrace sediments: Historical eruptions and climate

G. Vivaldo, C. Taricco, S. Alessio and M. Ghil

\section{Special Section: Change at the Poles: A Paleoscience Perspective}

\section{Science Highlights:}

- 2000 years of climate variability inferred from Arctic lake sediments

10

D.S. Kaufman

- Holocene paleoclimate of the Canadian Arctic Islands: The ACVAST project K. Gajewski, M. Peros, S. Finkelstein and M. Fortin

- Stable isotopes in tree rings from the Russian Arctic - a winter precipitation proxy? 14 S. Holzkämper and P. Kuhry
- Arctic thermokarst lakes and the carbon cycle M. Edwards, K. Walter, G. Grosse, L. Plug, L. Slater and P. Valdes

- Initial results of HOTRAX address a wide range of Arctic paleoclimate issues D.A. Darby, L. Polyak and M. Jakobsson

- Lake El'gygytgyn's emerging IPY record of Pliocene to recent Arctic change

J. Brigham-Grette, M. Melles, P. Minyuk, C. Koeberl and the Science Party

- Antarctic Paleobiology: Constraining reconstructions of past ice-sheet extent

L. Newman, P. Convey, J.A.E. Gibson and K. Linse

- Sea-ice proxies in Antarctic ice cores

R. Röthlisberger and N. Abram

- Accurate chronology for Antarctic ice cores on orbital timescales

K. Kawamura

- Antarctic Ice Sheet and climate history since the Last Glacial Maximum

M.J. Bentley and D.A. Hodgson

- Change in the Southern Ocean: Responding to Antarctica

L. Carter and G. Cortese

- New records of the role of Antarctic ice sheets in late Cenozoic climate

R. Powell, T. Naish, R. Levy and the MIS Science Team

\section{Workshop Reports:}

- Cenozoic bi-polar connections over millennia

- Recent change in the climate and atmospheric chemistry over Antarctica

- Ninth International Conference on Permafrost

\section{Editors:}

Series Editors:

Louise Newman and Thorsten Kiefer

Guest Editors:

Julie Brigham-Grette and Ross Powell

Text Editing: Leah Witton

Layout: Louise Newman

Hardcopy circulation: 2000

ISSN 1563-0803

Printed on recycled paper by Läderach AG - Bern, Switzerland

Cover images

Maps:

Antarctica - http://geology.com

The Arctic - www.arcticportal.org

Photos clockwise from top left: Piston corer weight stand - D. Darby Ice-corer cutting head - C. Gilbert (www. photo.antarctica.ac.uk) Polar Viking + drill rig - M. Jakobsson Lake El'gygytgyn UWITEC piston corer + DOSECC, Inc. GLAD-800 - J. Brigham-Grette Jumbo piston corer barrel - D. Darby ANDRILL hot water drill - L. Carter N.B. Palmer + drill rig - J. Wellner ITASE ice core system - P. Mayewski Center: ANDRILL drill rig - S. Nielsen

\section{Workshop Reports}

- What causes glacial-interglacial cycles?

- CLIVAR-PAGES-WCRP summer school on EI Niño

- PAGES Focus 4: Past Human-Climate-Ecosystem Interactions (PHAROS)

- Paleoclimate Modelling Intercomparison Project Phase 2

- Oxygen isotopes as tracers of Mediterranean climate variability

- Past climate variability in the Altai

- Climate extremes and their impact on Mediterranean societies
The PAGES International Project Office and its publications are supported by the Swiss and US National Science Foundations and NOAA. 